\title{
Computer-Based Structural Investigation of the SY-103 Waste Storage Tank Which Contains an Out-Of-Tolerance Bottom Bump
}

March 1976

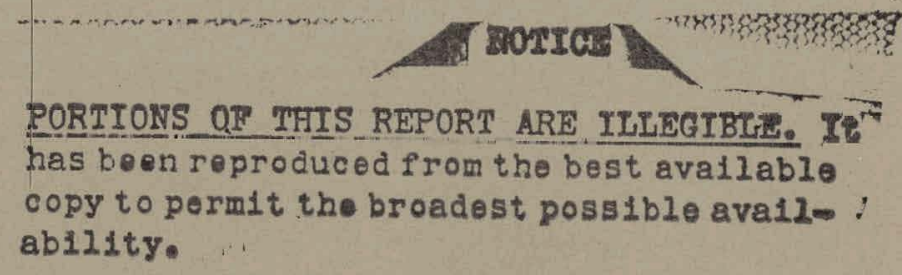

Prepared for the Energy Research and Development Administration under Contract $\mathrm{E}(45-1)$ : 1830 


\section{DISCLAIMER}

This report was prepared as an account of work sponsored by an agency of the United States Government. Neither the United States Government nor any agency Thereof, nor any of their employees, makes any warranty, express or implied, or assumes any legal liability or responsibility for the accuracy, completeness, or usefulness of any information, apparatus, product, or process disclosed, or represents that its use would not infringe privately owned rights. Reference herein to any specific commercial product, process, or service by trade name, trademark, manufacturer, or otherwise does not necessarily constitute or imply its endorsement, recommendation, or favoring by the United States Government or any agency thereof. The views and opinions of authors expressed herein do not necessarily state or reflect those of the United States Government or any agency thereof. 


\section{DISCLAIMER}

Portions of this document may be illegible in electronic image products. Images are produced from the best available original document. 


\section{NOTICE}

This report was prepared as an account of work sponsored by the United States Government. Neither the United States nor the United States Energy Research and Development Administration, nor any of their emplovees. nor any of their contractors, subcontractors, or their employees, makes any warranty, express or implied. or assumes any legal liability or responsibility for the accuracy, completeness or usefulness of any information. apparatus, product or process disclosed, or represents that its use would not infringe privately owned rights.

PACIFIC NORTHWEST LABORATORY

operated by

BATTELLE

for the

U.S. ENERGY RESEARCH AND DEVELOPMENT ADMINISTRATION

Under Contract E(45-1)-1830

Printed in the United States of America Available from

National Technical Information Service

U.S. Department of Commerce

5285 Port Royal Road

Springfield, Virginia 22151

Price: Printed Copy $\$ 700$, Microfiche $\$ 2.25$

6. $\%$ 
COMPUTER-BASED STRUCTURAL INVESTIGATION OF THE SY-103 WASTE STORAGE TANK WHICH CONTAINS AN OUTOF-TOLERANCE BOTTOM BUMP

W. E. Anderson

R. L. England

J. R. Friley

M. Vagins

for

ATLANTIC RICHFIELD HANFORD COMPANY

Richland, WA 99352

by

BATTELLE NORTHWEST IABORATORIES

Richland, Washington 99352

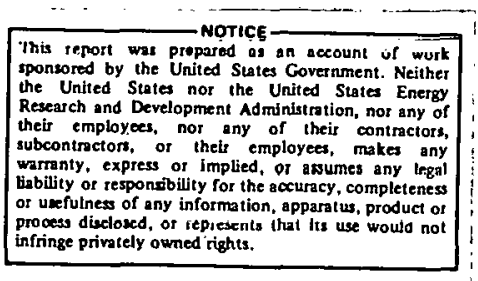


CONTENTS

SUMMARY

INTRODUCTION

AXISYMMETRIC ANALYSIS

ANALYSIS USING A NON-AXISYMMETRIC SHELL MODEL

RESULTS

CONCLUDING REMARKS

CONCLUSIONS

APPENDICES

A. Description of Computer Program MONSASTIFF

B. Geometric and Loads Calculations

C. Graphical Representation of Results for the Axisymmetric Analyses

D. Description of the MARC Computer Program

E. Graphical Representation of Stress Results from the Non-Axisymmetric Analyses

F. Comparison of Results with Experimental Strain Gage Data

G. Stress-Corrosion Susceptibility of Tank SY-103 as Evaluated by WE Anderson (BNW) 
COMPUTER-BASED STRUCTURAI INVESTIGATION OF THE SY-103 WASTE STORAGE TANK WHICH CONTAINS AN OUTOF-TOLERANCE BOTTOM BUMP

Summary

A computer-based structural analysis was performed on the inner tank of SY-103 in the 241-SY tank farm on the Hanford reservation. The objectives of this study were to determine the general stress condition of the inner tank for selected water-fill, hydrotest heights, and, to investigate the magnitude of local stresses. in the vicinity of an out-of-tolerance "bump" on the bottom of the inner tank under a loading equivalent to the anticipated waste'storage condition.

Results show that the stresses induced in flat-bottomed tank, due to hydrotest water-fill are quite low until fill heights in excess of 45 feet are encountered. Filling beyond this level, circumferential membrane compressive stresses in the upper knuckle become great enough to cause concern about the possibility of buckling. If the upper knuckle portion of the tank is effectively supported by the reinforced concrete roof when fill heights of approximately 43 feet are exceeded, the calculated stresses would not develop.

Investigation of the measured bottom bump in SY-103 indicates that total flattening will not quite occur under the anticipated operating conditions. Results show that there will be no localized yielding of the tank inner surface when it is filled to normal height with terminal waste slurry at Sp.Gr. $=2.0$.

The most severe tensile stress condition at the inner surface was slightly less than yield at expected service temperature; it occurred along the bump perimeter where servicefilled, pressure flattening of the prior bump curvature caused high flexural stresses. 
Flexure stresses are considered self-limiting, however, due to the back-up support provided by the foundation. since the localized nature of the high stresses and the back-up support of the foundation prevent further flexure, it is our judgement that these stress levels are structurally tolerable.

It must be pointed out that the stress levels as determined in this study are extremely sensitive to the exact shape of the "bump", and the results of this study are "accurate" only in the context of the accuracy of the physical measurement of the "bump" geometry.

Independent evaluation of this structural study and its relevance to stress-corrosion cracking was made by an experienced staff member of the Engineering Technology Department. He has concluded that expected service performance of the SY-103 tank has not been compromised by the slightly out-of-tolerance bump.

At this first release, comparison with experimental strain gage data is not included. 


\section{Introduction}

ARHCO is constructing several waste storage tanks in the SY-24I tank farm area. These are double-wall, steel tanks with a liquid waste storage capacity of one million gallons. One of these tanks, the SY-103 tank, contains an "out-of-tolerance" bump on the bottom plate of the inner tank. In order to develop data to help evaluation of the general structural adequacy of the tank, ARHCO requested the Structures \& Mechanics Section of Battelle Pacific Northwest Laboratory to carry out a computer based analytical investigation of the bumpy inner tank. objectives of the work:

- Determination of the stress and displacement conditions for the inner tank of SY-103 taken as a body of revolution, during several stages of its empty and hydrotest/fill conditions and to compare these values with experimental strain gage results.

- Use the data developed above as boundary conditions for a detailed three-dimensional finite element computer model for stress analysis of the specific "bump" under the anticipated waste fill condition.

Following the structural analysis, an independent interpretation of the significance of the results as it might affect the stress-corrosion cracking response of the tank was carried out and reported. 


\section{AXISYMMETRIC ANALYSIS}

The initial analysis undertaken on the SY-103 primary tank was performed using the digital computer program MONSASTIFF, a shell program based on the direct stiffness method of analysis (see Appendix A). The purpose of this analysis was to determine the stress and displacement conditions in the tank by treating it as a shell of revolution, under various loading conditions. In addition, it provided data which could be correlated with experimentally determined stresses in the tank, as well as providing boundary conditions for a non-axisymmetric model.

The basic geometry of SY-103 was determined from Vitro Drawing $\mathrm{H}-2-37772$, an elevation cross-section of the tank. It should be noted that in using this drawing to construct the model, no recognition is made of the octagonal weldment which comprises the majority of the bottom of SY-103. The cross-sectional drawing was made by taking a section at one of the vertices of the octagon, thus making the distance from the knuckle to the first shell thickness transition as short as possible. At another point the shell thickness may be larger closer to the center and the stress correspondingly smaller. Figure I reflects the pertinent details of the tank model.

In modeling, four basic types of parts were used. A spherical part was determined which would closely match the head of the tank. Tangent to this was placed a partial toroidal part representing the knuckle of the tori-spherical head. Cylindrical parts were then used to represent the side of the tank which ends with yet another partial toroidal part to represent the bottom knuckle. A series of degenerate or flat cones taking the form of flat annular plates were used to represent the bottom.

In order to simplify the modeling and subsequent input data, the inner surface of the tank was assumed to have no discontinuities requiring that the variations in shell thickness be accounted for solely by outer surface discontinuities. Each part used in the model maintained a constant thickness and variations in thickness 
BNWL-B- 475

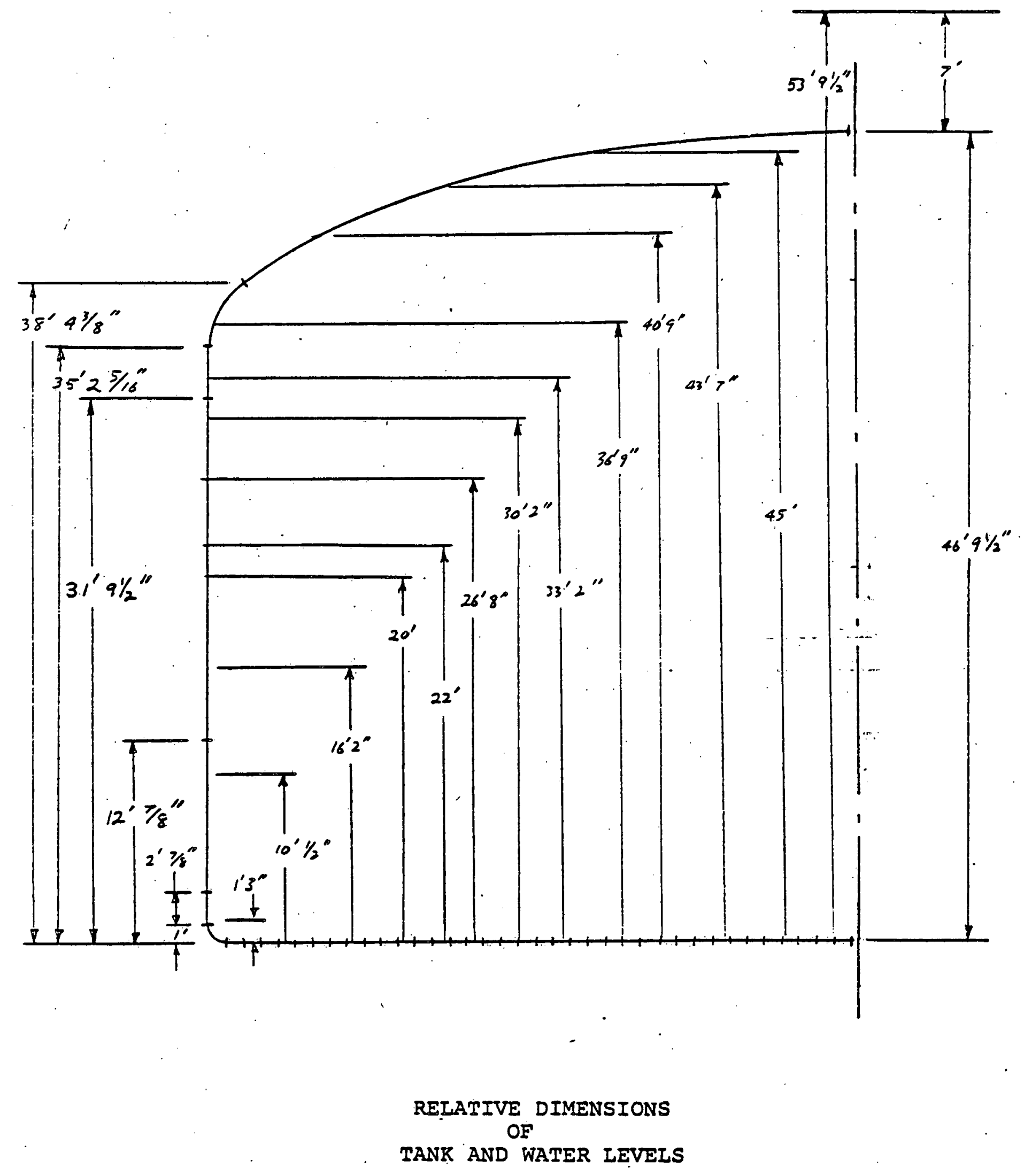

FICURE 1 
were accounted for by beginning a new part at each juncture of dissimilar thicknesses. In all, 43 parts were needed. Seven were used to model the shell from the top of the tank at the center line to the bottom of the lower knuckle. The remainder were degenerate cones, 36 in number, and comprised the bottom of the tank.

Since MONSASTIFF does not have the capability of modeling a plate which is continuously supported, it was necessary to approximate this condition by providing for a large number of point constraints. This lead to the 36 deverierate cnnig parts indicated previously. Constraines may be auplied only at the end of each part in MONSASTIFF so in order to support the tank bottom model at 36 one-foot intervals, it was necessary to provide 36 one-foot long parts. The constraints of these points along the bottom were such that axial motion, i.e., motion parallel to the center line or axis of revolution of the tank, was precluded. In addition, at the point representing the top of the tank at the center line, motion in a radial direction was precluded, as was circumferential motion. This was also the case at the point representing the bottom of the tank at the center line, where, in addition to radial and circumferential, axial motion was constrained. Under certain loading conditions, some changes were made in the constraints as will be explained in the discussion of the results. Due to the nature of the solution technique featured in MNNSASTISF, a discontinuity will occur if the shell closes on, $i . c$, , the shull parts terminate or begin on the centerline. For this reason it was necessary to allow a relatively small gap of six inches between the initial end of the first part and the final end of the last part. Obviously, from the above discussion, the model represented a free standing tank taking no consideration of the effect of the final concrete structure which might restrain or reinforce the primary tank in some manner.

Two types of loads were applied to the tank model. The first of these simulated the effect of dead weight loads on the structure, while the second type, really a series of loads, simulated the effect of filling the tank with water to various levels. 
Since MONSASTIFF allows loads to be expressed at up to eight points per part, the normal and meridional components of the weight of a unit length of meridion per unit length of circumference were calculated at at least two points per part, initial and final. The program then assumed a linear relation between values at consecutive points. In the case of areas of large curvature, notably the two toroidal areas, four points were used, initial, two intermediate, and the final.

Pressure loads were handled in an analogous but somewhat simpler manner. Given a particular water height, the pressure at the beginning and end of each part was calculated. These were specified for each part as a force normal to the tank wall in the outward direction, and again the program assumed a linear relation between values at consecutive points. The water heights at which the analyses were carried out are listed in Table 1, and the relative locations are shown in Figure 2. These heights were chosen because they correspond to the water heights at which strain gage readings were taken.

All calculations concerning loads may be found in Appendix B, along with calculations determining the geometry for the MONSASTIFF model. 


\section{TABLE 1}

WATER HEIGHTS USED FOR AXISYMMETRIC TANK ANALYSES

EMPTY (DEAD WEIGHT)

I'3"

$10^{\prime} 1 / 2$ '

$16^{\prime} 2 "$

$20^{\prime} 0^{\prime \prime}$

$2214 "$

$26^{\prime} 8^{\prime \prime}$
30 '2"

$33^{\prime} 2 "$

$36^{\prime} 9^{\prime \prime}$

$40^{\prime} 9^{\prime \prime}$

$4317 "$

$45^{\prime} 0^{\prime \prime}$

$53^{\prime} 9-1 / 2^{\prime \prime}$

* 53'9-1/2" is equivalent to seven feet above the top of the tank, obtained by filling of the risers. 


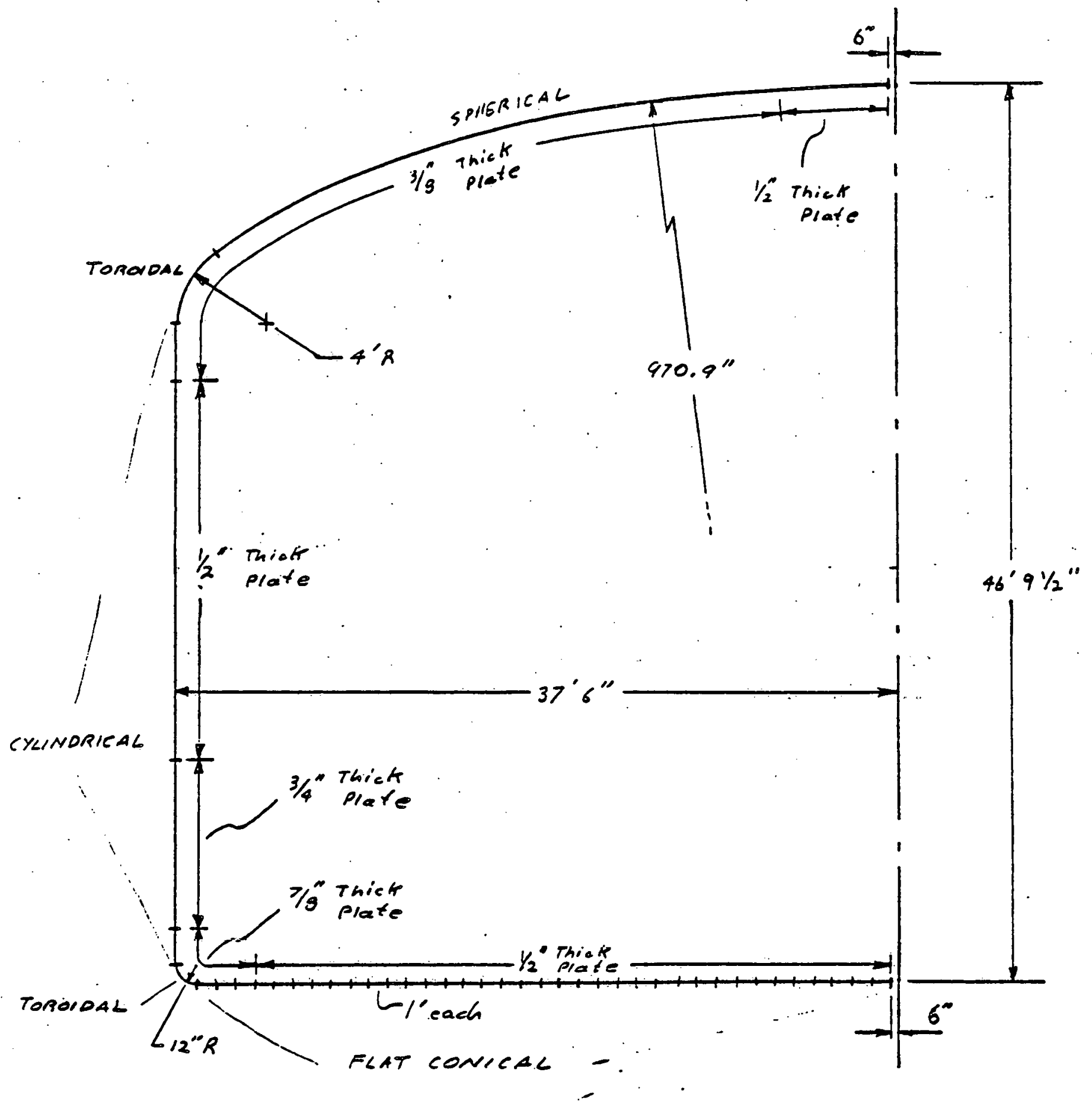

MONSASTIFF MODEL

FIGURE 2

$-9-$ 


\section{ANALYSIS USING A NON-AXISYMMETRIC SHELL MODEL}

The axisymmetric analysis previously discussed is a very economical solution technique to apply. Data preparation and computer costs are of a much lesser magnitude than the corresponding costs for a general non-symmetric finite element shell analysis. It may also be legitimately argued that solution behavior in regions far removed from the non-axisymmetric portion of the shell structure may be adequately modeled with an axisymmetric geometry. For regions near the non-a isymmetric portion, however, the two types of analysis can be expected to agree only "trend-wise".

For these reasons, it was felt that the most cost effective approach in the study of bump stresses was to first conduct several axisymmetric analyses. From these results, insight could be gained which would enable efficient formulation of the geometry and boundary conditions for a more elaborate non-axisymmetric shell analysis.

This lattcr analysis was carrled out by using the MARC computer program (see Appendix D). Element 8 described in the MARC User's Manual (see reference I) was used. This element is a doubly curved isoparametric triangular element based upon Koiter-Sanders shell theory.

The element is a relatively high-precision element possessing nine degrees of freedom at each of three vertex nodes. The apparent high cost of using such an element however is offset by the added versatility which the doubly curved element provides in simulating highly curved shell regions. The bump geometry and the knuckle geometry (two regions where high stresses are likely) of the problem under consideration can thus be modeled with less localized mesh refinement than would be the case if flat shell elements were used. 
A perspective plot (viewed from above) of the mesh configuration used in this analysis is shown in Appendix F. This model was composed of 186 nodes and 330 elements. The model represented a $90^{\circ}$ sector of the tank bottom and about 30 inches of the cylindrical wall. Elements with linearly varying thicknesses were used to model transitions in shell thickness which did not occur at element interfaces. Tank dimensions for this model were taken from vitro Drawing $\mathrm{H}-2-37772$.

The boundary conditions imposed can best be described by reference to Figure 3 . Along the radial edges $A B C$ and $F E D$, circumferential displacement was suppressed. In addition, vertical displacements were assumed to be symmetric in the circumferential direction. Also, along radial lines $A B$ and $F E$, vertical deflection was suppressed. Physically, this is equivalent to placing vertical planes through $A B C$ and FED, and constraining radial portions $A B$ and $F E$ to ride in radial slots while allowing vertical movement along the knuckle portions $B C$ and ED. Along the internal circumferential line AF, all displacements were suppressed, simulating a totally clamped condition.

The edge force resultants were taken from results of previously discussed axisymmetric analyses. These conditions simulate dead-weight gravity loading and hydrostatic pressure loading representing a fill height of 30 '2" with a liquid of specific gravity 2.0. Pressure loading corresponding to this condition was applied on the interior surfaces of all elements.

The mechanism of simulating the foundation contact and subsequent support was as follows. Beneath each node of the model, a very stiff spring was attached. The spring constant was chosen so that the pressure force in the vicinity of a node would only compress the spring about 0.005 inches. The effect of a nodal spring of course should only be included when the node is in contact with the foundation. 


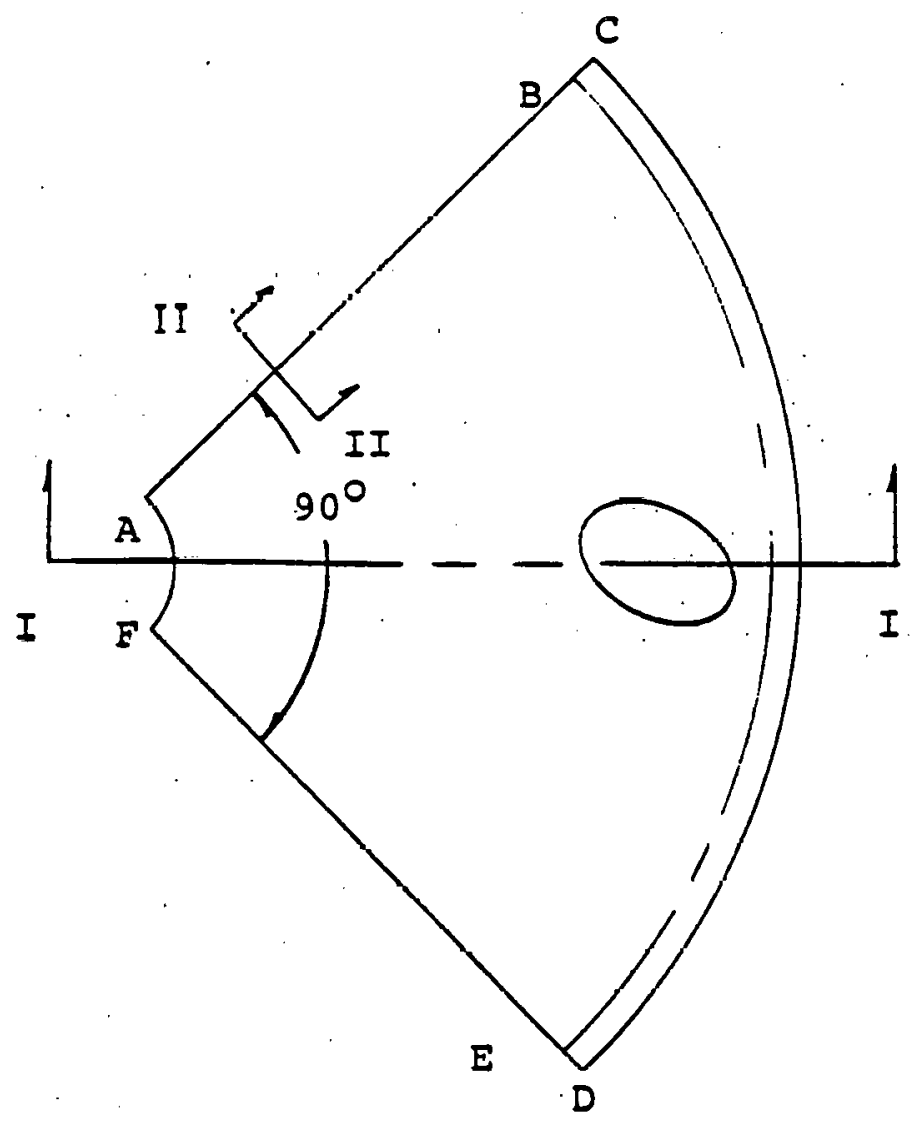

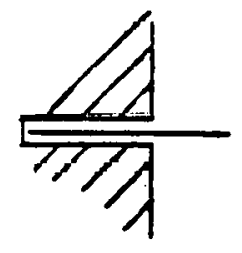

II

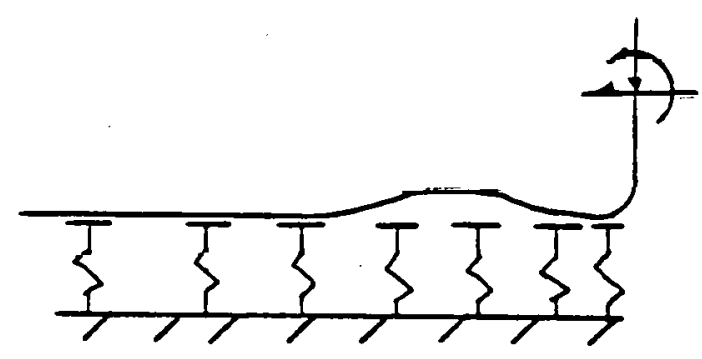

I I
$\mathrm{N}_{\phi}=147 \mathrm{lb} / \mathrm{in}$

$Q=12.4 \mathrm{Ib} / \mathrm{iz}$ $M_{\phi}=212 \frac{i n l b}{1 n}$

FIGURE 3. MARC MODEL DESCRIPTION 
If the mesh configuration is sufficiently refined, then the spacing of the springs would be very close. As a result of this, one could obtain a solution by gradually applying the pressure loading and connecting the springs as bottom contact was encountered. An iterative procedure of this sort could result in poor results if the mesh was not sufficiently refined. This would be due to the fact that high bending stresses could result from the plate bending through at non-supported areas and bending over the supported areas.

Rather than use a greatly refined mesh to prevent the occurrence of this "bend-through", an alternative iteration technique was employed. At all "contacted" nodes, the slope. of the shell was restraisied to so as to be tangent to the foundation. In-plane motion was not constrained, however, so that in-plane sliding and compression could occur as the pressure was applied and the bump began to flatten. If a nodal spring indicated a stretching force, the action taken on the next iteration consisted in removal of the spring and the previous tangent constraints at that node.

It should be mentioned that slopes at the nodes located along the bottom of the knuckle region were not fixed. The rationale for this was that the knuckle shell stiffness would be sufficient to prevent circumferential rotation, and that radial rotation should be allowed due to the presence of $N_{\phi}$ force resultant. In the final solution, these rotations were found to be very small.

By exercising careful judgment and from observation of the axisymmetric bump behavior the number of iterations required for the above procedure can be minimized somewhat. An initial estimate as to which nodes will "contact" under full pressure was made. Springs and tangential constraints were then imposed on those nodes. A solution under full loading was obtained and nodal deflections and spring forces were studied. If the estimate was correct, then all included springs would indicate compression and all nodes assumed not to be in contact would have corresponding 
deflections which did not pass through the foundation plane. If these conditions were not met, then a revised estimate on nodal contact was made and the procedure was repeated.

A total of four iterations were required to obtain a solution to within acceptable limits. The pressure loading was sufficient to flatten most of the "burp" nodes. The elevation of those nodes which didn't flatten decreased greatly. Displacements of non-flattened nodes and stress results for the converged solution are shown in Figure 4 in the Results section.

Stress resulte for the converged iterative solution are included in Appendix E. Care should be used in interpreting these contonour plots of stress results. The contour levels prepresent lines of constant meridional, circumferential, or shear stresses. These are not principal stresses. Consequently, a principal stress analysis must be performed before maximum normal or maximum shear stresses can be obtained. It is somewhat regretable that the current version of MARC does not allow contour plotting principal.stresses or maximum shear stresses.

The iterative analysis and resultant solution are based upon the assumption that no buckling of the tank bottom occurs due to the compressive stresses resulting from the flattening process. Precise determination of whether or not buckling will occur is very difficult analytical task due to the constantly changing bump bottom contour during the flattening process. Some insight may be gained, however, from a solution given in reference 2 for the buckling load of a simply supported spherical panel subjected to a concentrated vertical point load.

$$
\begin{array}{ll}
\text { Pcr }=\frac{\mathrm{Eh}^{3}}{\mathrm{R}}\left\{\sqrt{0.152\left(\frac{\mathrm{r}^{4}}{\mathrm{R}^{2} \mathrm{~h}^{2}}+74.9\right)}-2.88\right\} & (977 \text { inches }) \\
R=\text { Radius of the sphere } & (62.5 \text { inches }) \\
\mathrm{F}=\text { Radius of the circular base of the panel } & \left(30 \times 10^{6} \mathrm{psi}\right) \\
\mathrm{E}=\text { Young's modulus } & \left(0.5^{\prime \prime}\right)
\end{array}
$$


Using approximate geometrical values (shown preceding) taken from the bump in question, the predicted concentrated buckling load was found to be Pcr $=6,578 \mathrm{lbf}$. Dividing this value by the cross-sectional area of the bump base yields an equivalent buckling pressure of only 0.54 psi.

It is felt that such a small value of buckling pressure is misleading when applied to the bump in question. The preceding value was computed under the assumption that the base geometry of the spherical panel remained constant and boundary constraints remained fixed as loading was applied. The base of the bump, however, will move inward as pressure is applied, and this will in effect increase the bump stiffness, thus increasing the pressure at which buckling will occur.

Since an accurate solution of the buckling problem is not possible and since the iterative solution previously discussed is only valid strictly speaking if buckling does not occur, it was decided to obtain the stress configuration of the tank bottom under the assumption that total flattening occurred. Since the foundation supports the tank bottom and prevents further deformation, it may be argued that this constrained solution represents an upper bound estimate on bump stress levels.

This constrained solution was obtained by placing flattening constraints on vertical displacements and slope degrees of freedom, while allowing freedom for horizontal displacements. Edge boundary conditions and lateral pressure loading were treated in a fashion identical to those of the iterative solution. Plotted stress results for the constrained solution are given in Appendix $E$. In general, these stresses are only slightly higher than those of the iterative solution and regions of high stress levels for the two solutions are similar as can be seen from the figures in Appendix $\mathbf{E}$. 


\section{RESULTS : AXISYMMETRIC ANALYSIS.}

The results of the axisymmetric analyses are given in graphical form in Appendix C. The figures show the inside surface stresses (labeled INNER) and the outside surface stresses (labeled OUTER), in both the circumferential and meridional direction. In interpreting these results two points must be kept in mind. First, discontinuities will be noted in the stresses shown in the figures. Comparing the locations of these with Figure 1 it is seen that they occur at the points where a juncture between dissimilar thicknesses occur. This would be expected. 
Second, due to the fact that MONSASTIFF does not have the capability of modeling a continuously supported plate, multiple, closely spaced, ring supports were used. These supports allow the shell to undergo a false displacement on the bottom of the tank between constrained points, resulting in false bending stresses. Where possible, these stresses were removed before plotting. However, it was very difficult to arrive at these stresses in the $7 / 8$ inch plate at the low knuckle and little if any attempt was made to account for them.

Under dead weight load the stresses shown on pages $c-1$ through C- 6 were found. By investigating the shear loads at the point constraints, it was found that the constraints in a region extending eight feet in from the lower knuckle were restraining the vessel from lifting off the foundation. Freeing these points resulted in a lift off condition reaching a maximum height of 0.061 inch, located three feet in from the knuckle. The highest dead weight induced stresses were meridional stresses on the order of 5,000 psi in tension on the outer surface and 5,000 psi in compression on the inner surface, as shown on page $c-5$. The circumferential stresses also obtained a maximum in the lower knuckle on the order of 3,000 psi tensile stress on the outer surface and 750 psi compressive on the inner surface.

Stresses due to hydrostatic pressure only (no dead weight stresses) for the water levels given in Table 1 are presented in Appendix $C$, pages $c-7$ through $c-62$. It was found that as the water level reached or exceeded the 45 foot level, the lower knuckle began to lift off the foundation as a result of the upward force on the head of the tank. When these situations occurred, the appropriate constraints on the bottom of the tank were released and the tank was allowed to lift off. The stresses given for water levels of 45 feet and greater will reflect this condition. 
These effects due to high water levels relate to the construction and hydrotest procedures and mist be viewed in this light. For example, the largest stress result from the calculations occurs with a water height of seven feet above the tank and is located at the lower knuckle. It is a tensile stress in the meridional direction, well above yield; it does not, however, reflect a condition which would actually develop since the simple shell model does not include the effect of the concrete which would normally be present.

In general, below a water level of $43^{\prime} 7^{\prime \prime}$, the most highly stressed areas are at the bottom of the lower knuckle which exhibits high meridional stresses and the region on the side of the tank between three feet and twelve feet from the bottom, depending on the water level, which exhibits high circumferential stresses.

The stress condition in the shell for the 30'2" water level is of interest as it is representative of the stress conditions for all water levels below 43'7" as well as closely approximating the design fill level. As pointed out previously, the highest stresses occur near the bottiom of the lower knuckle and in the wall of the tank. Page C-3l shows the maximum circumferential stress occurring in the wall of the tank at approximately four feet and twelve feet above the bottom of the tank. The stress is tensile and approximately $6,000 \mathrm{psi}$ on both the inner and outer surfaces. On page c-34, it can be seen that the maximum meridional stress occurs at the bottom of the lower knuckle and is 10,000 psi compressive on the outer surface and 10,000 psi tensile on the inner surface. The stresses shown do not include dead weight.

The actual stresses at a point may be found by combining the dead weight stresses with those found for a particular water level. In the case of the 30'2" water level, the lower knuckle meridional stresses due to water alone are about 8000 psi, while those due to dead weight are about 3,000 psi; both inner and outer stresses are about the same, 11,000 psi. The inner surface is in tension. See pages $c-5$ and $c-34$. The meridional stresses 
in the floor of the tank remain unchanged, relatively speaking.

Circumferential stresses in the wall of the tank are due primarily to the water load. Addition of the dead weight load to the 30'2" water load results in a combined circumferential stress on the inner surface of 7000 psi tension in the wall, approximately three feet above the tank bottom. See pages C-I and C-31. Circumferential stress on the outer surface reaches 8000 psi tension in the wall approximately two feet above the bottom of the tank; see pages $c-1$ and $c-31$.

It should be pointed out again that the above stresses are due to the combined water loads (specific gravity of 1.0), and the dead weight. Extrapolating, stresses which would result from wastes at specific gravities of 1.7 and 2.0 are found by multiplying the water-only stresses by 1.7 and 2.0 , respectively; dead weight stresses are then added to these, and approximate stress conditions for the tank thereby calculated for each loading condition.

In the previous discussion it was indicated that the highest stresses occurred in the lower knuckle region. The figures on pages $c-63$ through $c-66$ show the stresses in this region for a $30^{\prime 2} 2$ fill height for fluids having specific gravities of 1.7 and 2.0, with dead weight included. Page $\mathrm{C}-66$ indicates that the largest meridional stress is tensile and on the order of 22,000 psi on the inside surface and 22,000 psi compressive on the outer surface, for a specific gravity of 2.0 , with dead weight included. Naturally, the stresses are of the same relative magnitude and sense but of lesser magnitude for a specific gravity of 1.7. For constructional steel SA-516 GR. 65 at $250^{\circ} \mathrm{F}$ the minimum yield strength, according to the ASME Boiler and Pressure Vessel Code, is interpolated as $31.2 \times 10^{3}$ psi*. This indicates that no yield should be expected in the critical lower knuckle region, for the design fill height of $30^{\prime} 2$ ".

Comparison of strain gage results with calculated stresses awaits completion of the experimental report.

*Section VIII, Division 2 (1974), Table ACS-2, pp. 44-45. 


\section{RESULTS: Non-Axisymmetric Shell Analysis}

Iterative Solution

The non-axisymmetric iterative solution performed by use of the MARC computer program indicated that a pressure loading equivalent to a fill height of 30!2" -- Sp. Gr. 2 flattened most but not all of the bump area. Locations of regions which did not totally flatten are shown in Figure 4. This analysis assumed that the bump behaved in an elastically stable fashion as loading was applied. Contour plots of non-principal stress values for this solution are presented in Appendix E.

In addition to these results, localized maximum values for tensile, compressive, and shear stresses on the inner surface of the tank bottom for this iterative solution of full service filling of the SY-103 tank's bumpy bottom are presented in Figures 5 through 7. These include dead weight loads.

\section{Constrained Solution}

In the second non-axisymmetric analysis performed by use of the MARC computer program (the constrained solution), the bump reglon was flateened and then held by application of nodal constraints. Inner surface contour plots of non-principal stress values for the constrained solution are presented in Appendix E.

Localized maximum values for tensile, compressive, and shear stresses on the inner surface of the fully flattened builiy tank bottom of SY-103 are shown 1n Figures 8 through 10 .

In view of the state-of-the-art knowledge about techniques for obtaining a stability estimate of bump behavior, we suggest that stresses resulting from the constrained solution represent realistic, conservative estimates of bump stress levels. 
We note that the two solutions are, indeed, very similar; compare Figure 5 with Figure 8, for example, or 6 and 9. There are only very modest differences in stress levels at a given point, from the two solution methods, and, the constrained solution values are generally larger than the values from the iterative solution. This similarity of results adds a dimension of confidence to the bump analysis. We tend to believe that the calculations are more precise than the measurements of the bump itself reasonably warrant, and hold this point out for proper perspective.

Along similar lines, the bump stability was mentioned as difficult to establish. That is, whether or not all of the bump would indeed flatten, or just some of it, could not be stated with any certainty. This is due to non-linear displacement restraint caused by the foundation itself. The maximum tensile stresses on the interior of the tank are caused by the flattening action. This may occur when the pressure head is as low as half-normal, or even less. Consequently, the same maximum stress in the bump should be: expected even for less-than-full conditions, or, for filling with waste at lower specific gravities. 


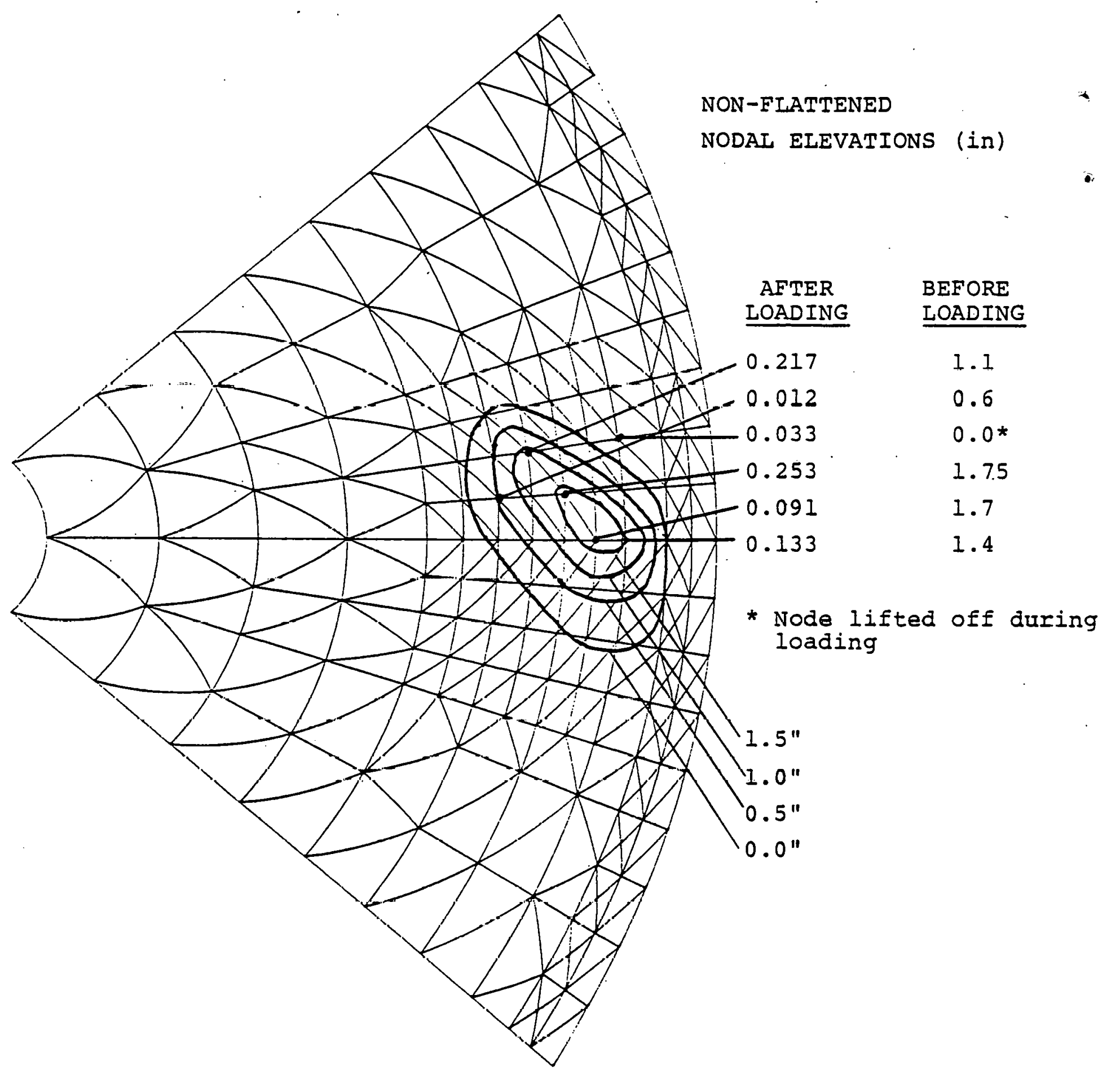

FIGURE 4. NON-FLATTENED NODAL ELEVATIONS FOR THE ITERATIVE SOLUTION. 


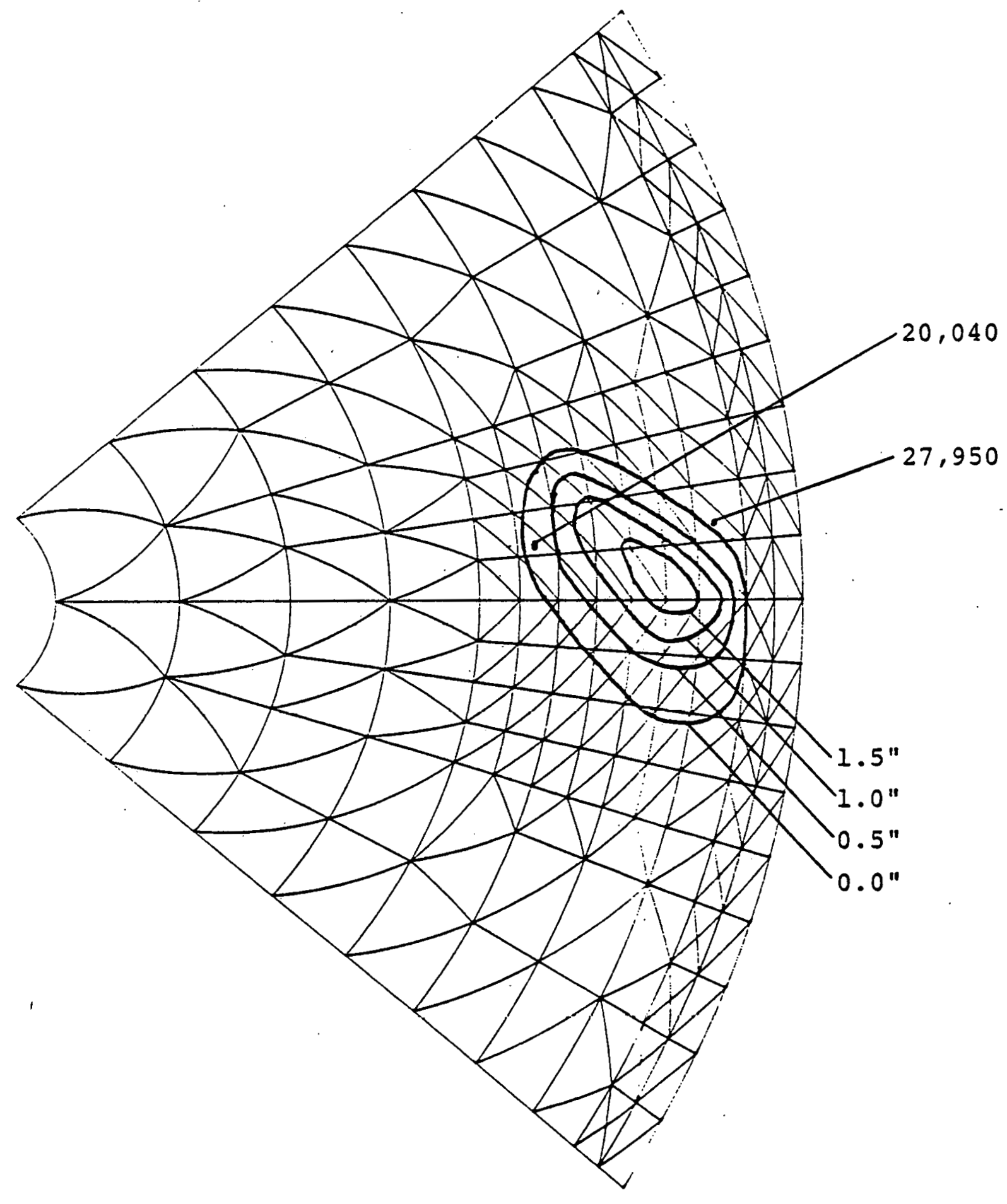

FIGURE 5. INNER SURFACE TENSILE STRESS RESULTS FOR THE ITERATIVE SOLUTION WHICH WERE GREATER THAN 20,000 psi 


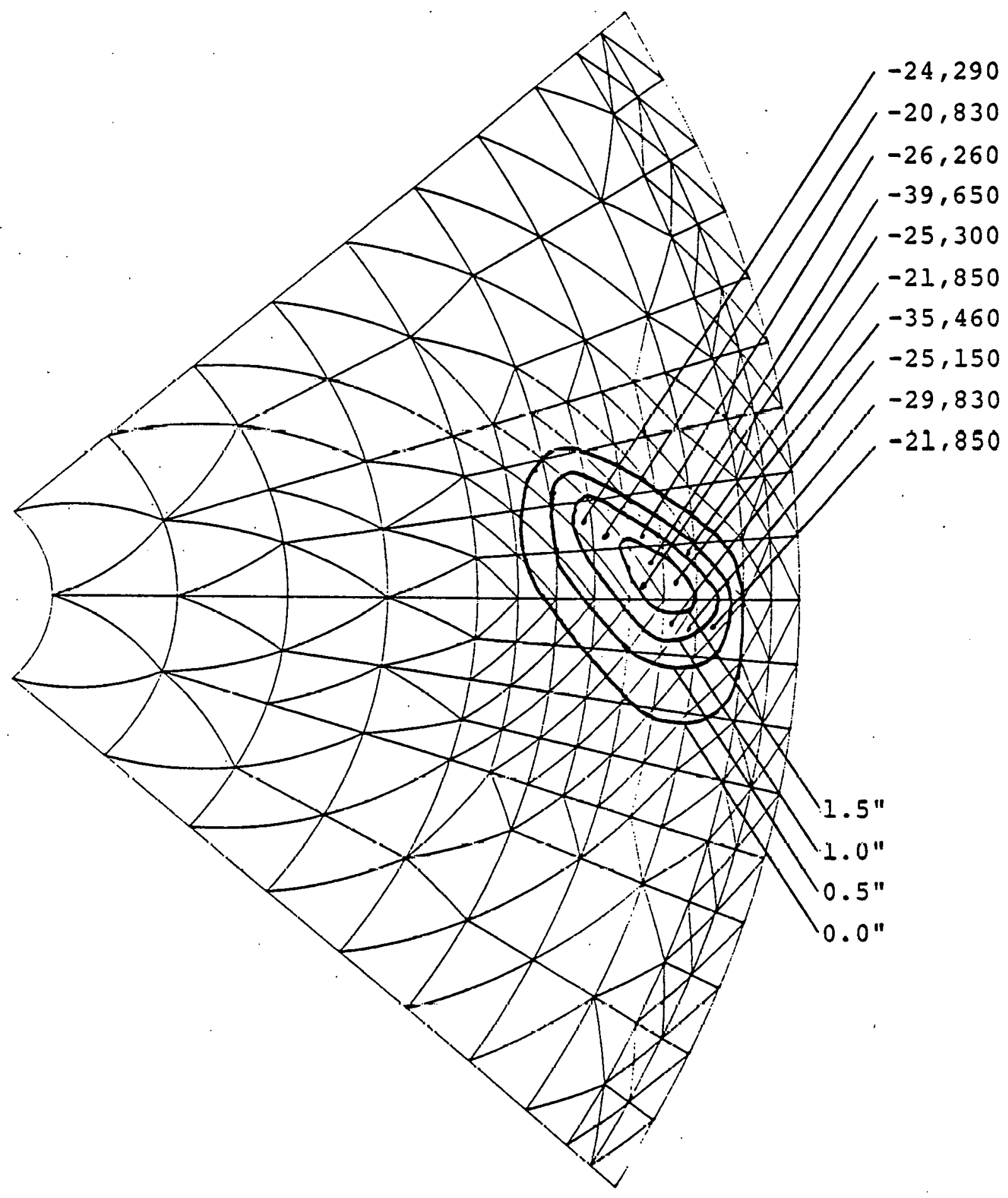

FIGURE 6. INNER SURFACE COMPRESSIVE STRESS RESULTS FOR THE ITERATIVE SOLUTION WHICH WERE GREATER THAN 20,000 pSi IN MAGNITUDE. 


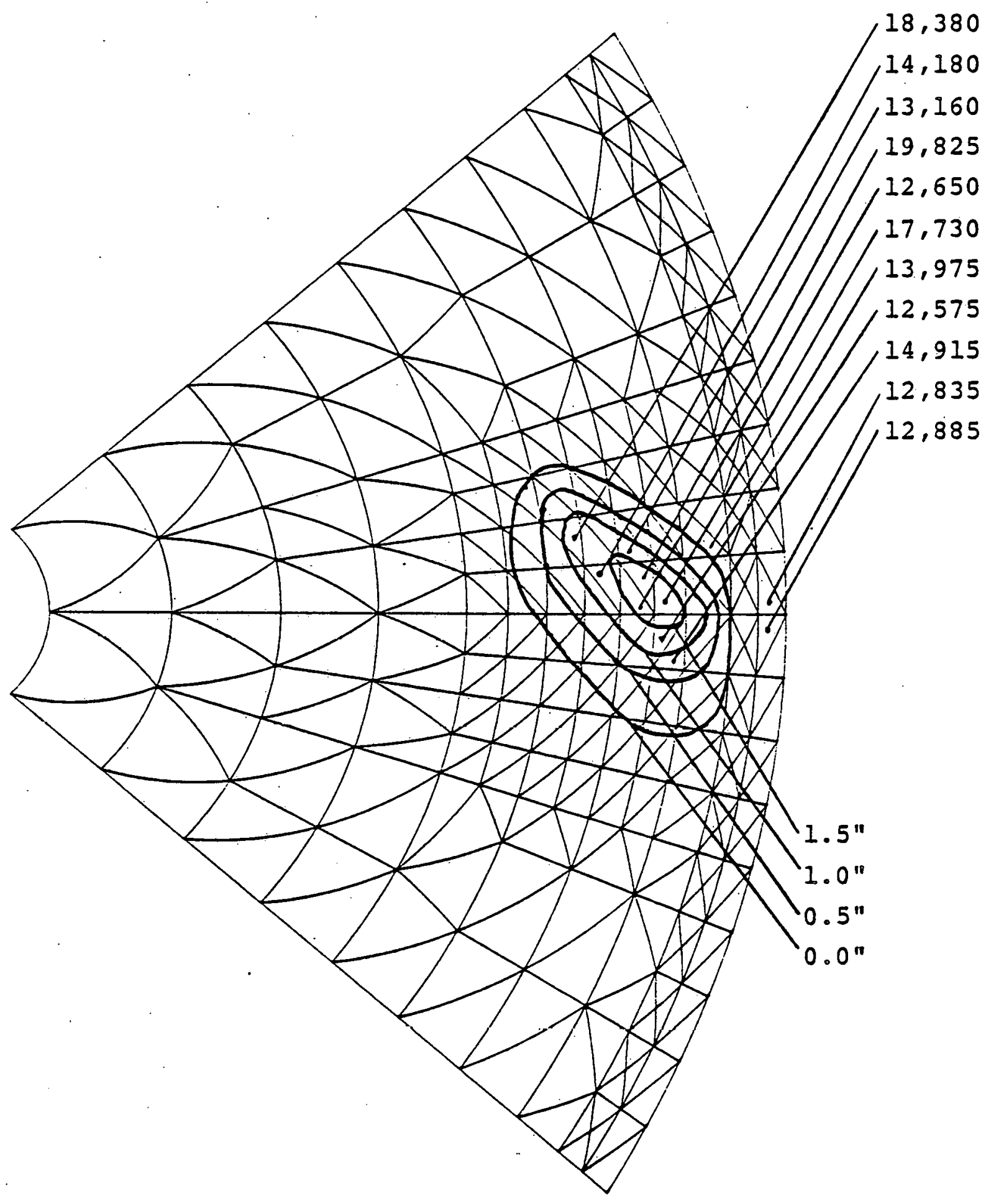

FIGURE 7. INNER SURFACE SHEAR STRESS RESULTS FOR THE ITERATIVE SOLUTION WHICH WERE GREATER THAN 12,000 psi. 


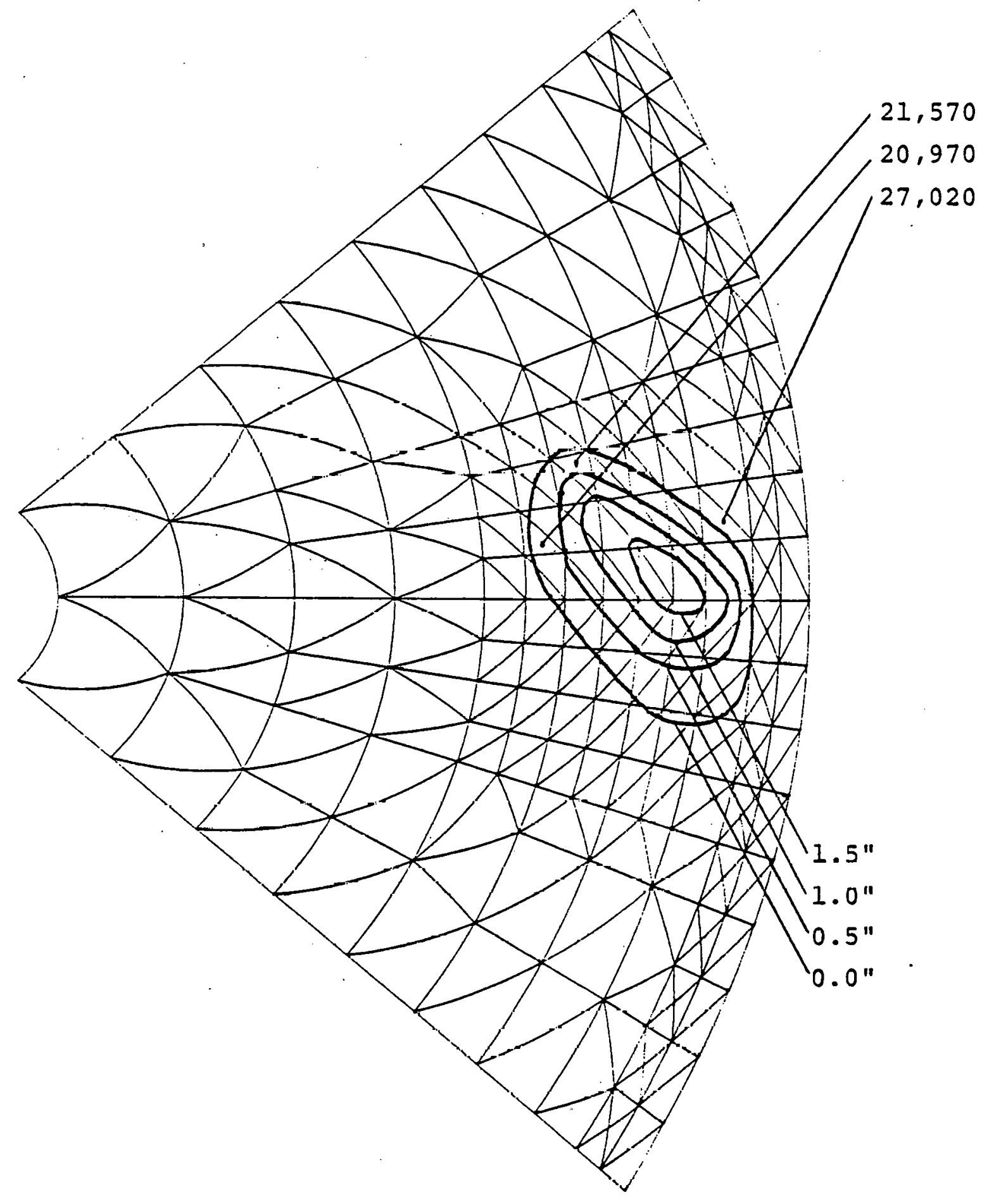

FIGURE 8. INNER SURFACE TENSILE STRESS RESULTS FOR THE CONSTRAINED SOLUTION WHICH WERE GREATER THAN 20,000 psi 


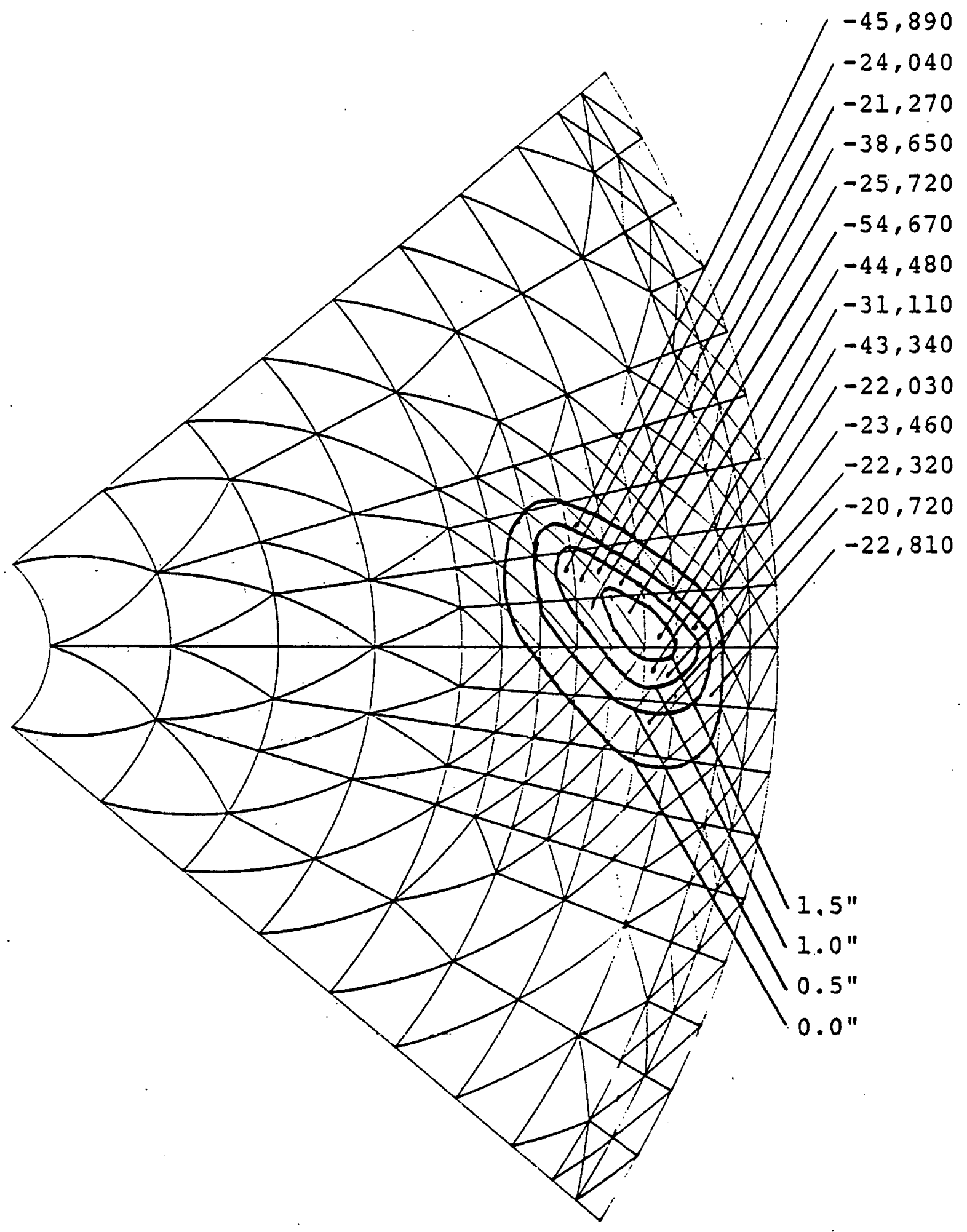

FIGURE 9. INNER SURFACE COMPRESSIVE STRESS RESULTS FOR THE CONSTRAINED SOLUTION WHICH WERE GREATER THAN 20,000 psi IN MAGNITUDE. 


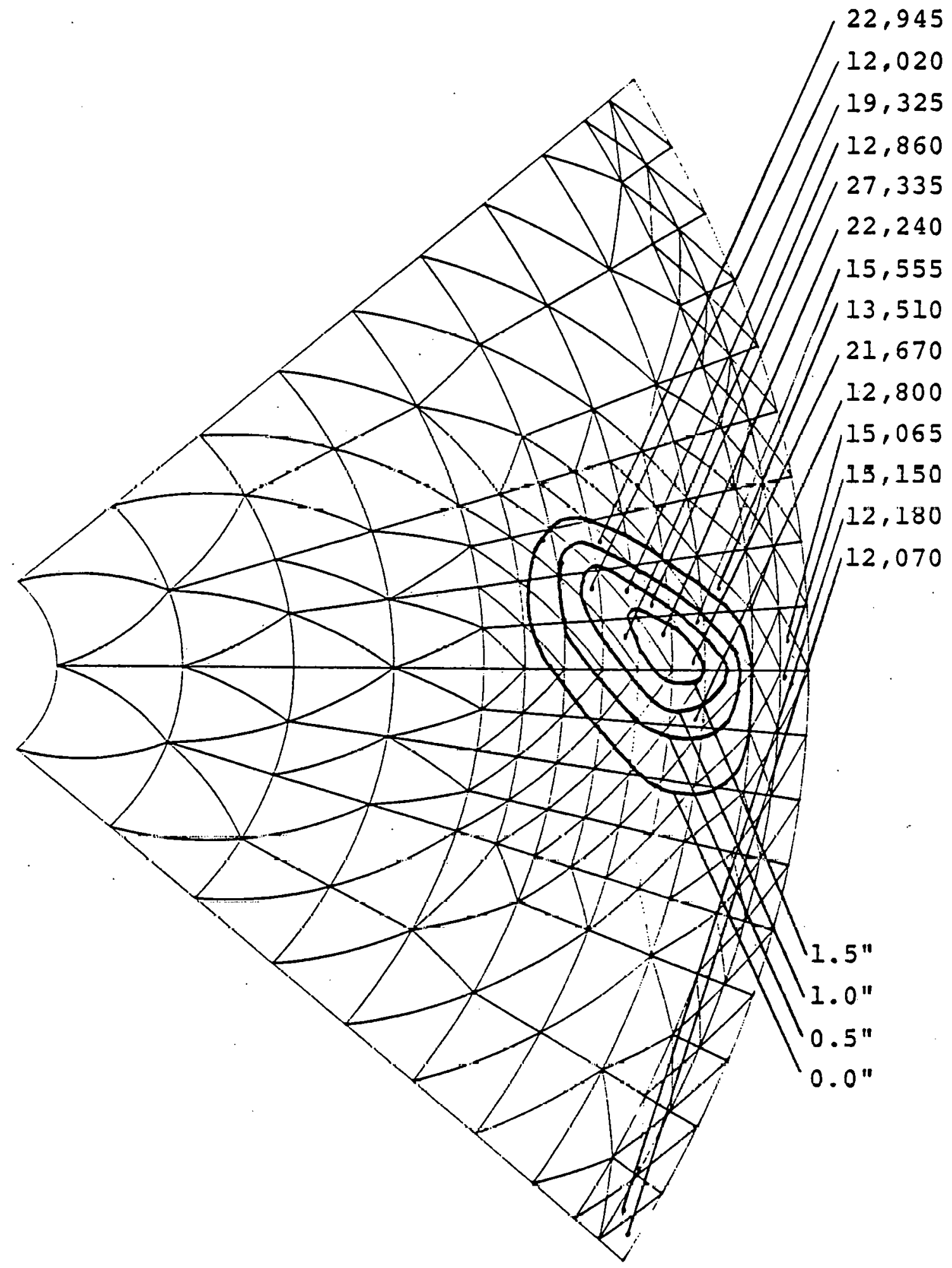

FIGURE 10. INNER SURFACE SHEAR STRESS RESULTS FOR THE CONSTRAINED SOLUTION WHICH WERE GREATER THAN 12,000 psi. 


\section{CONCLUDING REMARKS}

An ASME code category for fabrication irregularities such, as the "bump" under investigation does not exist. Therefore, a strict "code check" cannot be made. Due to the localized nature of the high stress region, and due to the back-up support of the foundation to prevent further bending, these stress levels should be self limiting. Because of this, it is our judgment that these stresses are tolerable.

It is beyond the scope of this work and the sufficiency of the developed data to render judgments about the stresscorrosion performance of the subject tank. However, considering the important role that stress corrosion will play in the longlife adequacy of the tank, the stress-corrosion question must be addressed. Stress analysis results were therefore presented to a staff member in the Engineering Technology Department of Battelle-Northwest (Mr. W. E. Anderson) who has conducted evaluations of this sort for analogous problems. (His recent publications bearing on this interpretative role are listed as 8 and 9 in the references.)

The arguments he makes are described in Appendix G. From these he provides the following summary conclusions.

\section{CONCLUSIONS}

Stresses caused by the flattening of the bumps or wrinkles noted in the subject tank should not compromise the integrity of the storage tank beyond that which would be experienced if the tank bottom had not been bumpy or wrinkly.

The subject tank should provide satisfactory performance under the expected service conditions and there should be no undue concern for placing the tank in operation insofar as stress-corrosion problems associated with the bumps or wrinkles are concerned.

These conclusions are a result of an engineering analysis. of the existing tank. The analysis cannot be regarded as a means of assigning confidence limits on the behavior of Tank SY-103 or other similar storage tanks. 


\section{REFERENCES}

1. MARC - CDC Users Information Manual, Volume I, Publication No. 17309500, Rev. G, July 1, 1975, Control Data Corporation

2. Timoshenko, S. P., and Gere, J. M., Theory of Elastic Stability, Second Edition, 1961, McGraw Hill Book Company, pg 519 .

3. Literature data and Hanford Reports by EL Moore and R Maness on Stress-Corrosion Cracking in Ass-Welded and Stress-Relieved Specimens of various Configurations.

4. Present Report; cf. pp. $25-27$

5. Interpretation of stress-corrosion literature by WE Anderson.

6. Engineering judgment of WE Anderson, based on experience with structures fabricated by commercial firms.

7. Monthly Operational Reports from Savannah River.

8. Anderson, W. E., cf. pp. 249-250 in International Metallurgical Reviews, Vol. 17, December 1972, pp 240-263.

9. Anderson, W. E., "Engineering Utility and Significance of Stress Corrosion Cracking Data" in Specialists Meeting on Stress Corrosion Testing Methods, AGARD C.P. 98, 1971. 
DESCRIPTION OF THE COMPUTER PROGRAM MONSASTIFF

MONSASTIFF (multilayer Orthotropic Nonsymmetric shell Analysis Stiffness) is a digital computer program written in FORTRAN IV. It is based on the direct stiffness analysis using numerical integration procedures. The program has been designed such that an engineer with little or no experience in shell theory and programing will be able to use the program easily and have confidence in the results. Many internal checks have been included to assure that the input to the program is reasonable. If it appears that certain input is incorrect, no computations are made. The user is informed where he has incorrect input so that he may make the appropriate corrections or additions.

MONSASTIFF will determine the displacements, forces and stresses for a composite shell of revolution. In this work, a composite shell is defined as a shell composed of a number of distinct parts which may have the following shapes: cylindrical, spheroidal, ellipsoidal, paraboloidal, conical and toroidal. The shell wall may be composed of four different layers of orthotropic materials. The shell layers are specified by giving their location with respect to a reference surface.

Mechanical and temperature loadings can be applied to the shell. For nonsymmetric loadings, the user must determine the Fourier harmonics of the loadings and perform the appropriate number of shell calculations. Temperatures can vary along the shell meridian as well through the thickness of the wall. The latter can be accomplished by specifying the temperature on the inner and outer surfaces and on three internal surfaces of the shell wall.

A shell spinning about its longitudinal axis can be analyzed. A shell subjected to harmonically varying mechanical or temperature loadings can also be analyzed.

Loading on the structure may be forces, displacements, pressures, temperatures or response spectrums. Loadings may be arbitrary time functions for linear and nonlinear dynamic analyses. $A-1$ 
BNWL-B-4.75

LAST PAGE B-12

\section{APPENDIX B}

\section{CONTENTS}

1

2

3

4
MONSASTIFF Model

Determination of Head Geometry

Dead Load Calculations

Hydrostatic Pressure Load

Determination
Page $B-1$

Page $B-2$

Page $B-5$

Page $B-7$ 


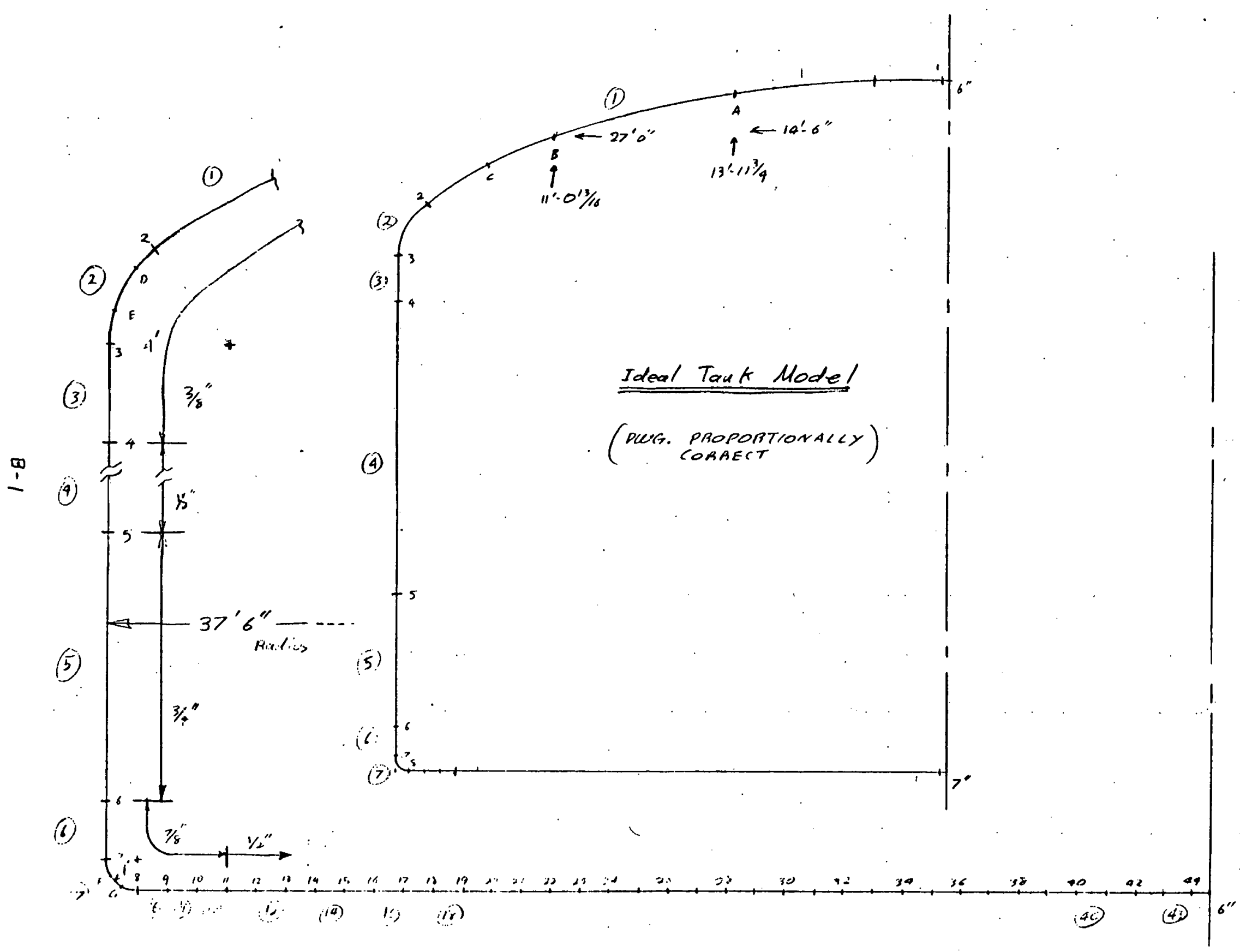



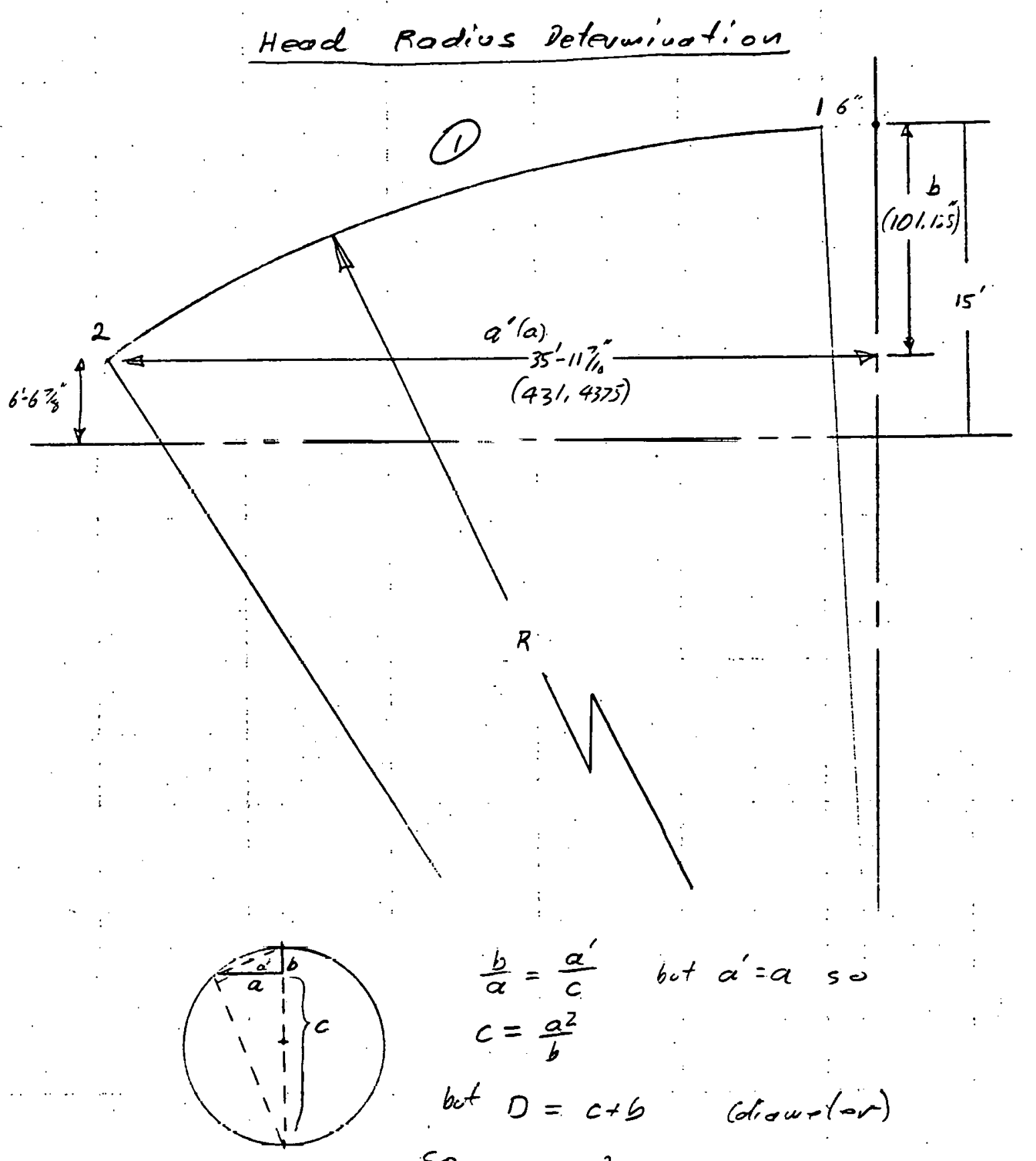

$$
\begin{aligned}
& \frac{b}{a}=\frac{a^{\prime}}{c} \quad \text { bot } a^{\prime}=a \text { so } \\
& c=\frac{a^{2}}{b}
\end{aligned}
$$

but $D=c+b$ (diawelor)

so

$$
R=\frac{a^{2} b+b}{2}
$$

$$
\begin{gathered}
R=\frac{(431,0375)^{2} /(101,125)+(101,135)}{2} \\
R=970.90 \mathrm{in}(8000164) \\
\vdots \\
\vdots \\
\vdots \\
\vdots
\end{gathered}
$$

- 
Knuctile Begion frowetuy

chord of the cirele sbown purviously is

$$
\begin{gathered}
l=\sqrt{a^{2}+b^{2}}=\sqrt{\left(431.4375 j^{2}+(101.185)^{2}\right.} \\
l=443.13
\end{gathered}
$$

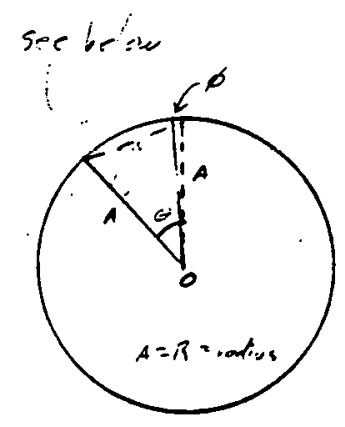

$$
\begin{aligned}
& l^{2}=2 A^{2}-2 A^{2}-\theta=\theta \\
& \cos \theta=\frac{l^{2}-2 A^{2}}{-22^{2}} \\
& \cos \phi=\frac{e^{2}-2 A^{2}}{-2 A} \quad \bar{l}=6^{\prime \prime} \\
& \phi=\operatorname{Arccos}\left[\frac{6^{2}}{-2(970.9)^{2}}+1\right] . \\
& \phi=.3541^{\circ}
\end{aligned}
$$

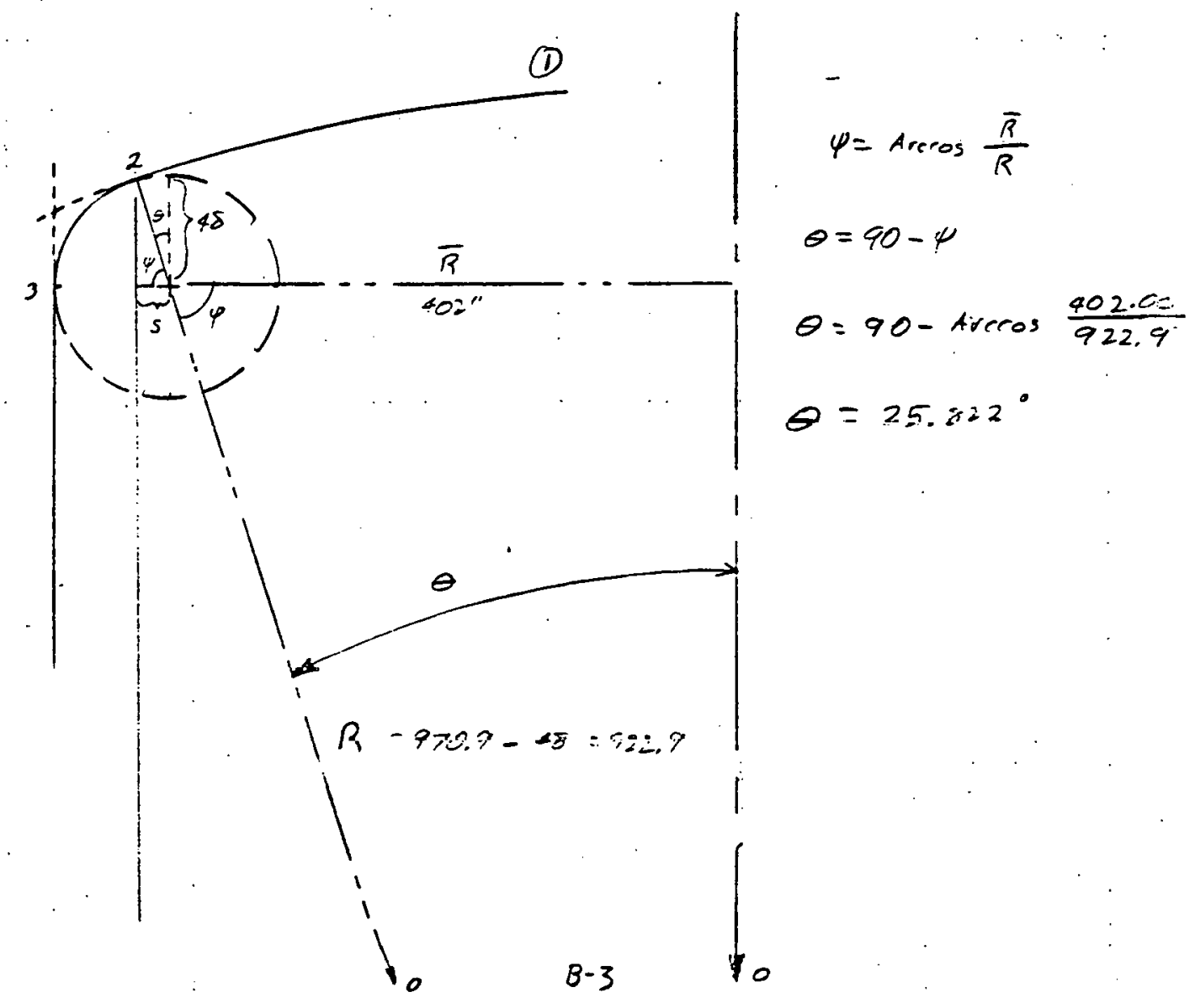


$\quad: \quad \frac{\text { Addifion of } 6^{\prime} \text { rodios }}{1 / 2^{\prime \prime} \text { plate to touk keod }}$ 
Dead Weight Load Calculations

4

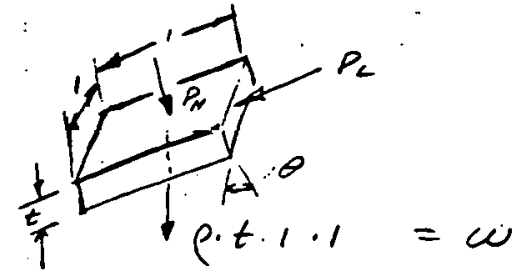

$$
\begin{array}{ll}
P_{L}=\frac{\omega}{1 \cdot t} \sin \theta & P_{N} \frac{\omega}{1.1} \cos \theta \\
P_{L}=\frac{\rho(t)(1)(1)}{(1 t)} \sin \theta & P_{N}=\frac{\rho(t)(1)(1)}{1.1} \cos \theta \\
P_{L}=\rho \sin \theta \text { (Psi) } & P_{N}=\rho(t) \cos \theta(p s)
\end{array}
$$

$$
p=.284 \mathrm{lbf} / \mathrm{in}^{3}
$$

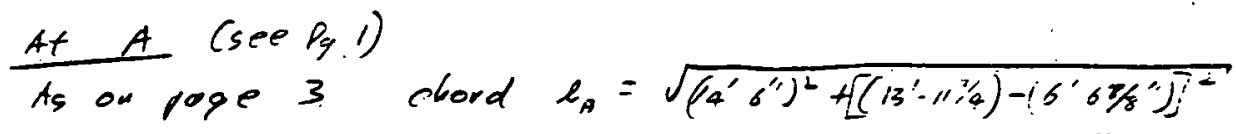

$$
l_{0}=\sqrt{(30276)+(7898.77)}
$$

$B=970.9 \mathrm{in}$

$l_{A}=195.38 \mathrm{in}$

$$
\begin{aligned}
& \theta=\operatorname{Ascro}: \frac{l^{2}-2 R^{2}}{-2 B^{2}}=\operatorname{Arccos} 1-\frac{l^{2}}{2 R^{2}} \\
& \theta_{A}=\operatorname{Arrros}\left[1-\frac{195.88^{2}}{2(970.5)^{2}}\right] \\
& \theta_{A}=11.55
\end{aligned}
$$

$$
\text { Af B } \begin{aligned}
\left(\text { see } P_{g}^{\prime}\right) & =\sqrt{\left(27^{\prime} j^{2}+\left[\left(11^{\prime}-0 \% / 6\right)-16^{\prime} 6 \%^{\prime}\right)\right]^{2}} \\
& =\sqrt{104976+2909,25} \\
e_{B} & =328,46
\end{aligned}
$$

BD 


$$
\begin{gathered}
\theta_{8}=\operatorname{Arrros}\left[1-\frac{328.05) 2}{2(9.00 .9)^{2}}\right] \\
\theta_{0}=19.480
\end{gathered}
$$

A $C$

$$
\begin{aligned}
& \theta_{c}=\frac{\theta_{B}+\theta_{2}}{2} \\
& \theta_{c}=\frac{19.48+25.822}{2}=22.651^{\circ}
\end{aligned}
$$

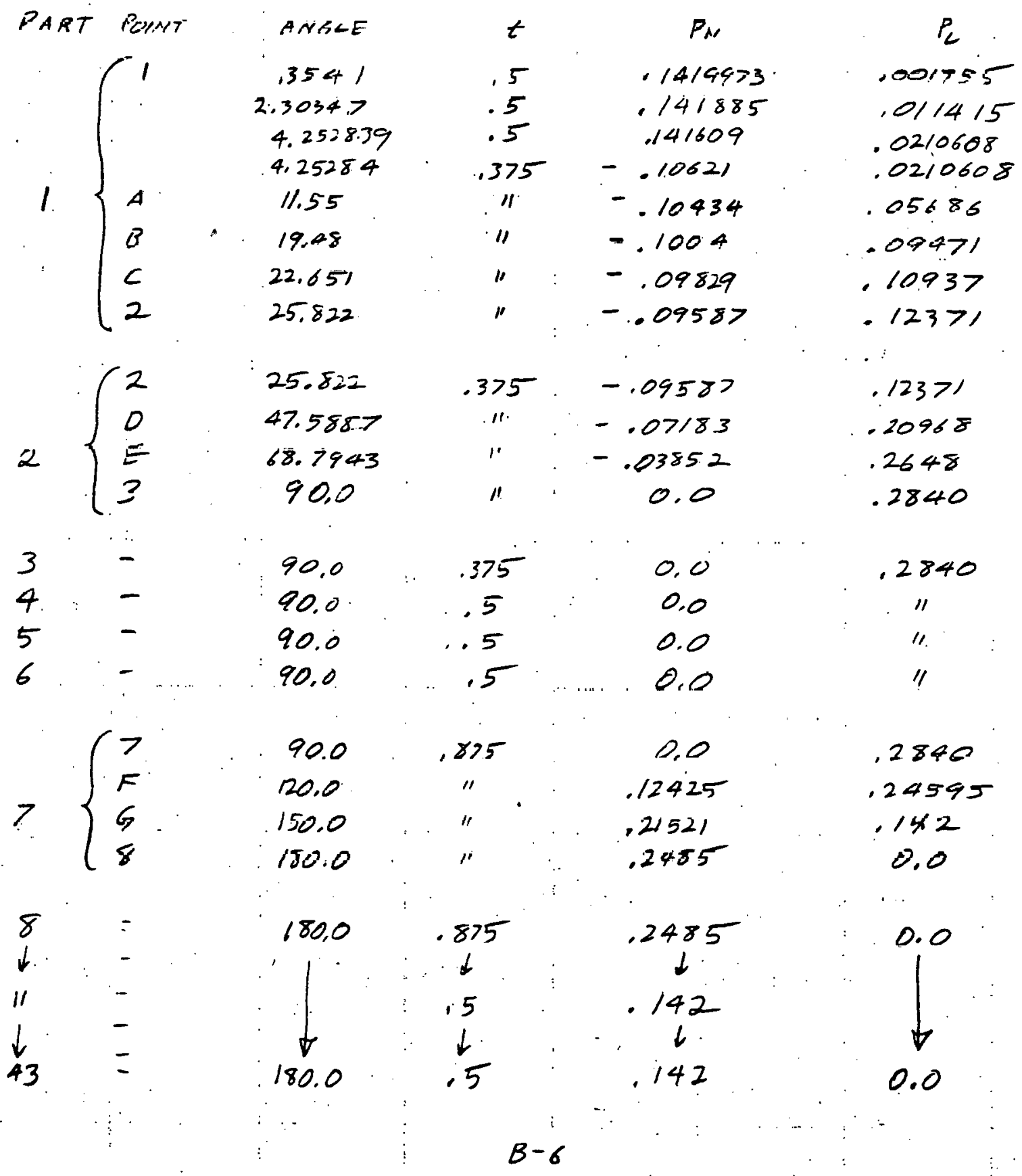


$\frac{\text { Pressuve loods for }}{a_{5} \mathrm{H}_{2} \mathrm{O} \text { 40ig }}$

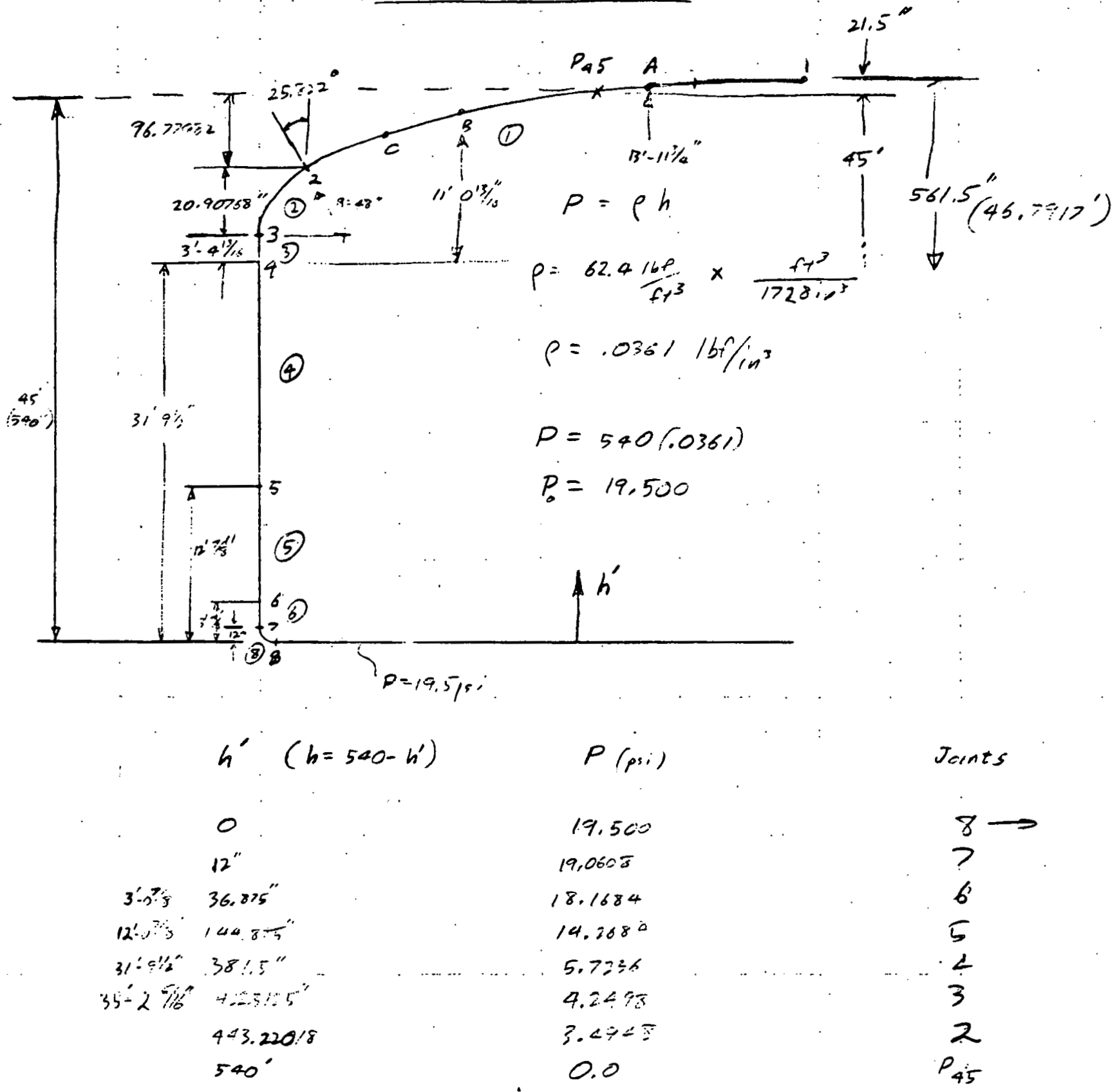

see $p p>8 \%$ for lorotion st $P_{45}$

$B-7$ 

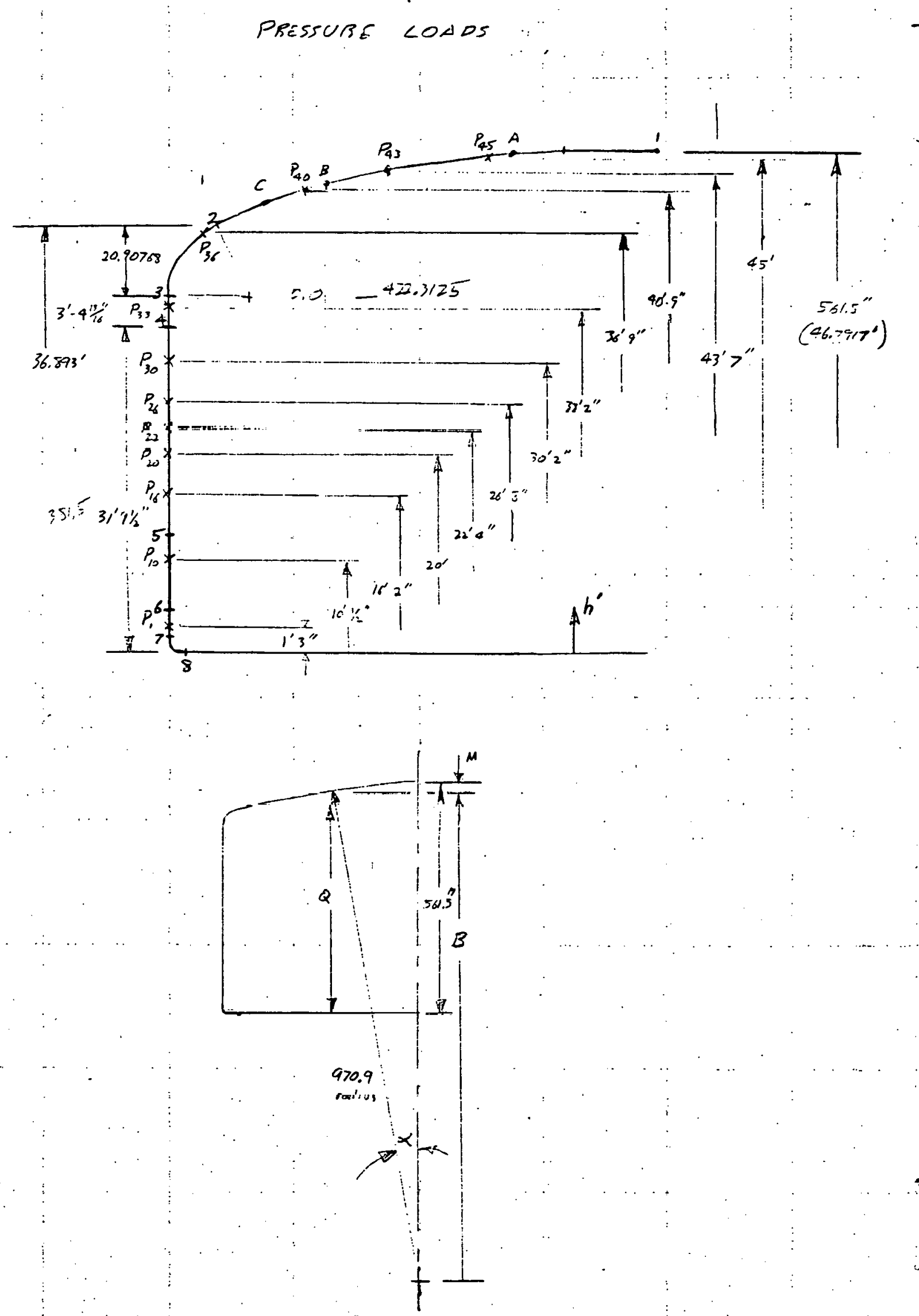

B- 8 
8

$$
\begin{aligned}
& \begin{array}{cccc}
Q & M & B & \alpha \\
& 561.5-Q & .970 .9-M & \text { Arcos }=\frac{B}{400.9}
\end{array} \\
& \begin{array}{cccl}
45^{\prime}\left(540^{\prime}\right) & 21.5 & 949.4 & 12.08020537 \\
43^{\prime} 7^{\prime \prime}\left(523^{\prime \prime}\right) & 38.5 & 932.4 & 16.1892 .334 \\
40^{\prime} 9^{\prime \prime}\left(484^{\prime \prime}\right) & 72.5 & 898.4 & 22.782282 \\
36^{\prime} 7^{\prime \prime}\left(441^{\prime \prime}\right) & 120.5 & 850.4 & 28.84971335
\end{array}
\end{aligned}
$$

$$
\begin{aligned}
& P(s, i)=p h \text { (os ow poge } 6 \quad p=.0361 \text { ) }
\end{aligned}
$$

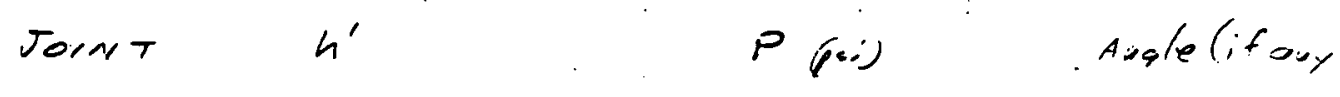

$$
\begin{aligned}
& 43^{\prime}>^{\prime \prime} \quad\left\{h=523-h^{\prime}\right\} \\
& \begin{array}{ll}
P_{43} & 523 \\
2 & 443.22018 \\
3 & 422.3125 \\
4 & 381.5 \\
5 & 124.575 \\
6 & 36.875 \\
7 & 12 \\
8 \rightarrow & 0
\end{array} \\
& 0.0 \quad 16,18923834 \\
& 2.88005 \\
& 25.822 \\
& 3.63482 \\
& -90.0 \\
& 40^{\prime}-9^{\prime \prime} \quad\left\{n=489-n^{\prime}\right\} \\
& \begin{array}{ll}
P_{40} & 489 \\
2 & 403.22018 \\
3 & 422.3125 \\
4 & 381.5 \\
5 & 104.515 \\
6 & 36.875 \\
7 & 12 \\
8 \rightarrow & 0
\end{array} \\
& \begin{array}{lc}
0.0 & 22.282282 \\
1.65465 & 25.822 \\
2.8074 & 90.0 \\
3.88075 & \\
12.4251 & \\
16.3217 & \\
17.3 .197 & \\
17.6529 &
\end{array}
\end{aligned}
$$




$$
\begin{aligned}
& \text { Jornt h' ppsi) Augle (ifoky) } \\
& 36^{\prime} q^{\prime \prime}:\left\{h=441-h^{\prime}\right\} \\
& P_{36} \quad 441 \\
& 0.67462 \\
& 2.14795 \\
& 10.6901 \\
& 14.5889 \\
& 6 \quad 36.575 \\
& 12 \\
& 15.4869 \\
& 8 \rightarrow 0 \\
& 33^{\prime} z^{\prime \prime} \quad\left\{h=398-b^{\prime}\right\} \\
& P_{33} \quad \vdots \quad 398 \\
& 4.381 .5 \\
& 5 \quad 144,8>5 \\
& 36.575 \\
& \begin{array}{l}
7 \\
8 \rightarrow \quad 12
\end{array} \\
& 30^{\prime} z^{\prime \prime} \quad\left\{h=362-4^{\prime}\right\}
\end{aligned}
$$

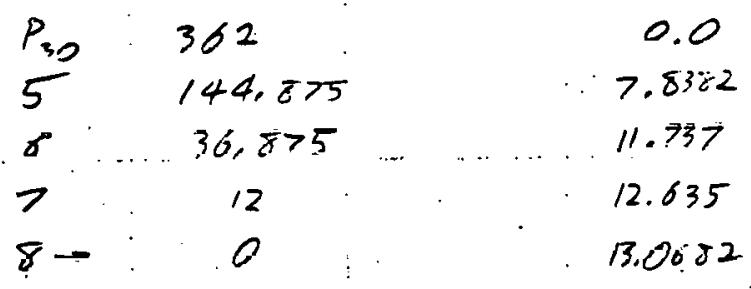

$$
\begin{aligned}
& 26^{\prime \prime} \delta^{\prime \prime} \quad\left\{h=320-4^{\prime}\right\} \\
& P_{26} \quad 3=0 \\
& \text { o. } 0 \\
& 5: 148.875 \\
& 36.375 \\
& 7 \quad 12 \\
& 6.3270 \\
& 10.220 \mathrm{~J} \\
& 11.1186 \\
& 8 \rightarrow \vdots 0 \\
& 11.552 \\
& \text { B-10 }
\end{aligned}
$$


JOINT

$$
\begin{gathered}
h^{\prime} \\
22^{\prime} 4^{\prime \prime} \quad\left\{h=268-h^{\prime}\right\}
\end{gathered}
$$

$\frac{P_{22}}{5}$

268

0.0

140,375

4.4448

6

36.875

8.3436

7

12.0

9.2416

$8 \rightarrow$

0.0

9.6748

$$
\text { 2o. } \quad\left\{h=240-h^{\prime}\right\}
$$

$$
\begin{aligned}
& \begin{array}{lcr}
P_{20} & 240 . & 0.0 \\
5 & 100.875 & 3.4340 \\
6: 875 & 7.3528 \\
7 & 12.0 & 8.2308 \\
\delta \rightarrow & 0.0 & 8.664
\end{array} \\
& { }_{16}^{\prime} 2^{\prime \prime} \quad\left\{h=194-h^{\prime}\right\}
\end{aligned}
$$

$\begin{array}{cc}P_{16} & 194 \\ 5 & 140.875 \\ 6 & 30.875 \\ 7 & 12.0 \\ 8 \rightarrow & 0.0\end{array}$

0.0

$$
1.7734
$$

$5.67: 2$

6.5702

7,0034

$$
10^{\prime} 0^{\prime \prime}{ }^{\prime \prime} \quad\left\{h=120,5-h^{\prime}\right\}
$$
$P_{10}$
120.5
0.0
36.875
3.01886
$7 \quad 12.0$
3.91635
$8 \rightarrow$
4,35005 


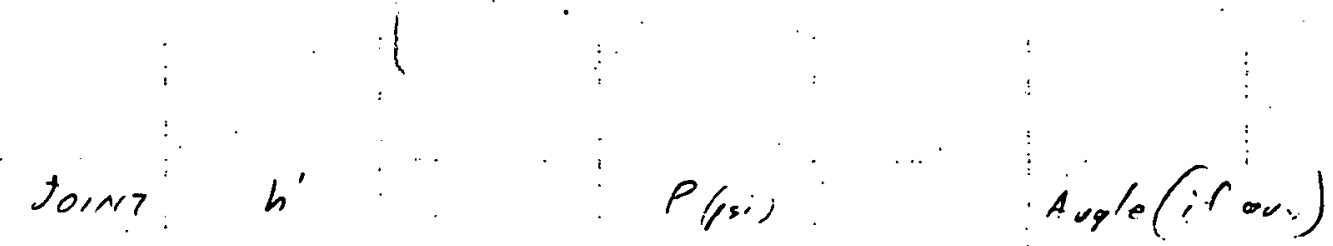

$$
\begin{aligned}
& 1^{\prime \prime} \quad\left\{n=15-6^{\prime}\right\} \\
& P_{1}: 15.0: 0.0 \\
& 7 \quad 12.0 \quad .1083 \\
& 8 \rightarrow \quad 0.0 \quad .5415
\end{aligned}
$$$$
\text { Iff obous tout beod }
$$$$
h=6,5,5.69^{\prime} .
$$

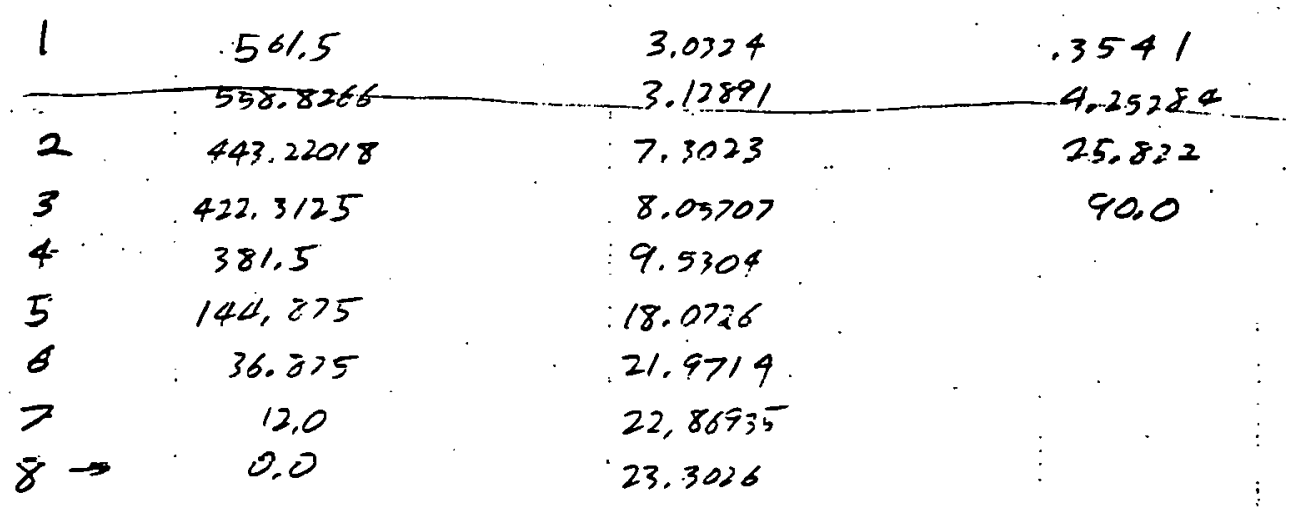

$B-12$ 


\section{APPENDIX C}

GRAPHICAI REPRESENTATION OF MERIDIONAI AND CIRCUMFERENTIAL STRESSES FOR VARIOUS WATER LEVELS

NOTE: The scales on the various figures contained in this Appendix are not consistent. Use great care when comparing stress levels between figures.

Pages $C-63$ and $C-64$ show results for assumed waste fill to $30^{\prime} 2$ " at Sp. Gr. of 1.7 (including dead weight)

Pages $c-65$ and $C-66$ show the same for Sp. Gr. of 2.0 


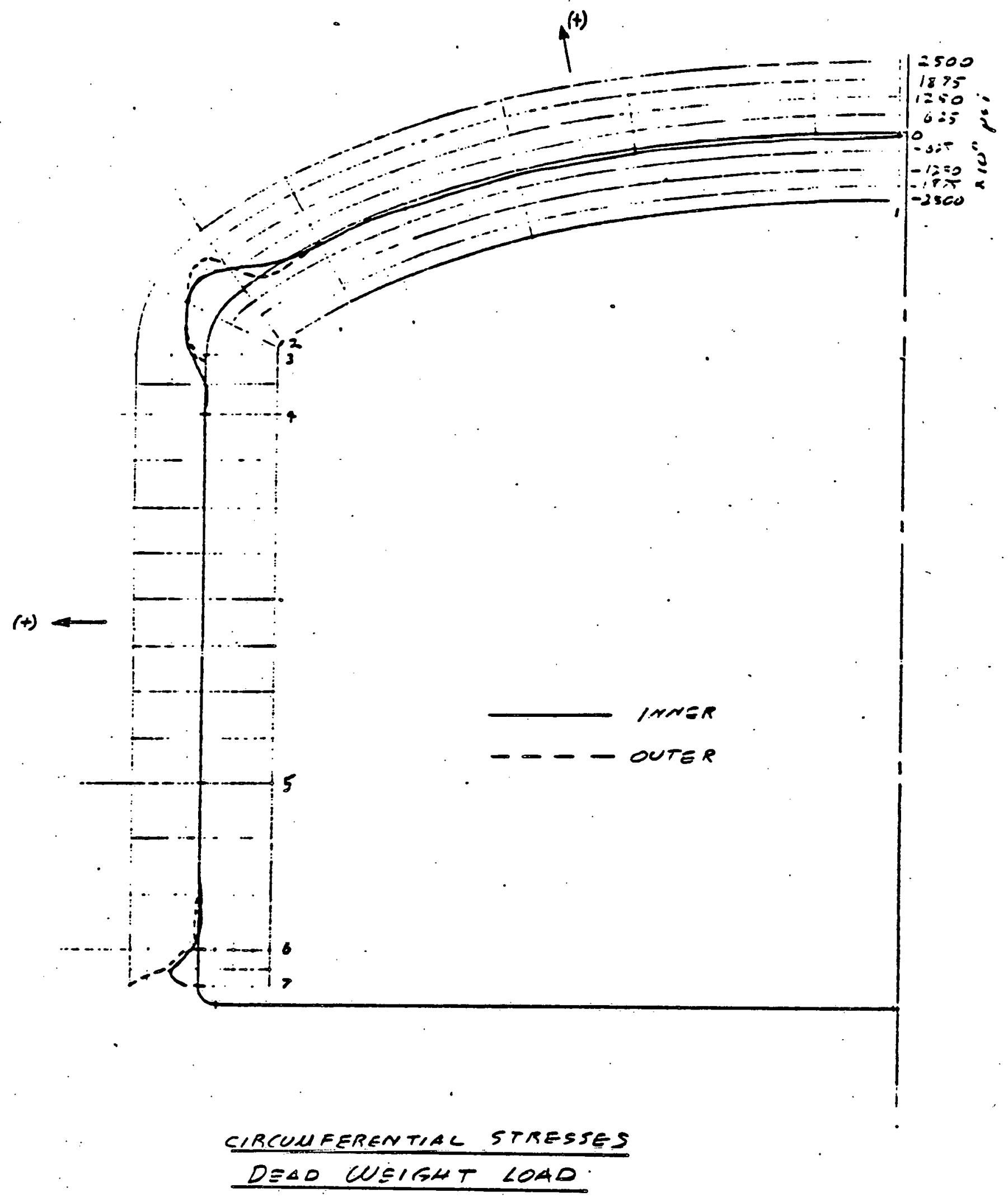




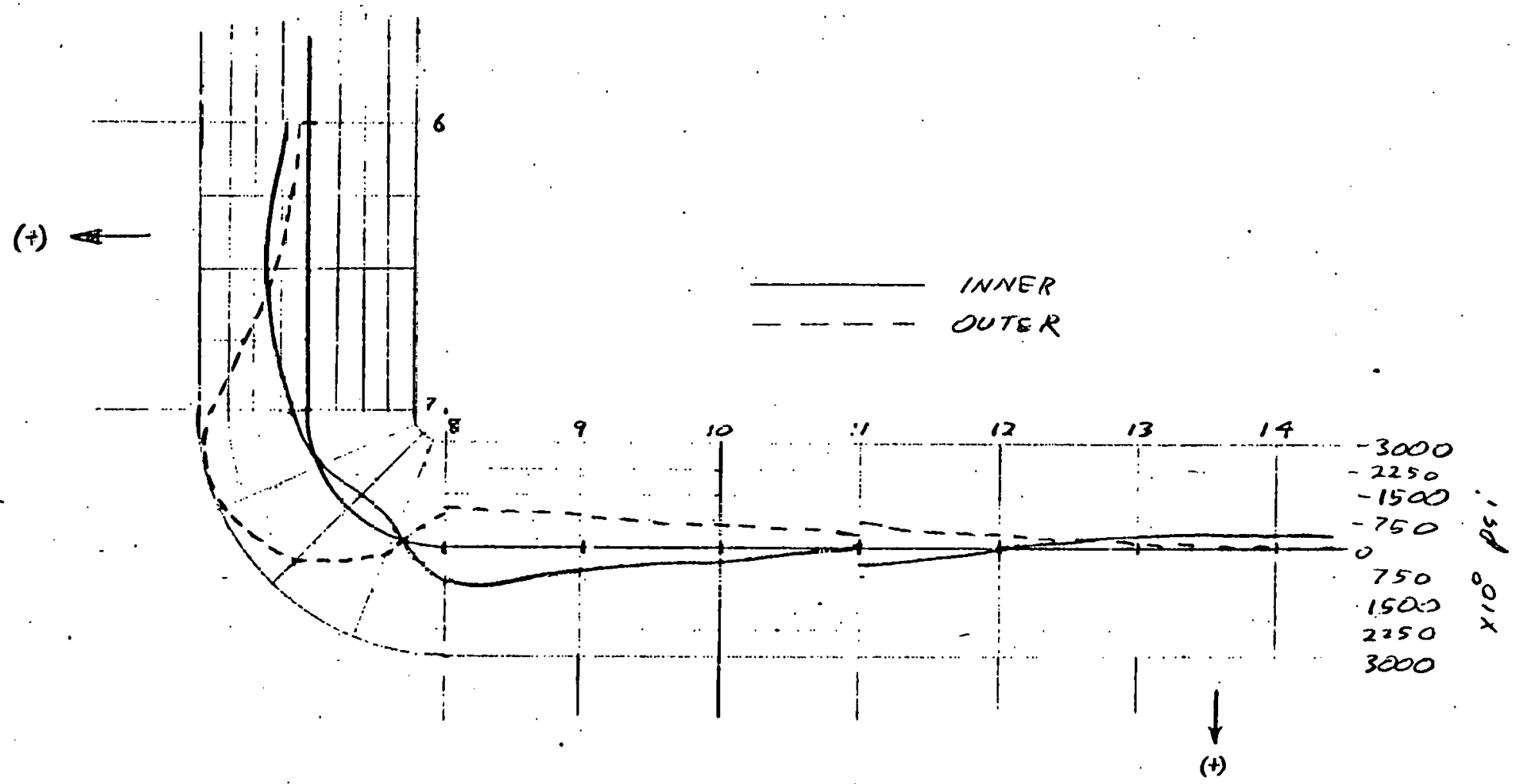

$\frac{\text { CIRCONFERENTIAL STRESSE: }}{\text { PEAD WEIGHT LOAD }}$ 


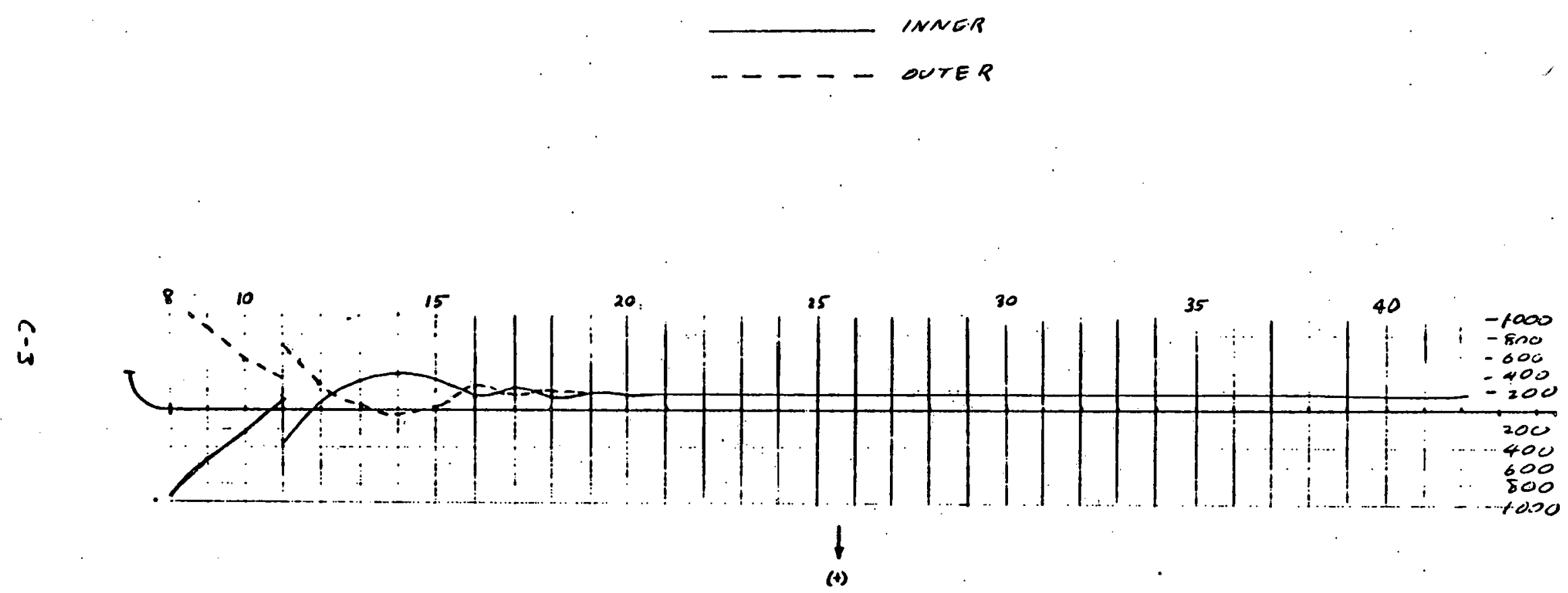

CIACUMAERENTIAL STRESSES

PEAD WEIEHT LOADS 


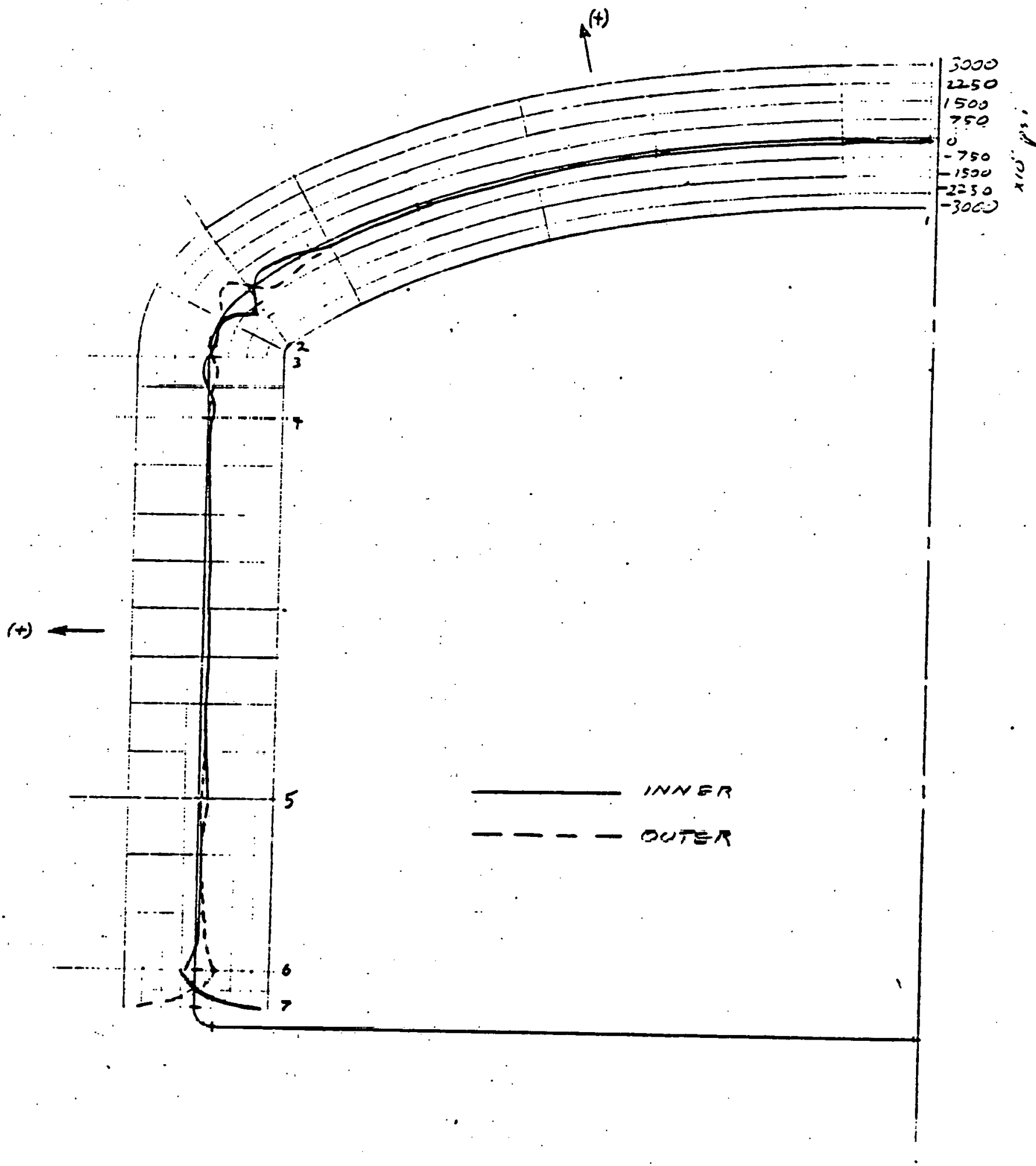

MERIDIONAL STRESSES

DEAO WEIGHT LOAD 


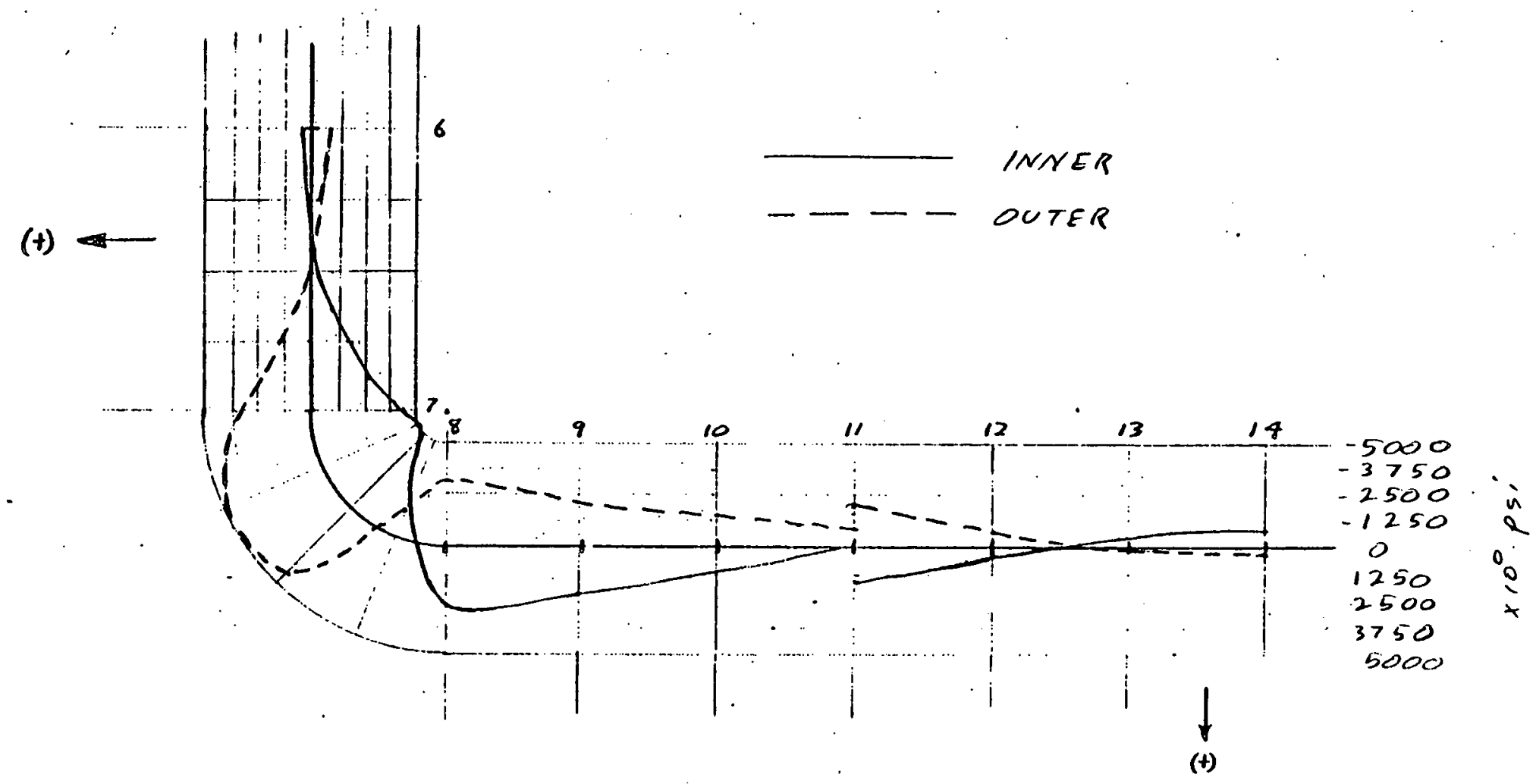

MERIDIONAL STRESSES

DEAD WEIGHT $\angle O A D$ 

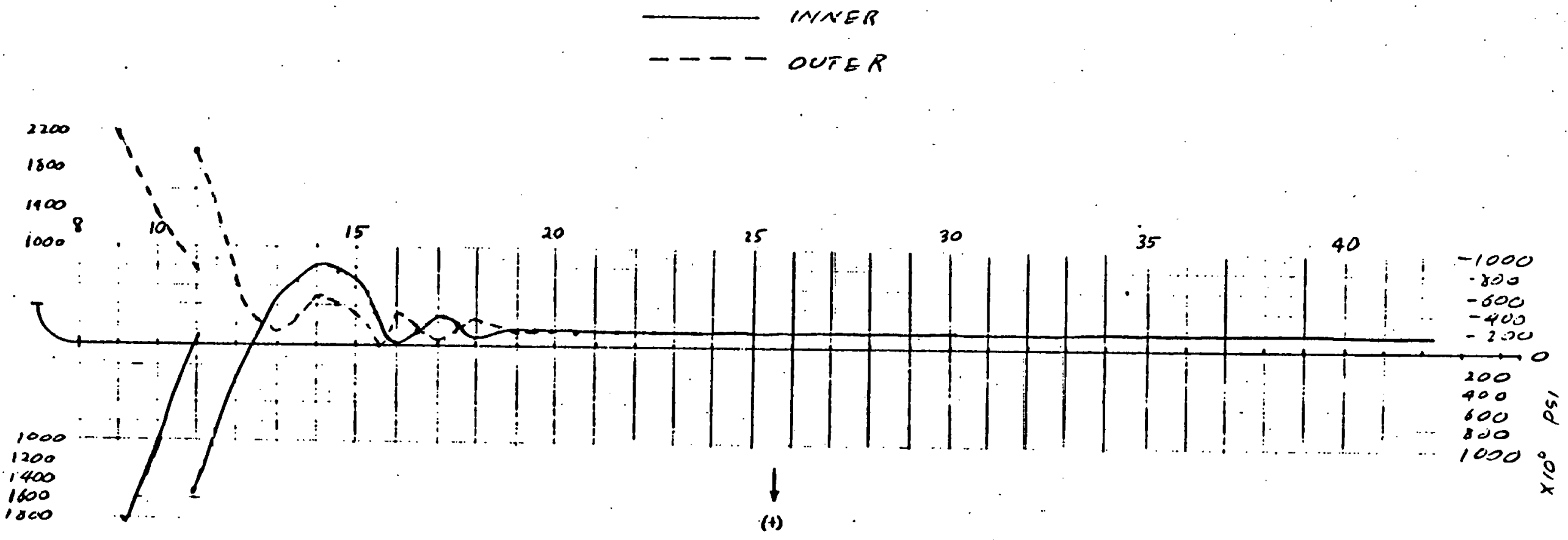

MEBIDIONAL STIESSES
DEAD WEIEHT LOAD 


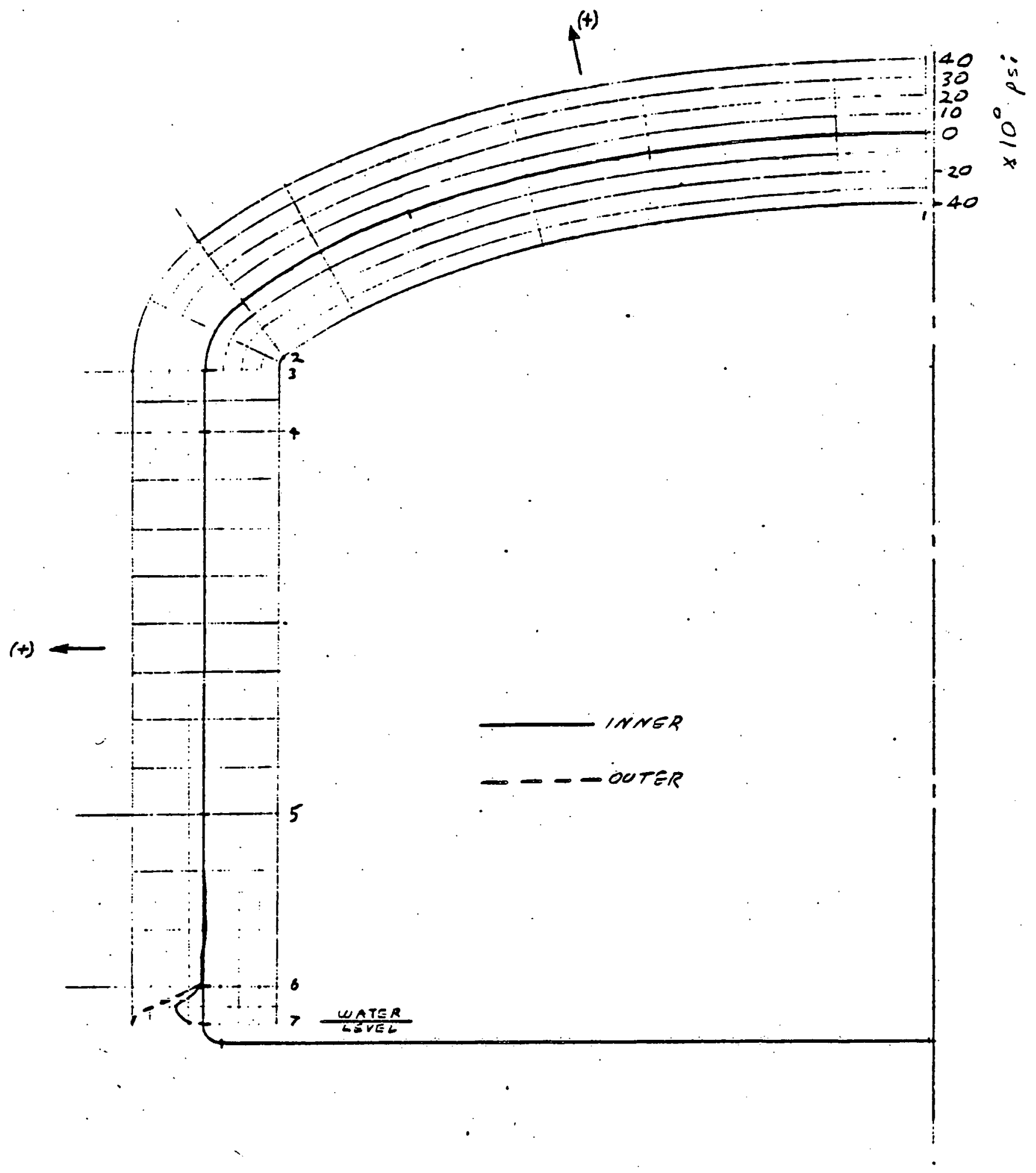

$\frac{\text { CIRCUMFEPENTIAL STREESES }}{I^{\prime} 3^{\circ} \text { WATER LEVEL }}$ 


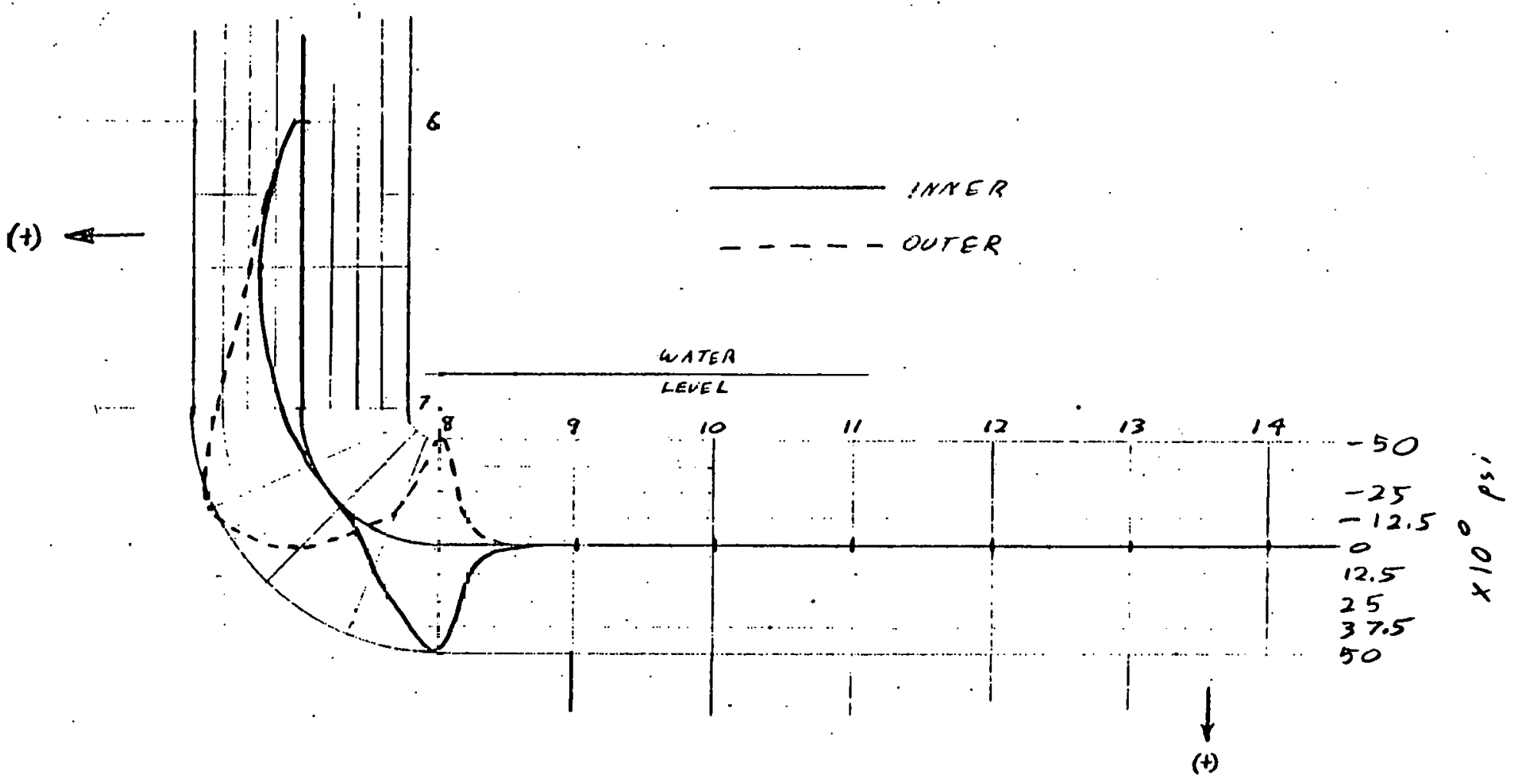

$\frac{\text { CIRCUMFERENTIAL STRESSES }}{I^{\prime} 3^{\prime \prime} \text { WATER LEUEL }}$ 


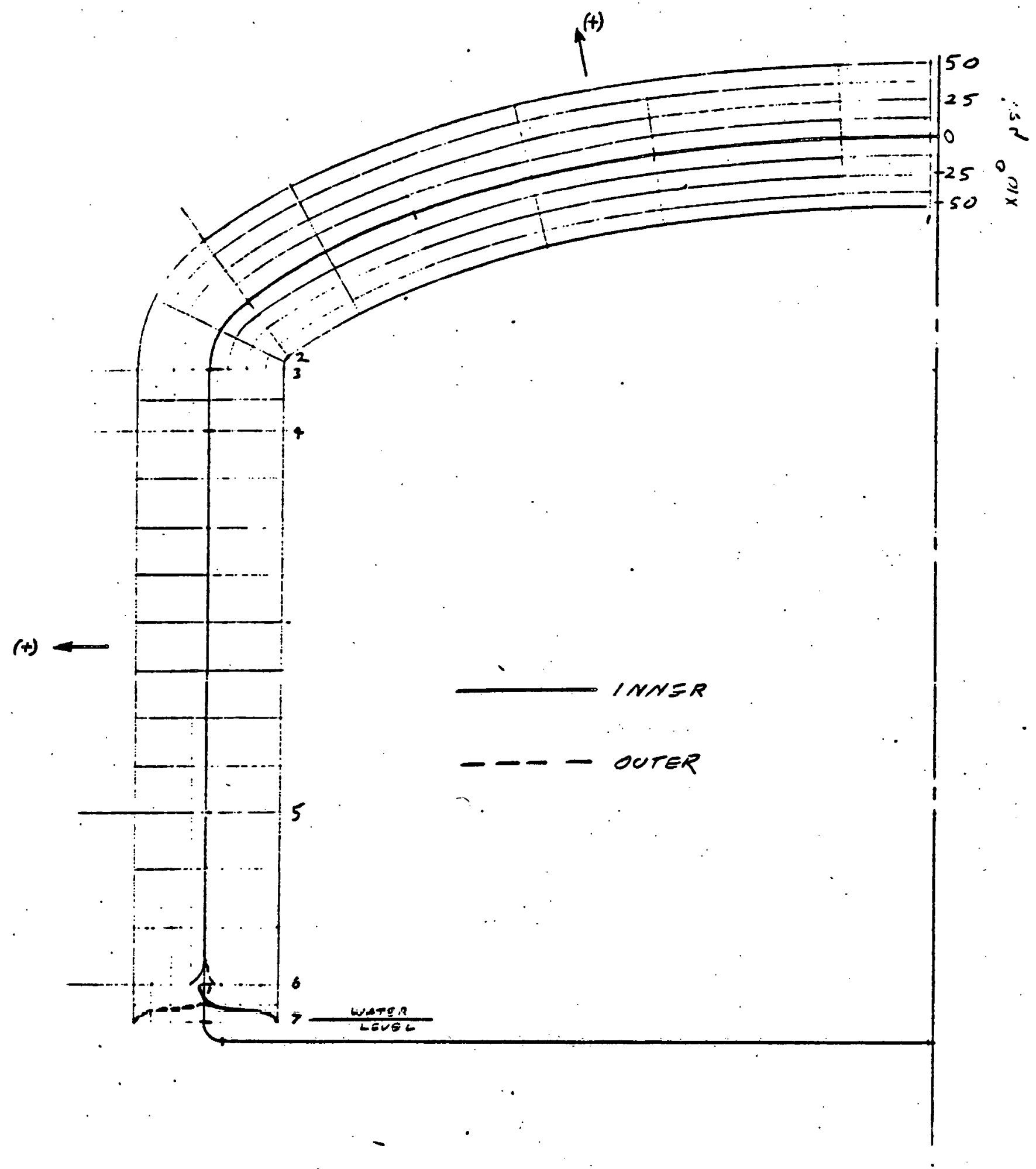

MERIOIONAL STRESSES

1' 3' WATER LEUEL

$6-9$ 


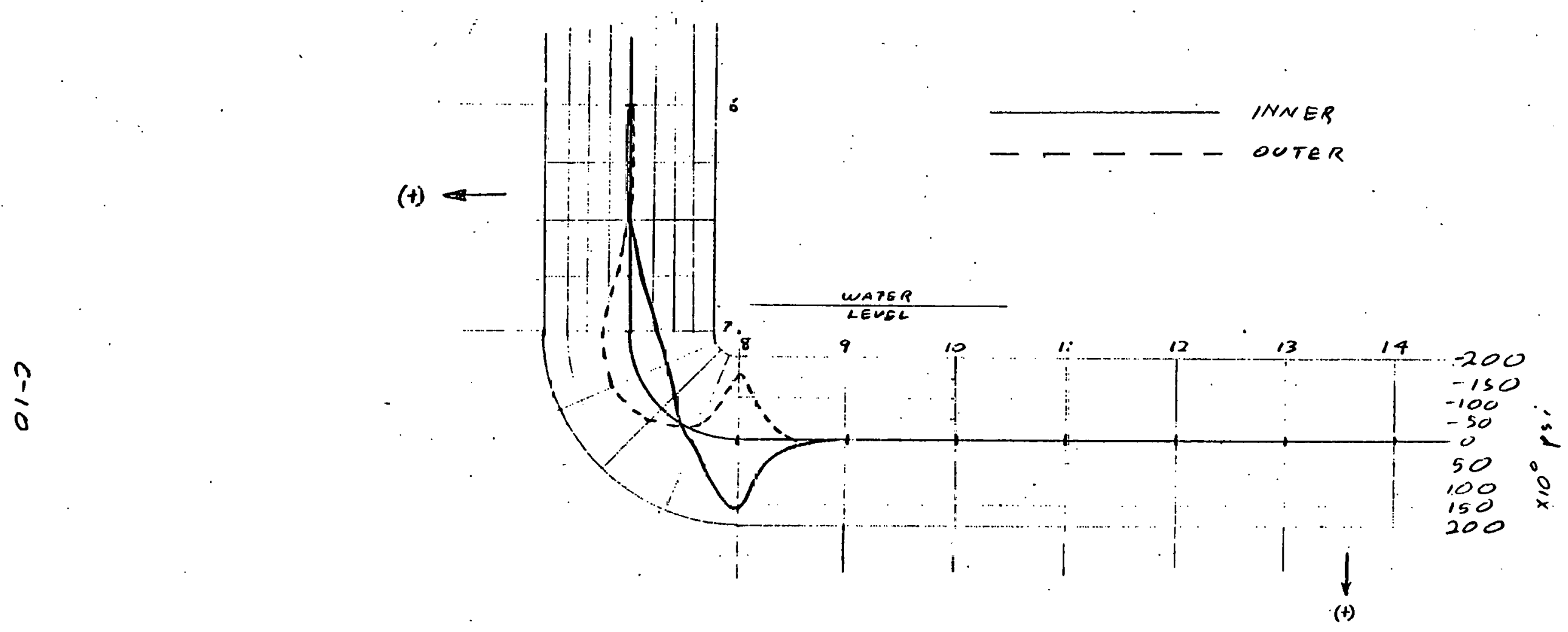

$\frac{\text { MERINIONAL STRESSES }}{\text { I'3' WATER LEUEL }}$ 


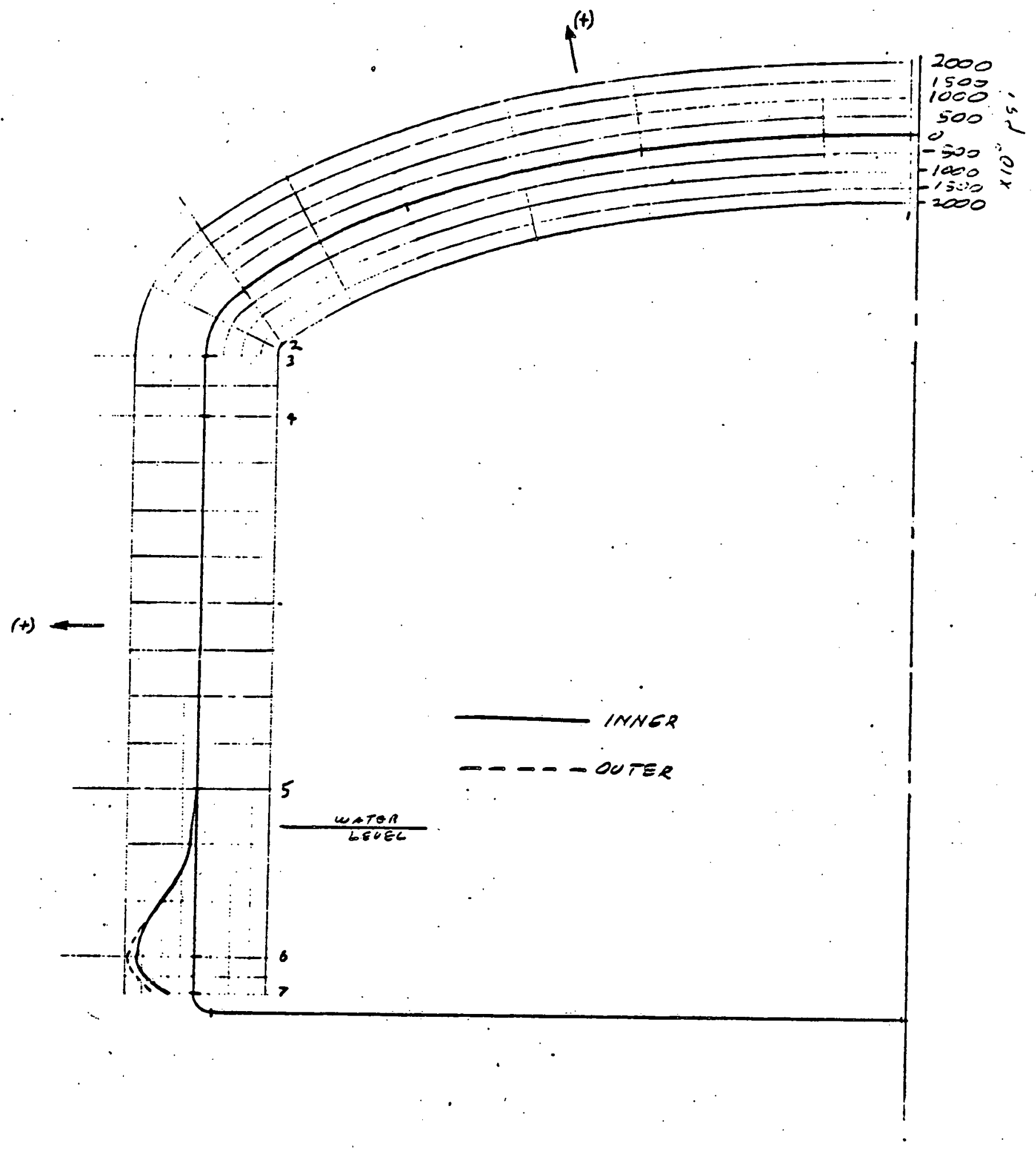

CIBCUMFEAENTIAL STRESSES

$10^{\prime} 1 / 2$ " WATER GEVEL 


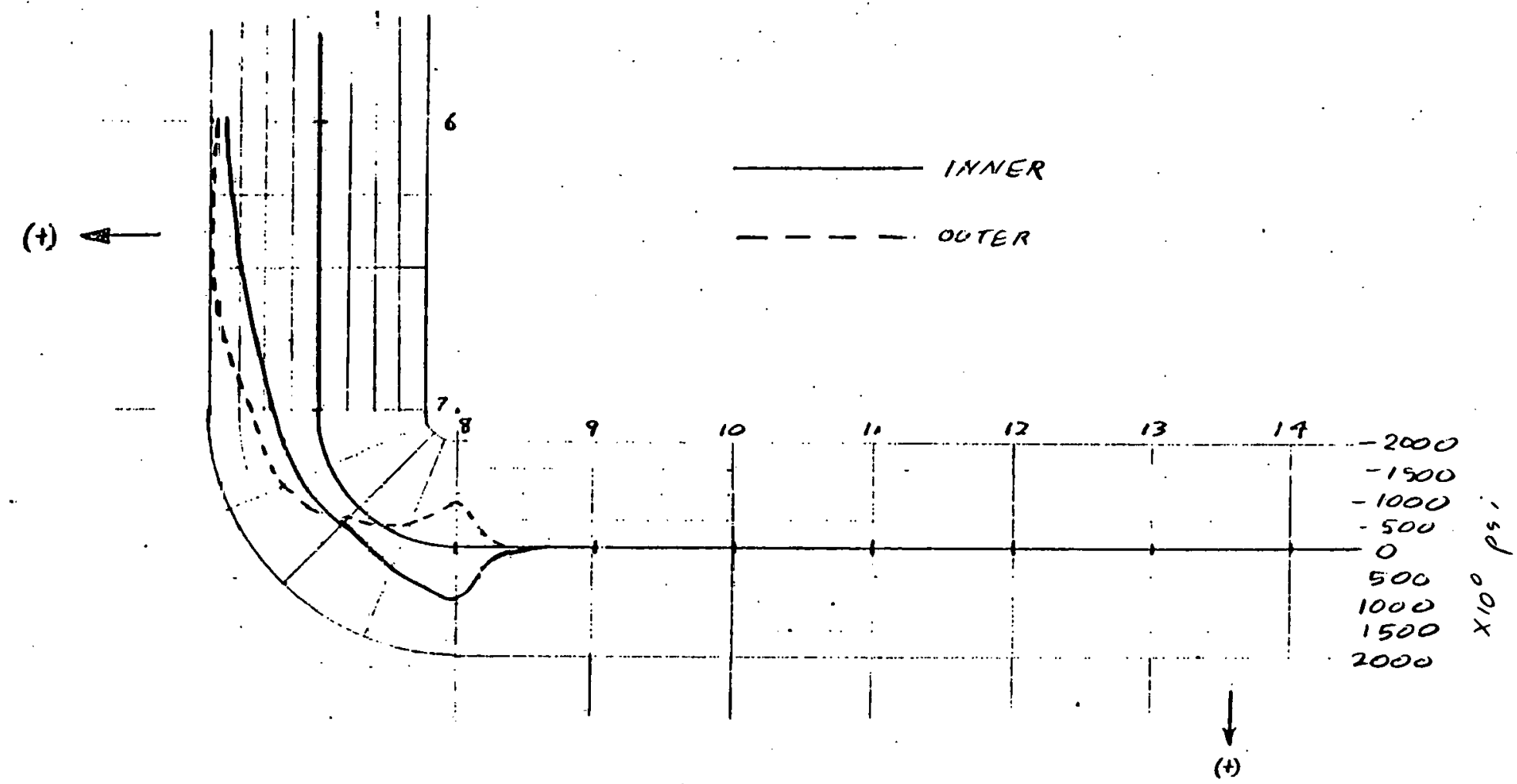

$\frac{\text { CITCUMFEPENTIAL STRESTES }}{10^{\prime} 1 / 2^{\prime \prime} \text { WATER LEVEL. }}$ 


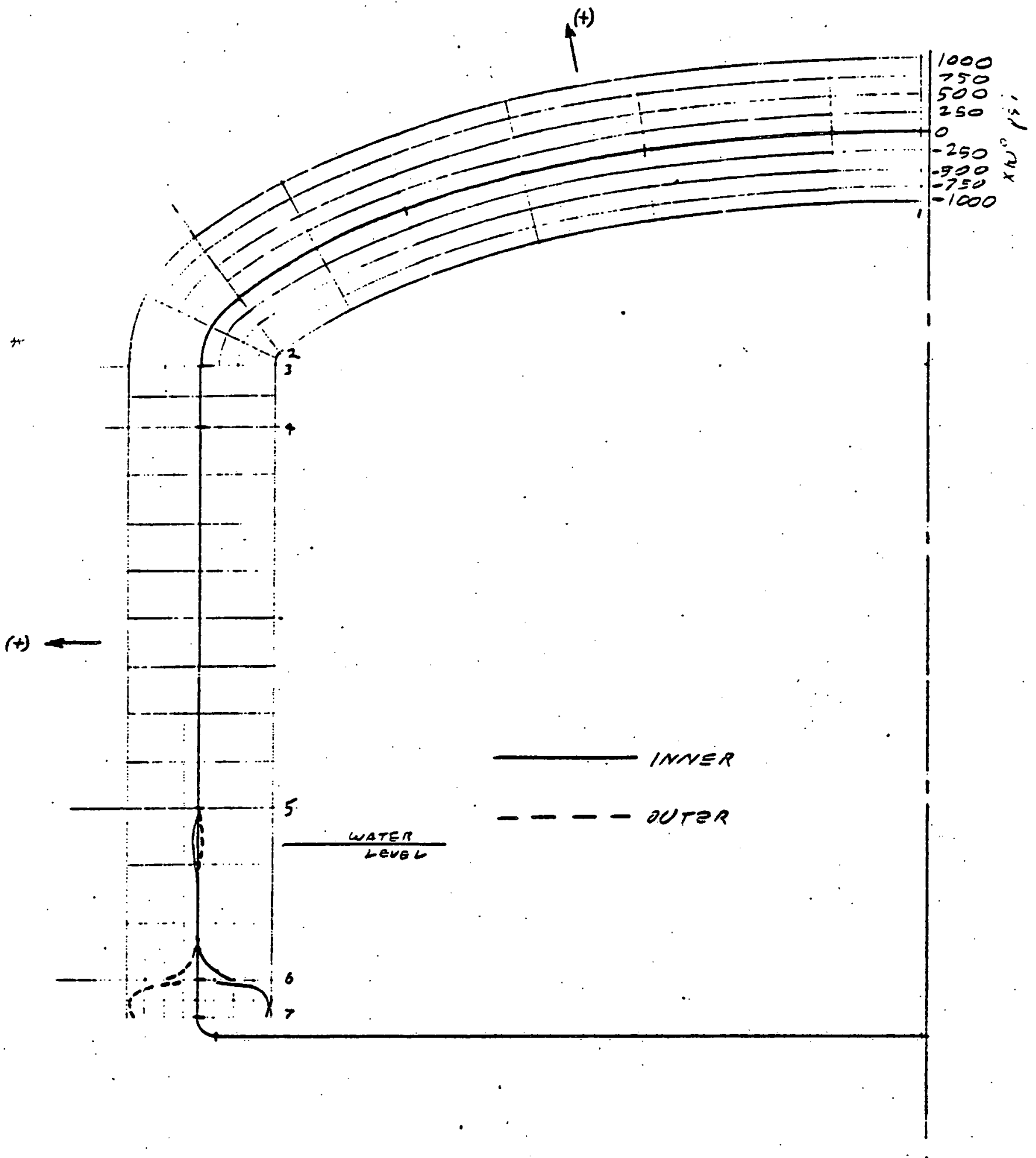

\section{MERIDIONAL STRESSES \\ $10^{\prime} 1 / 2 "$ WATER LEVEL}




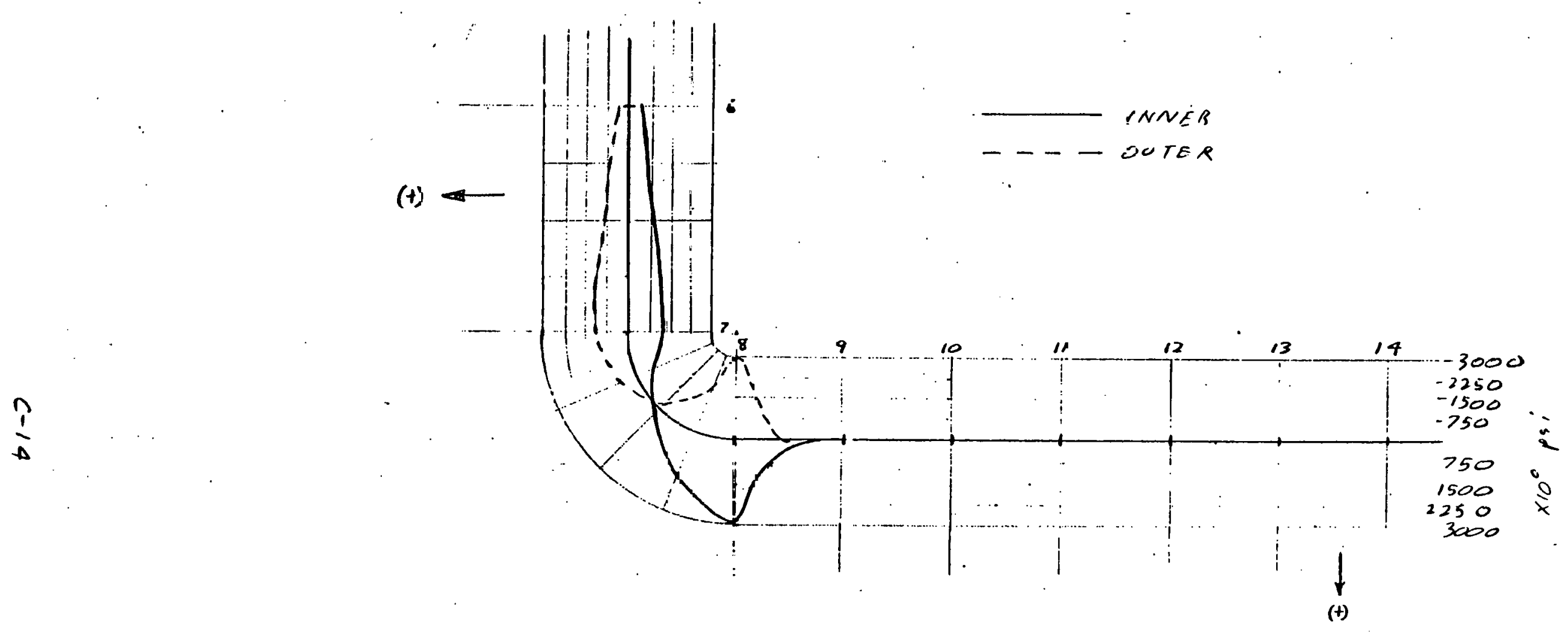

MERIEIONAL STRESSES 


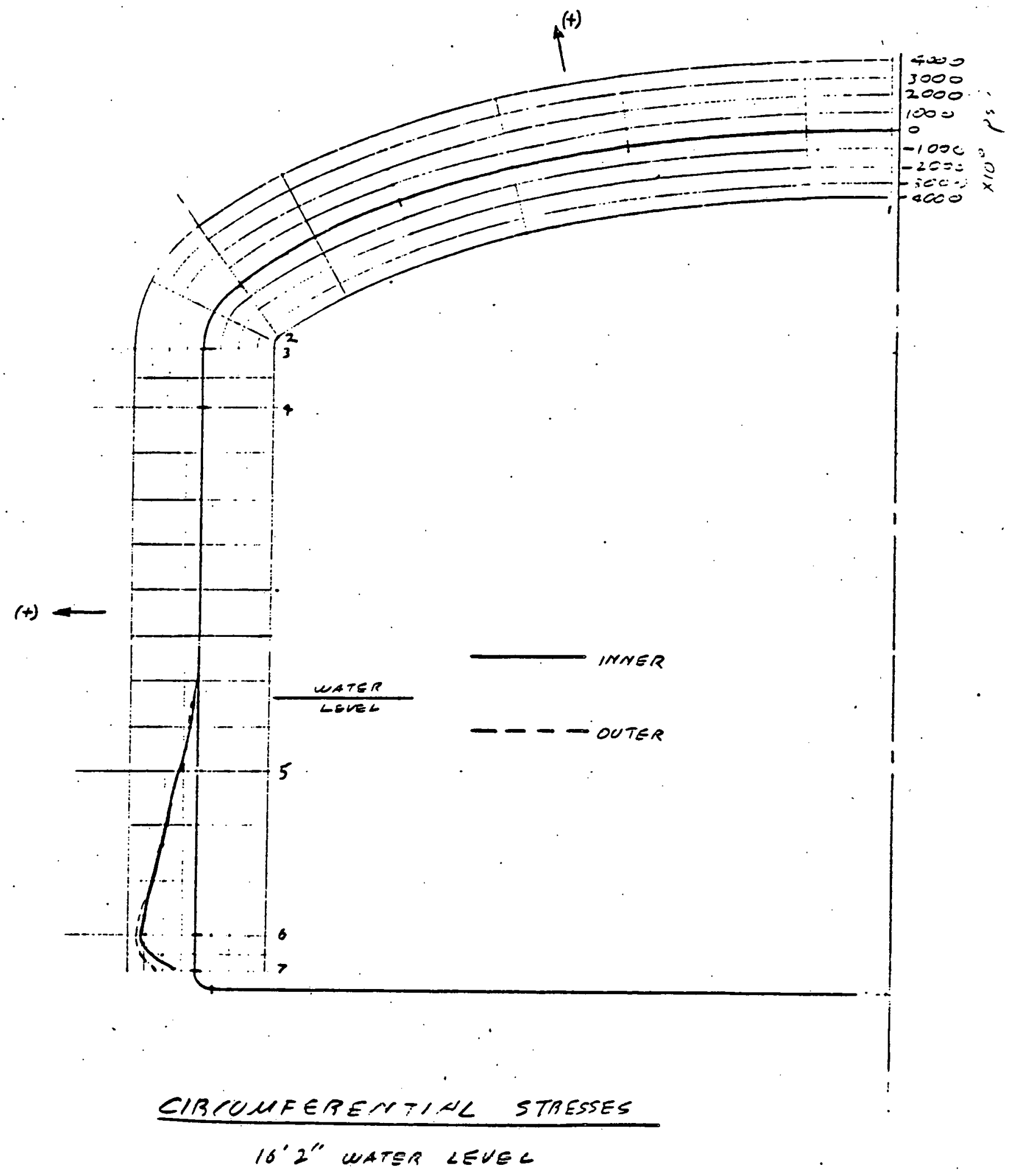




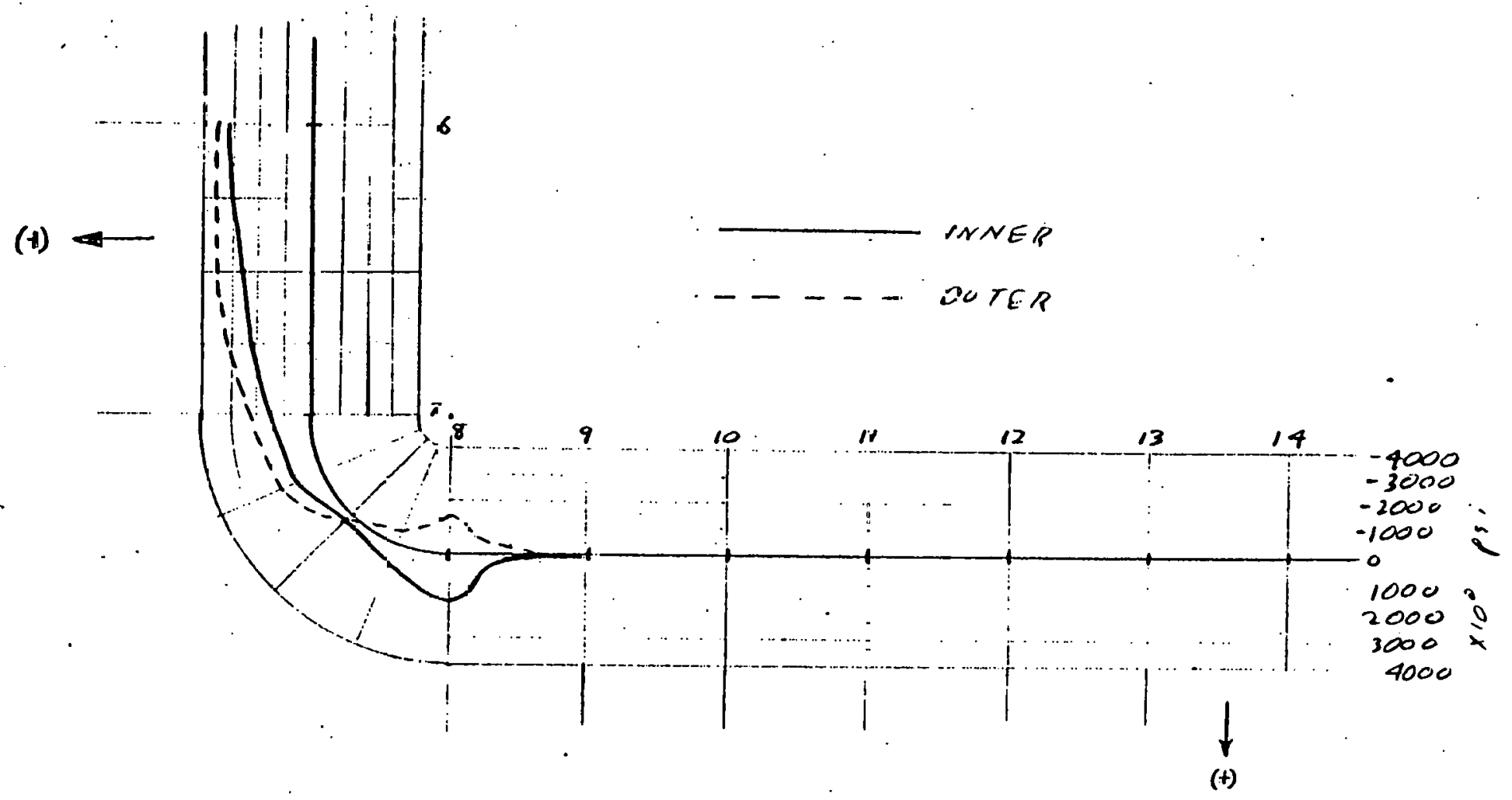

CIRCUMFERENTAL STRESSES

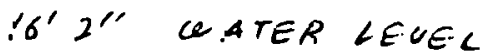




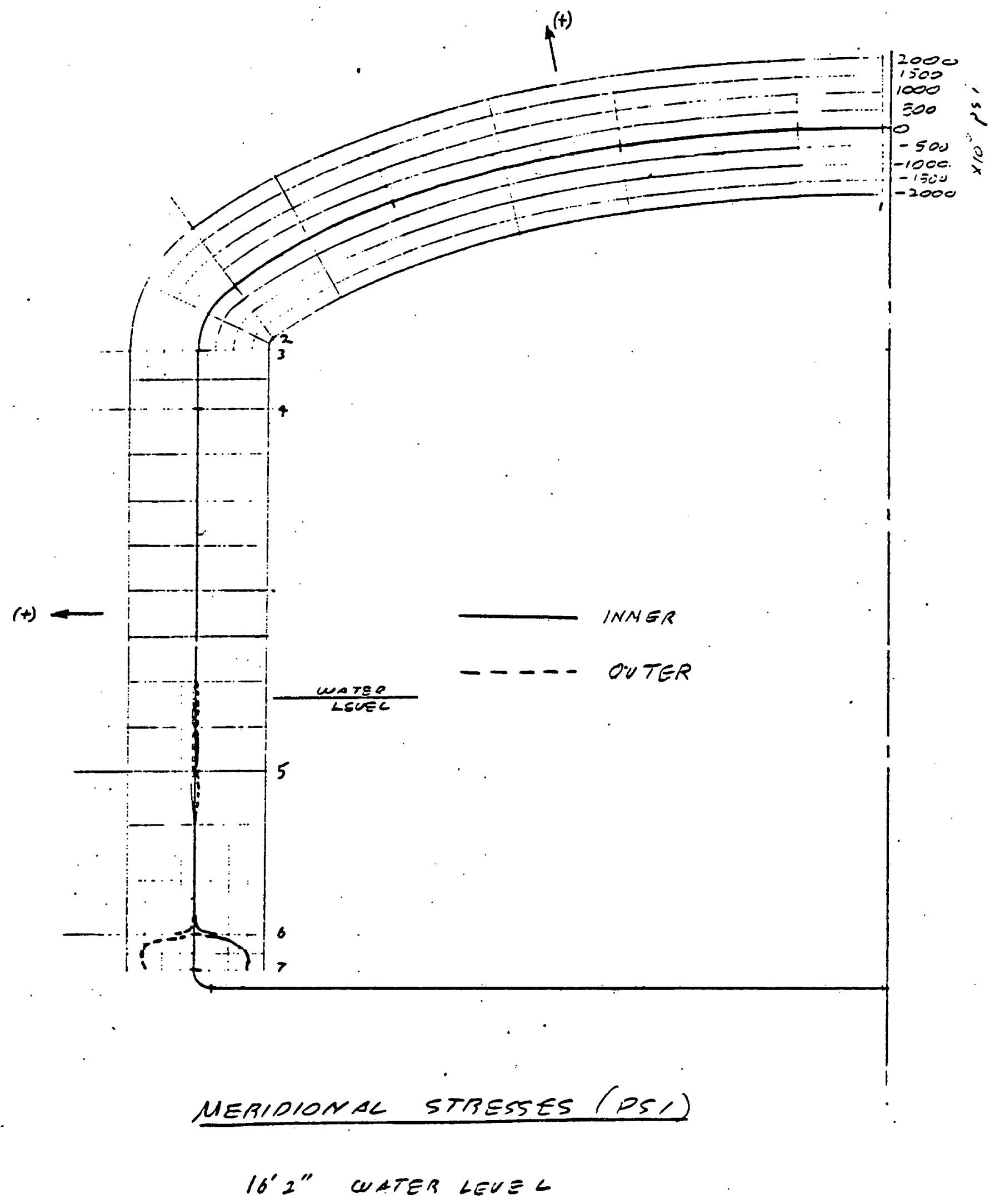




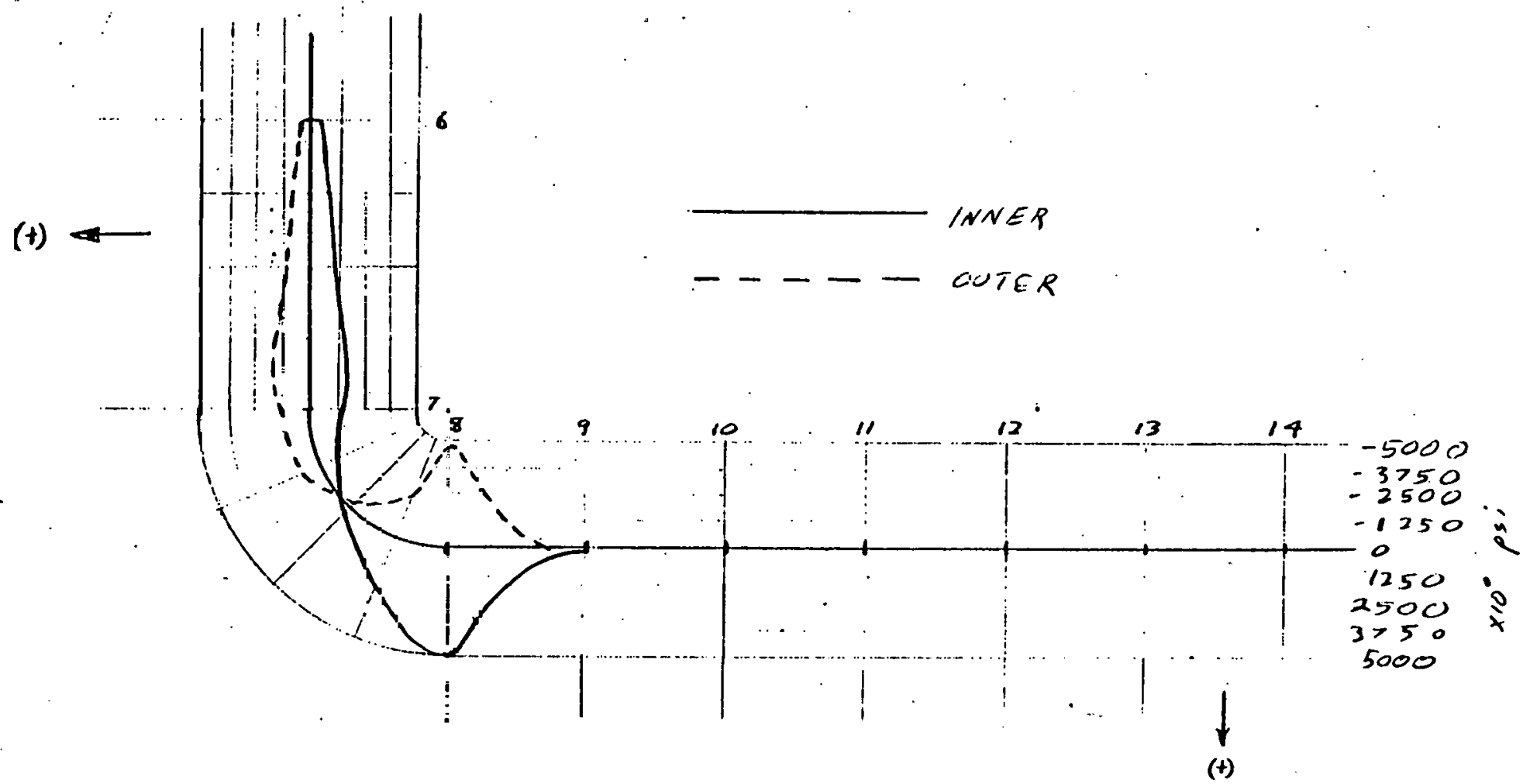

MEAIDIONAL STRESSES

16' $2^{\prime \prime}$ WATER LEVEL 


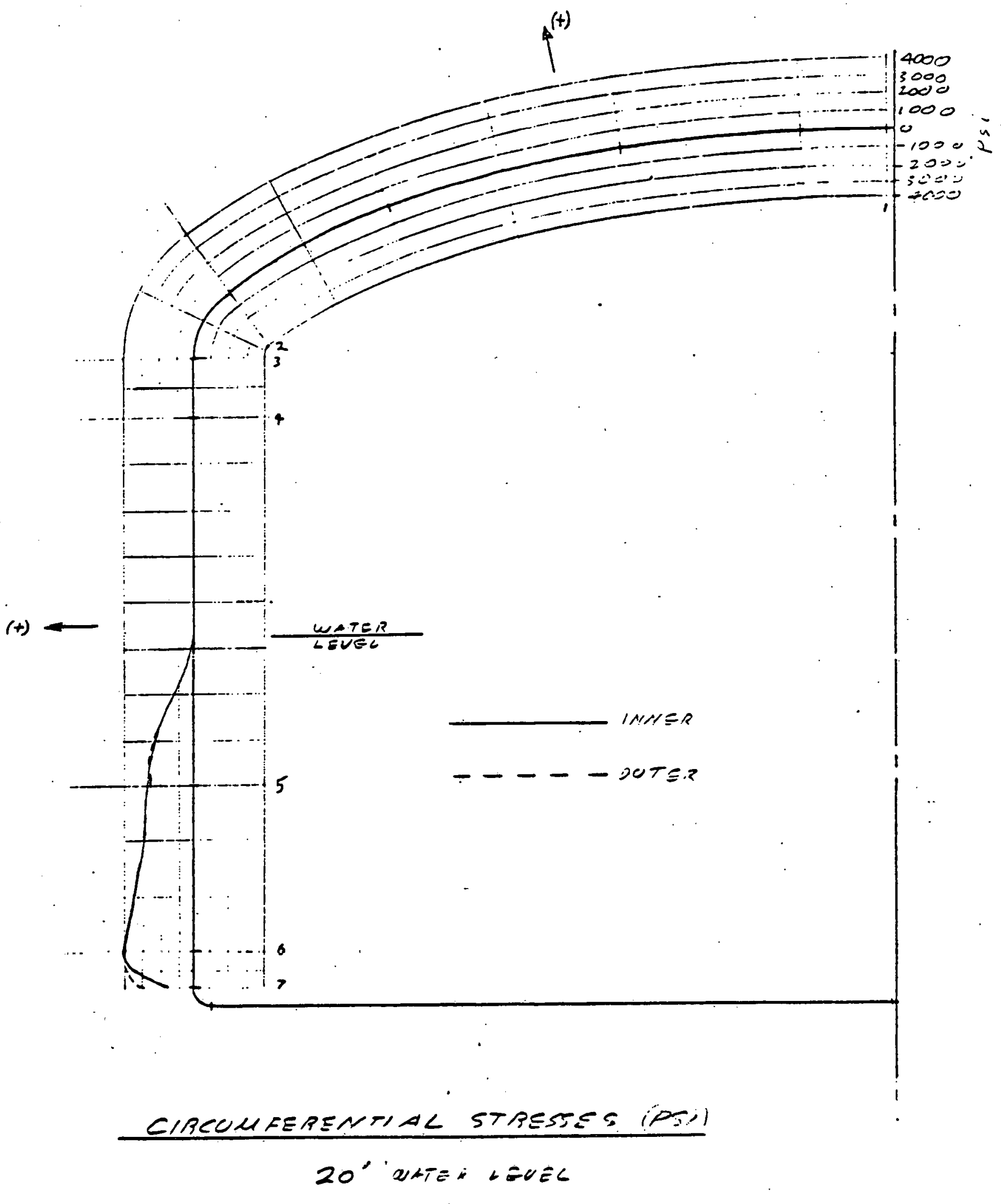




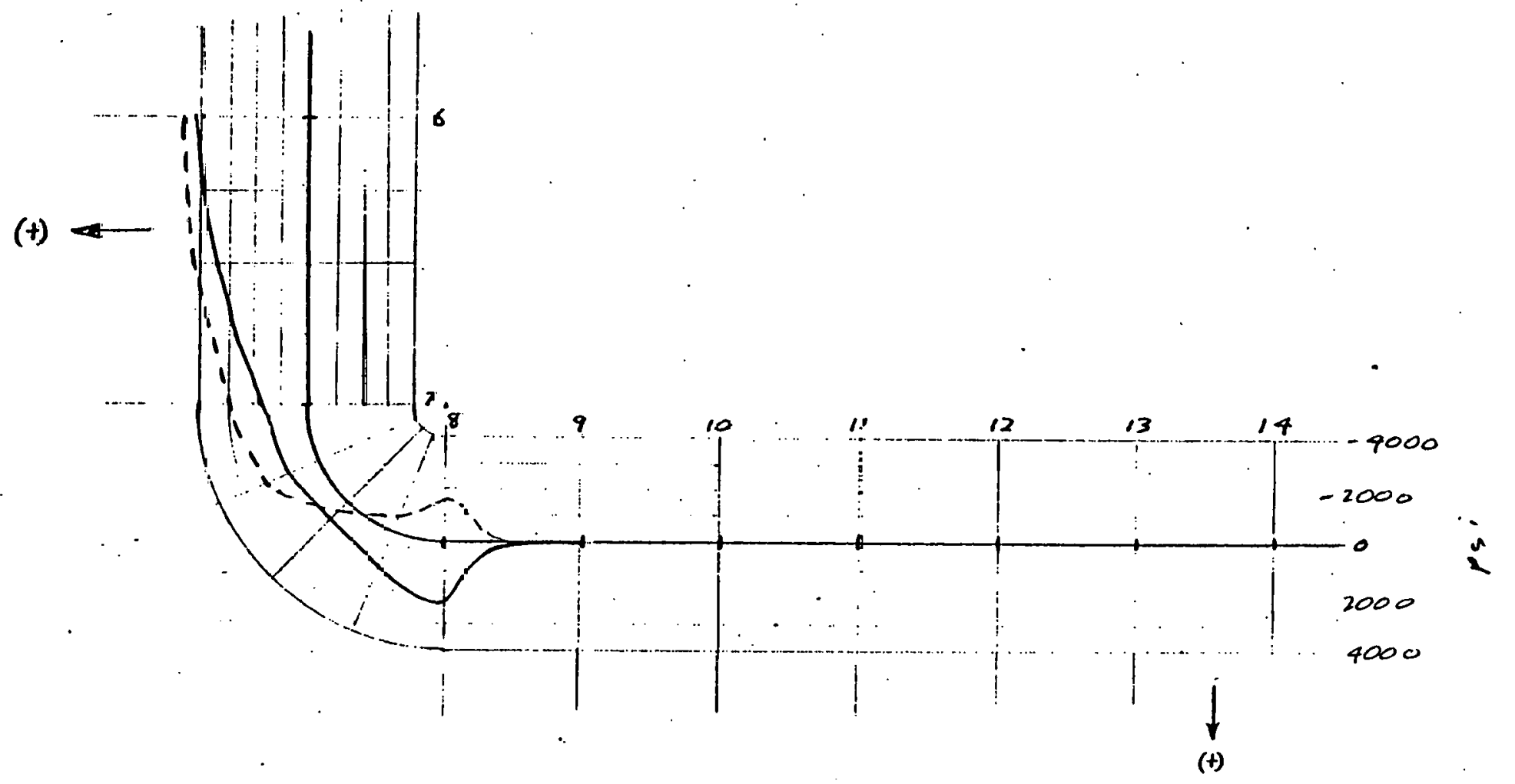

CIBCUMFERENTIAL STRESSES

ZO' MATEK LEUEL 


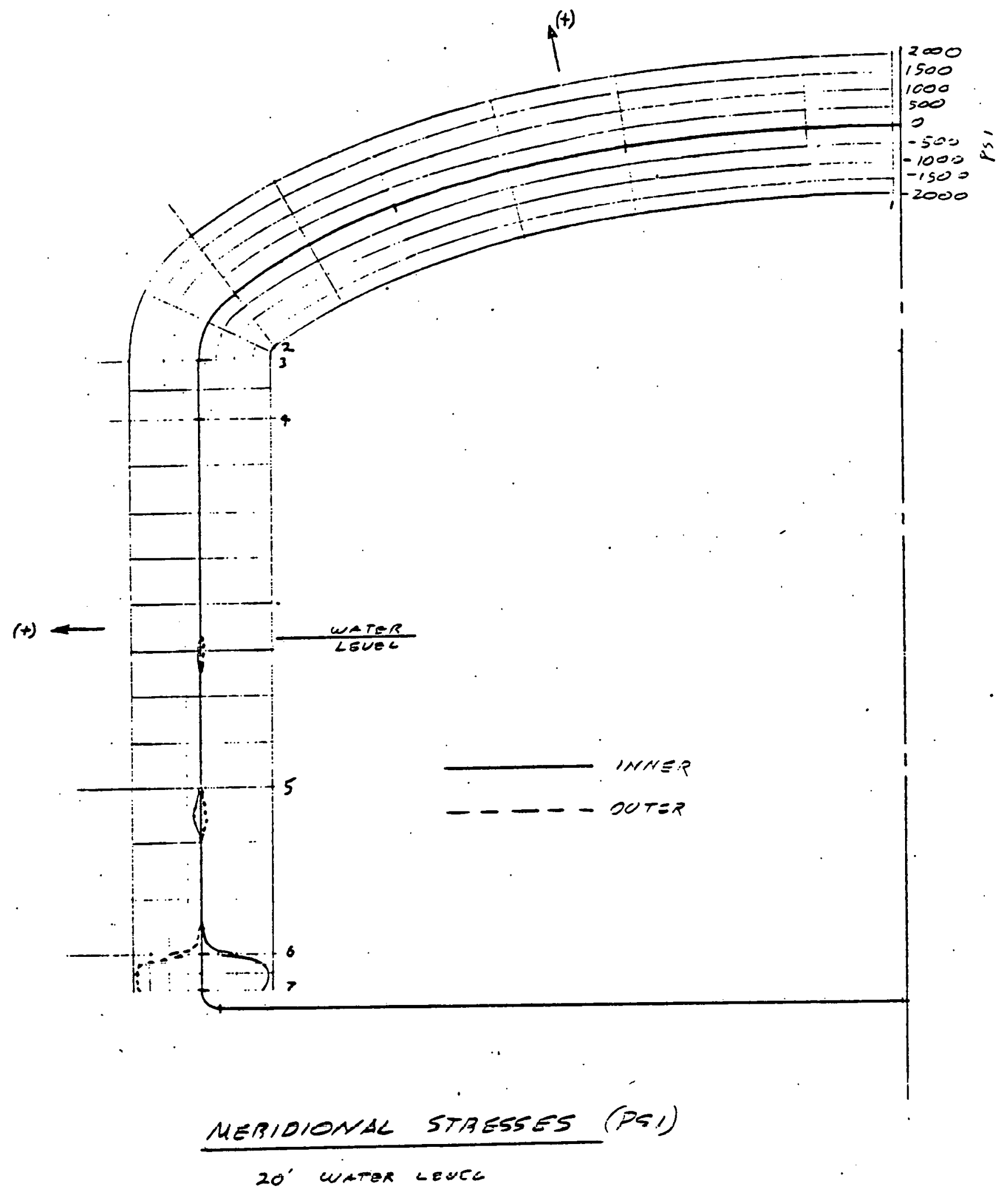

$$
-21
$$




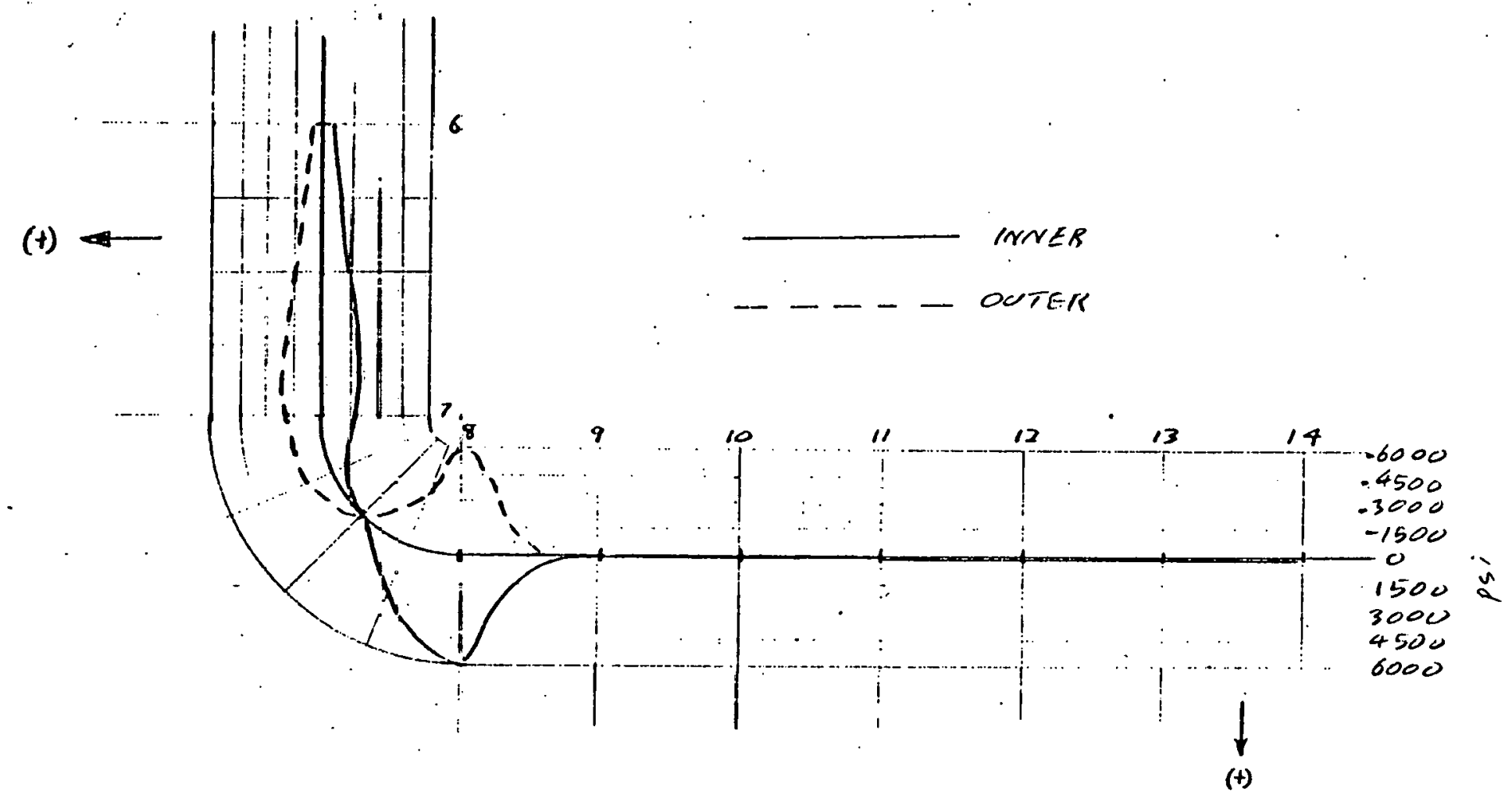

MEBIDIONAL STIRESES

$$
20^{\prime} \text { WATER LEVEL }
$$




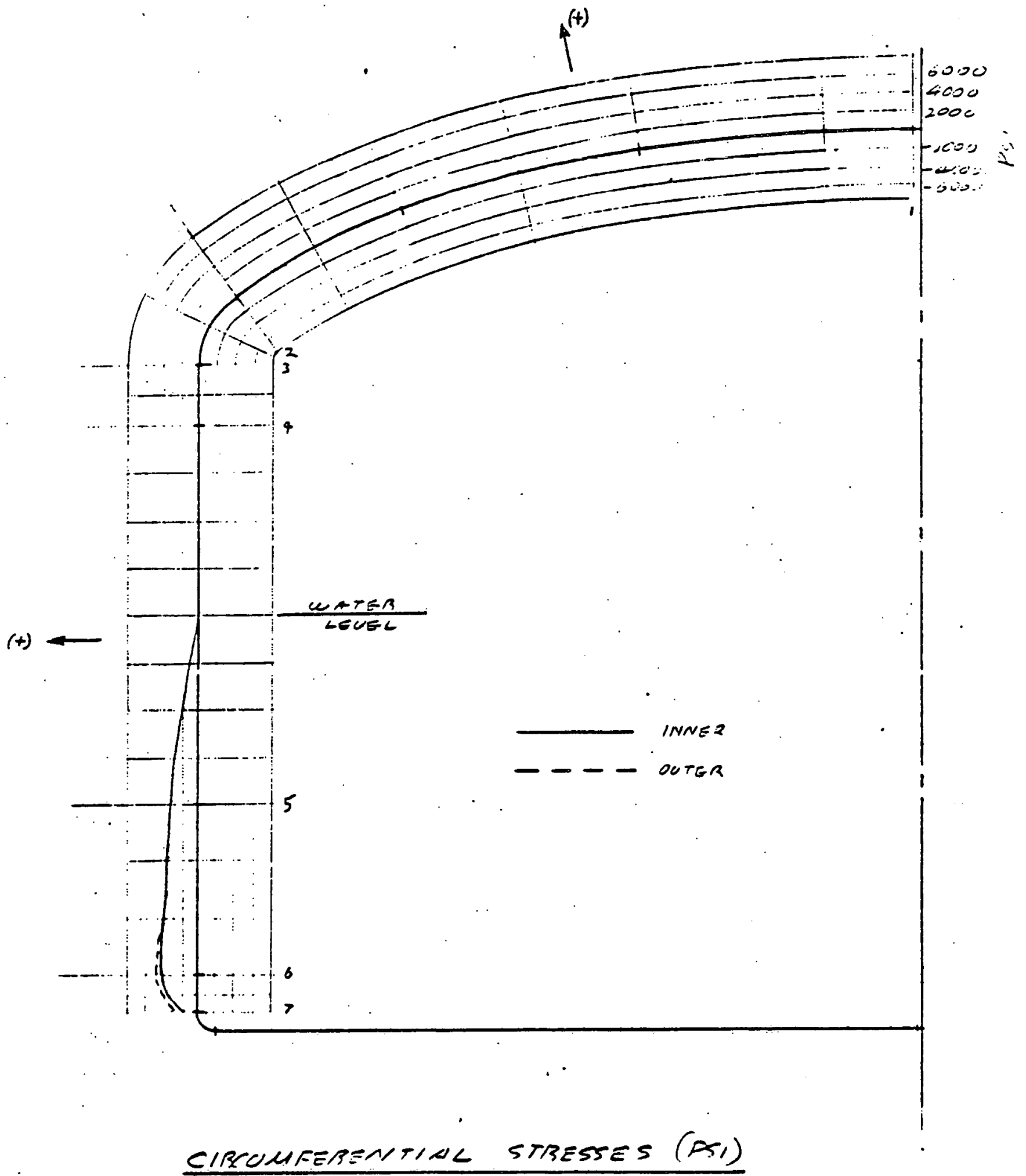

$22^{\prime} 4^{\prime \prime}$ WHF LEUEL. 
$n$
1

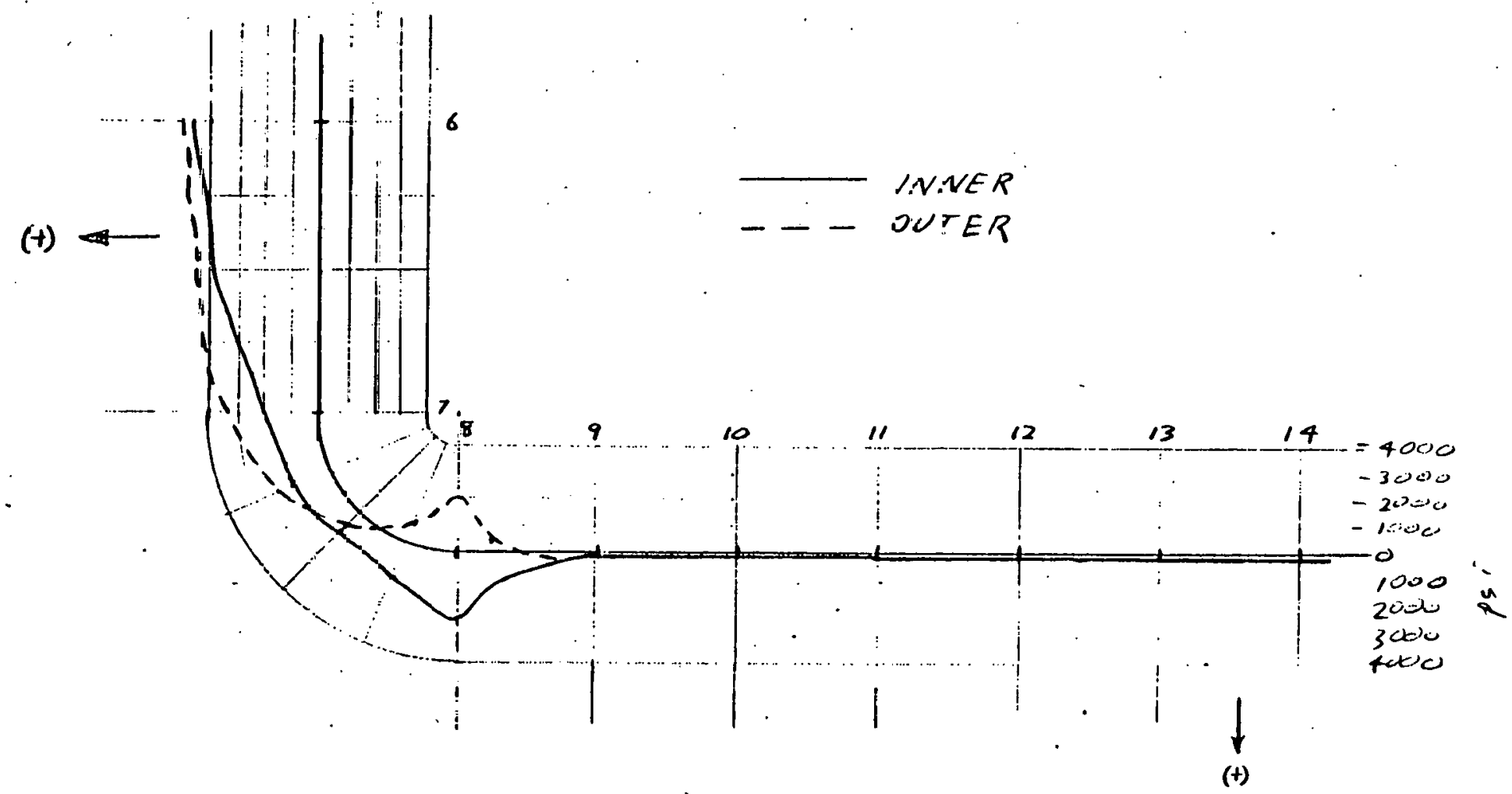

CIRCUUFERENTIAL STRESSES

$23^{\prime} 4^{\prime \prime}$ WATER LEWEL 


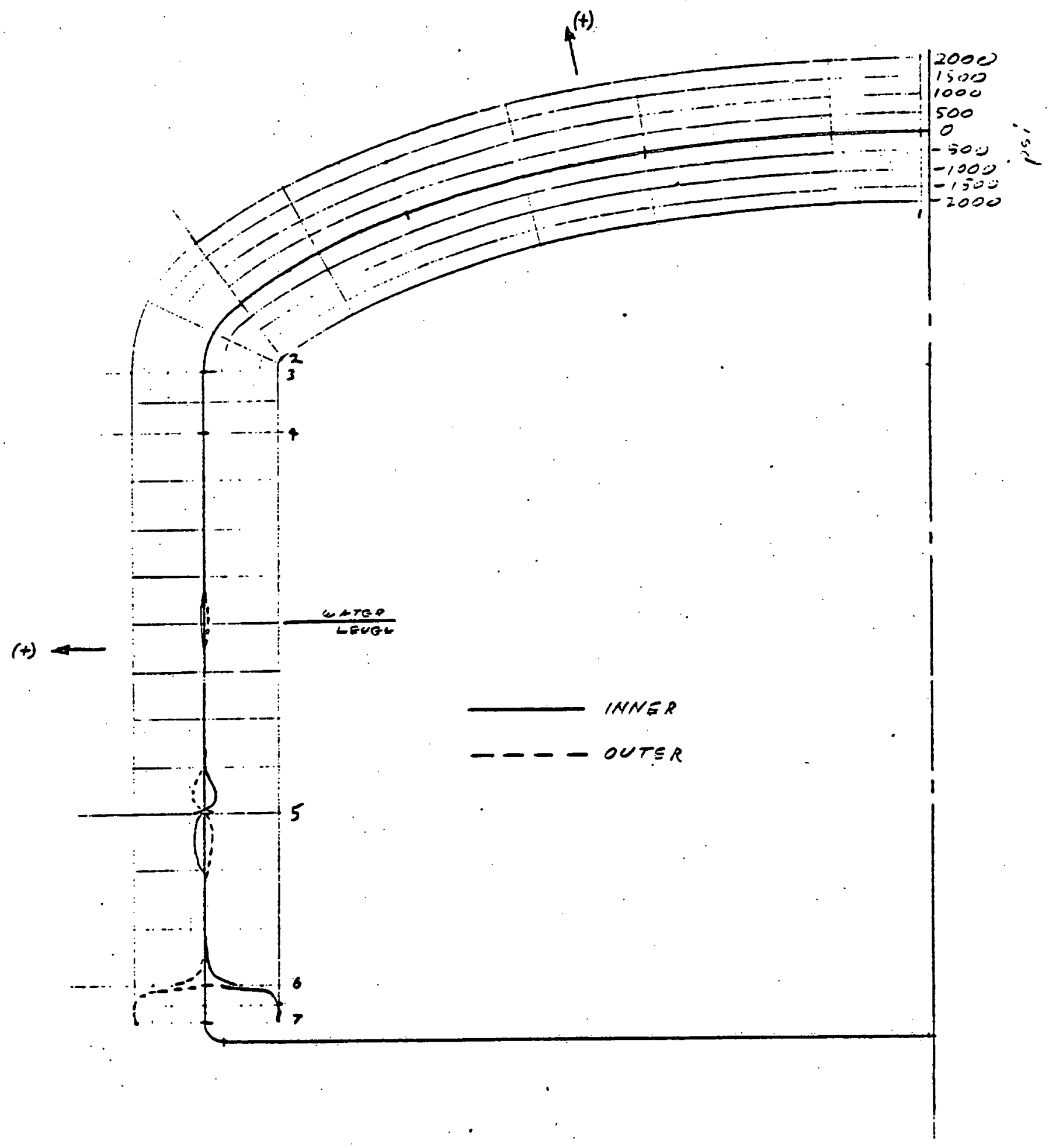

MERIDIONAL STRESSES (PS')

$22^{\prime} 4^{\prime \prime}$ WATER LEVEL

$c-25$ 


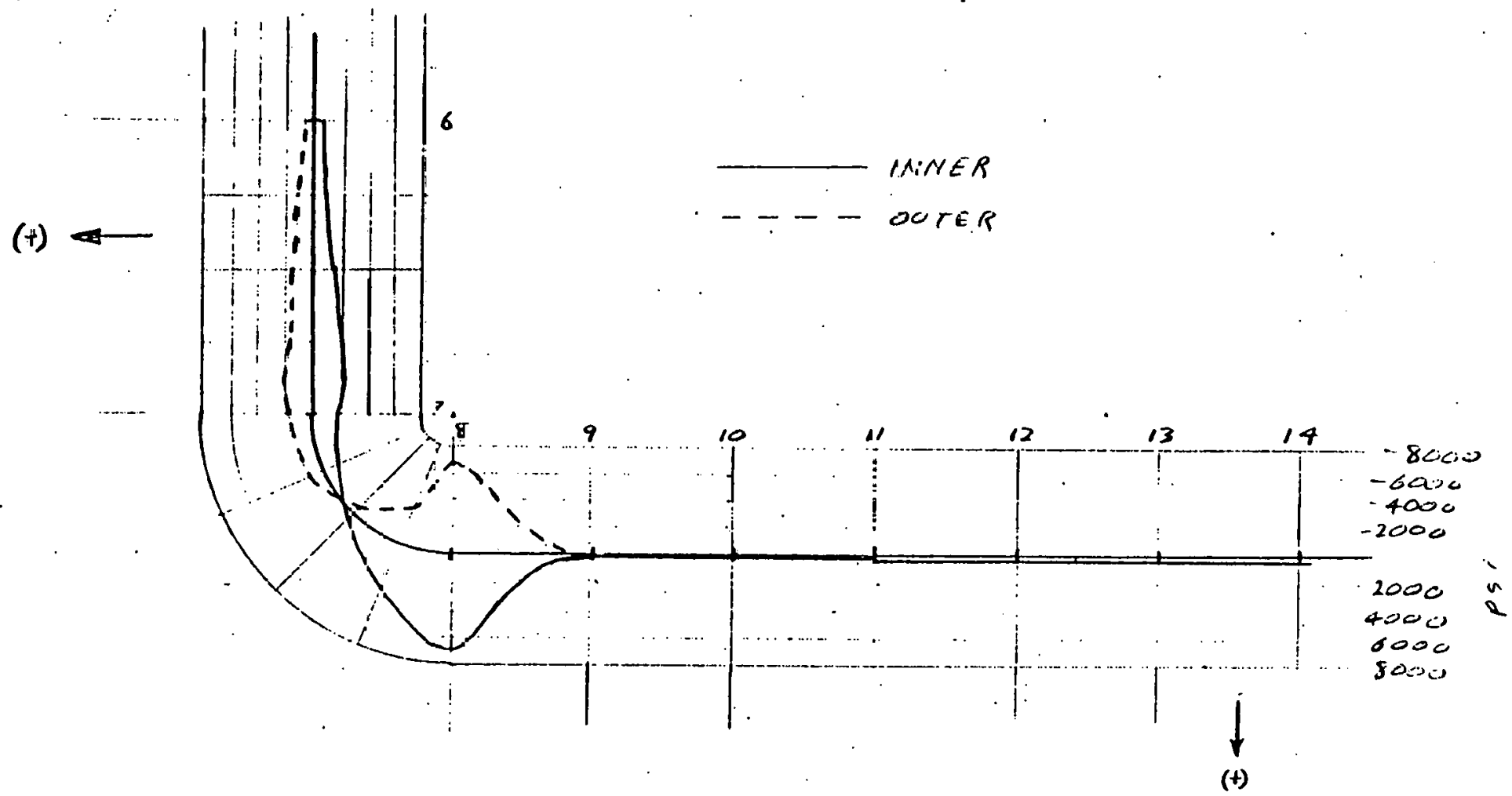

MERIDIONAL STRESSES (AY)

$22^{\prime} 4^{\prime \prime}$ Water LEVEC 


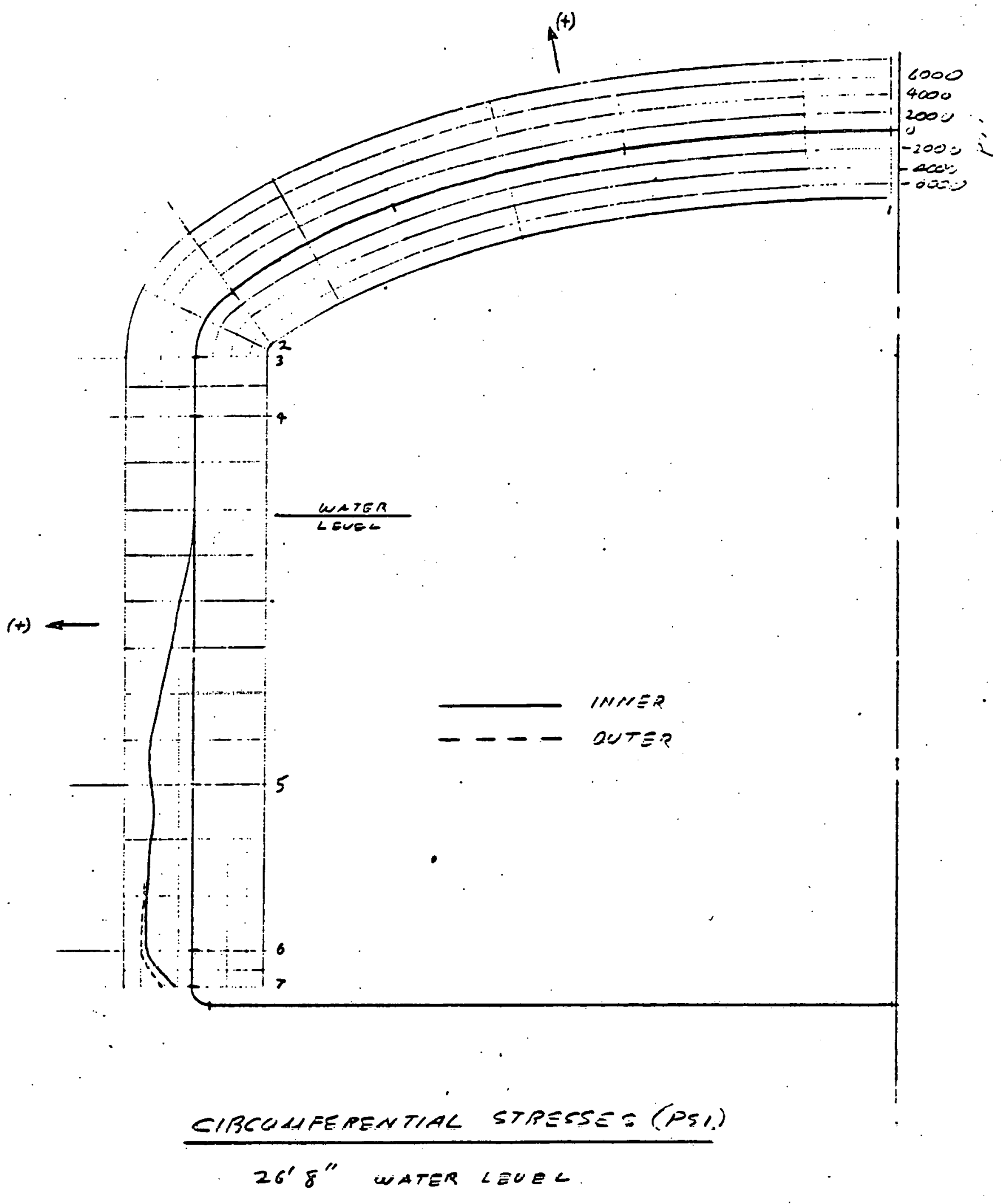




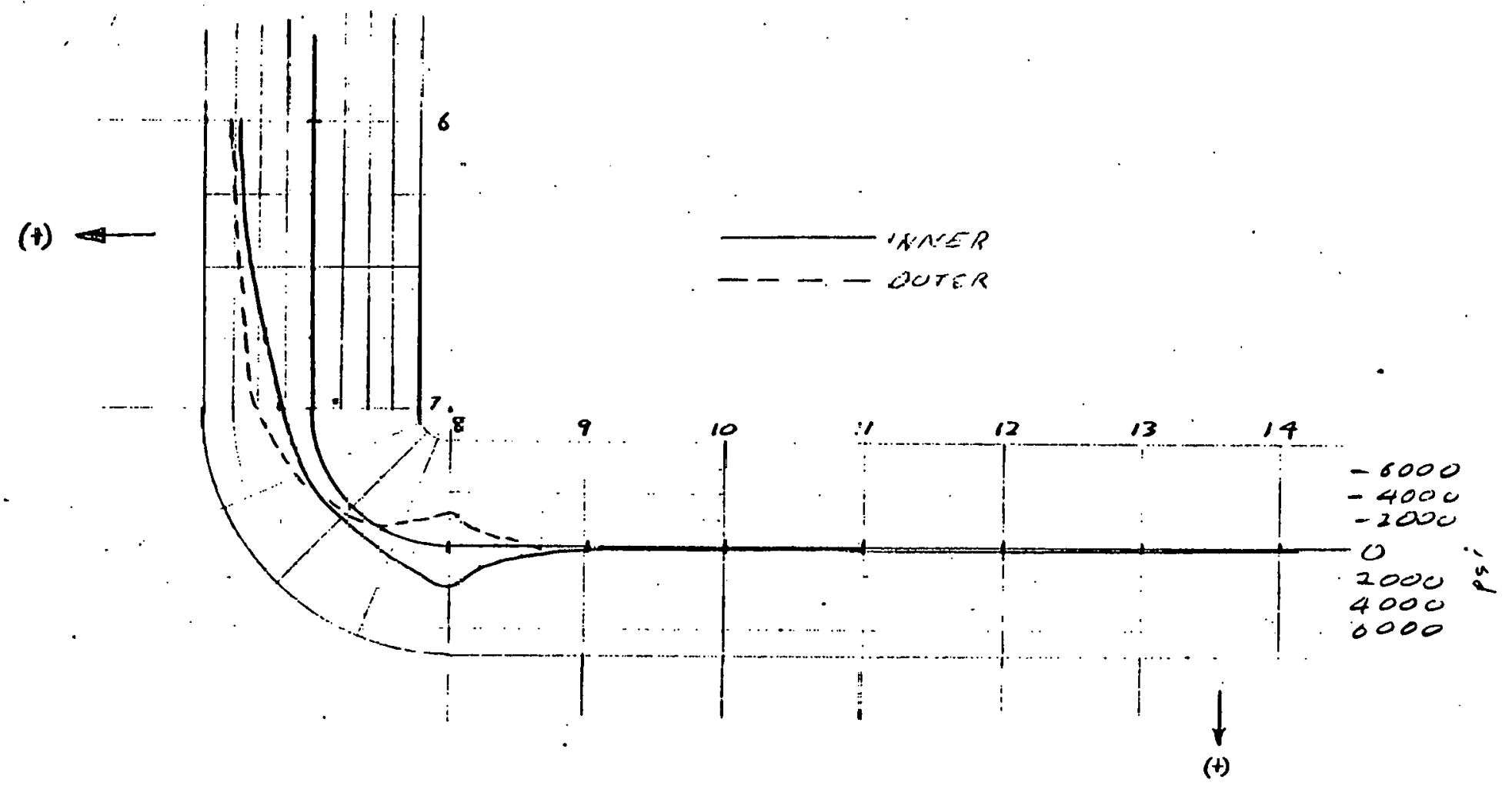

$\frac{\text { CIRCUMFERENTAL STRESSES }}{26^{\prime} 8^{\circ} W A T E S \text { I SWLC }}$ 


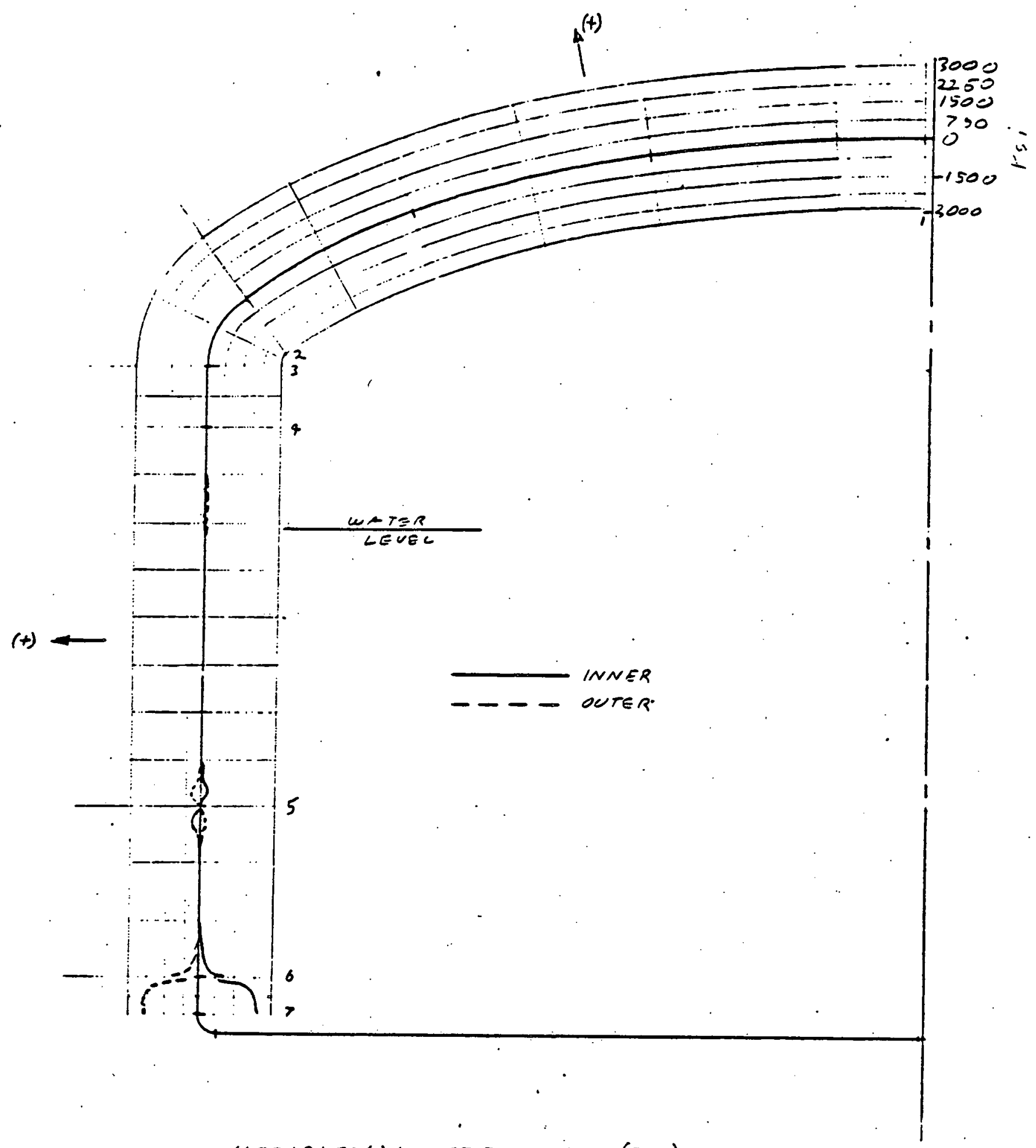

MERIDIONAL STRESSES (PSI)

$$
20^{\prime} 8^{\prime \prime} \text { WATER LEVEL }
$$

$$
c-29
$$




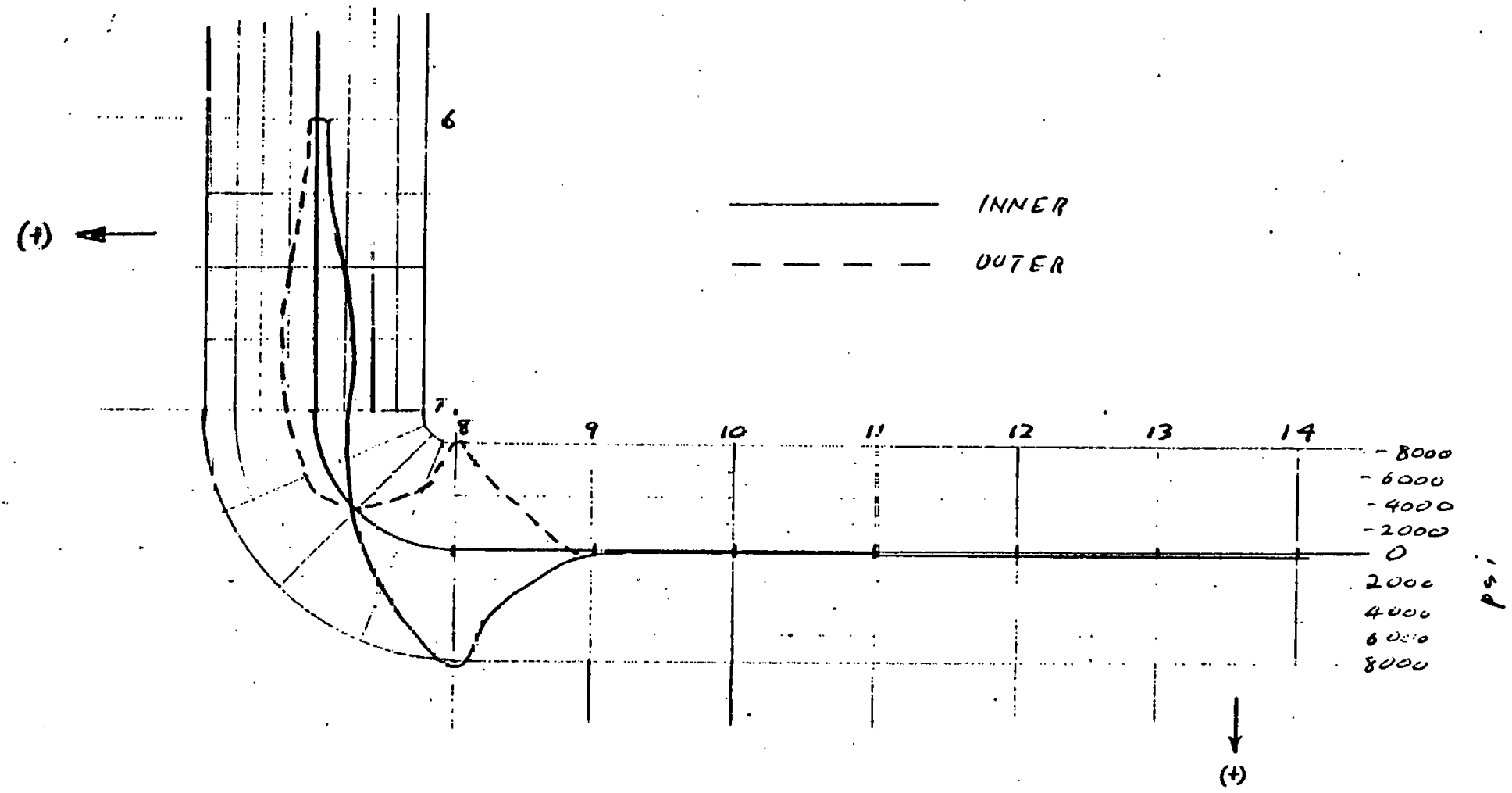

MERIN10NAL STIEOES

$26^{\prime} 8^{\prime \prime}$ WATER LELEL 


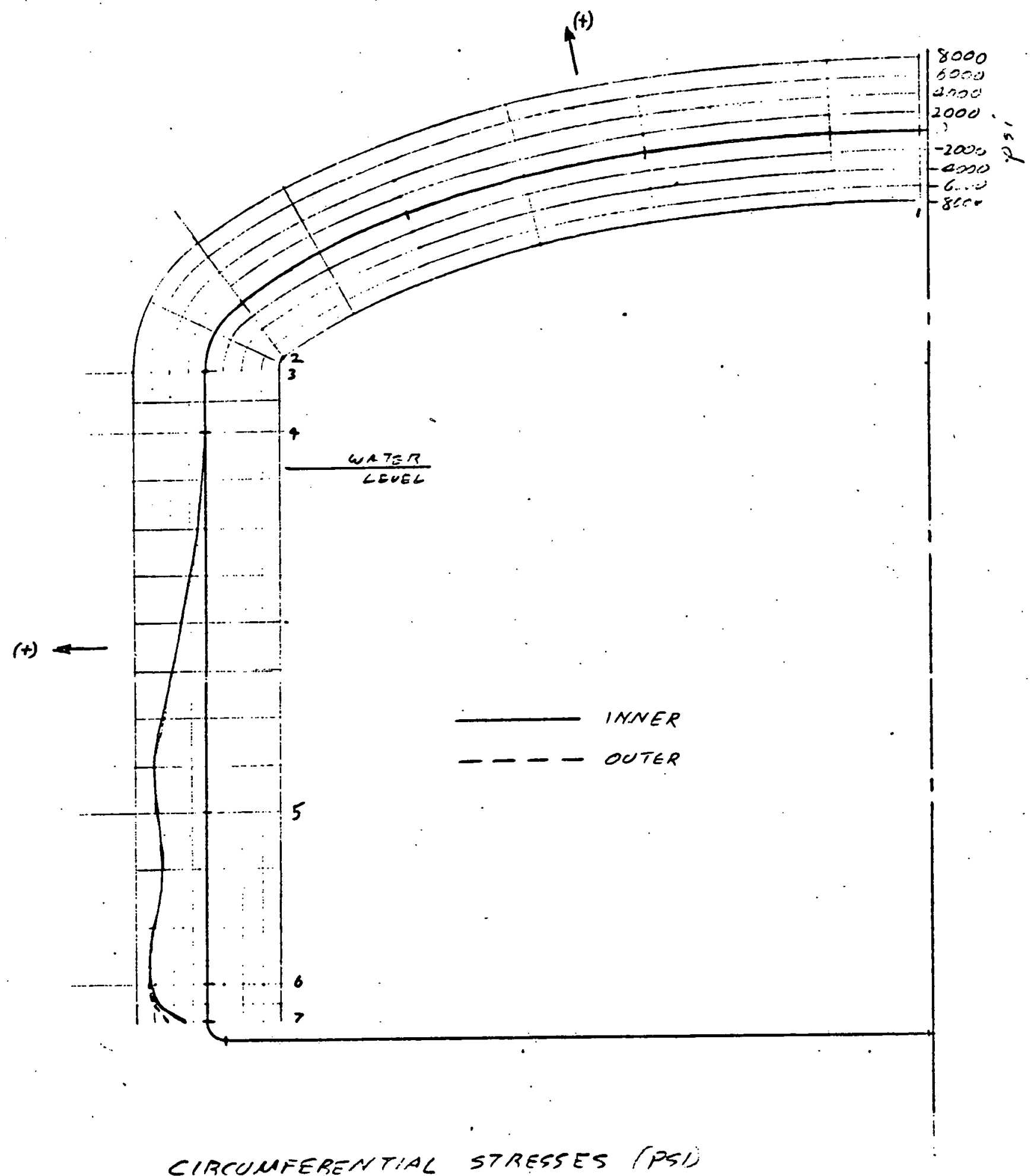

CIRCUMIERENTIAL STRESSES PPSI

$30^{\prime} 2^{\prime \prime}$ WATER LEUEL

$(-3)$ 


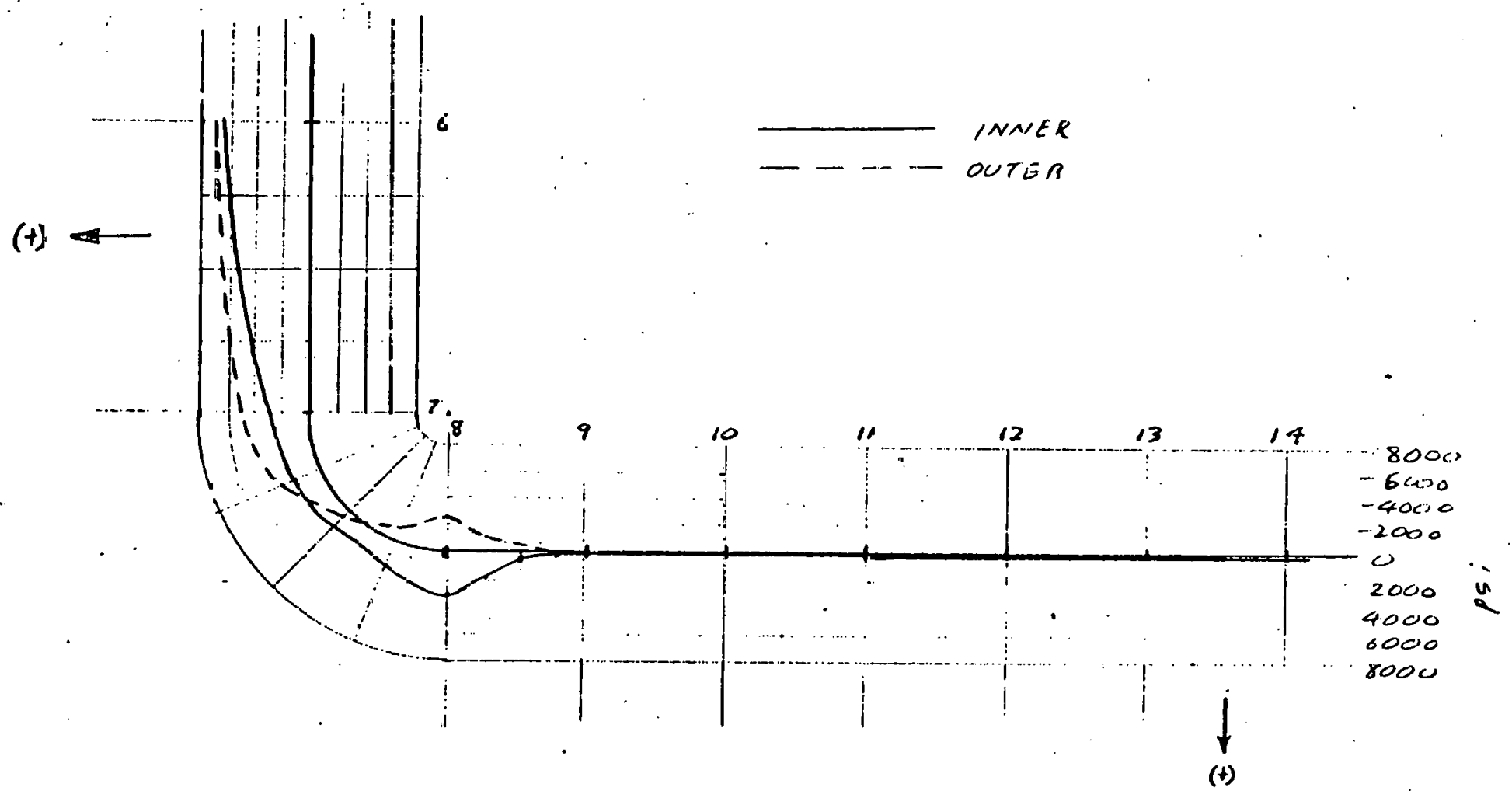

CIRCUMFERENTIAL STISESES

$30^{\prime}$ 2" WATER LEUEL 


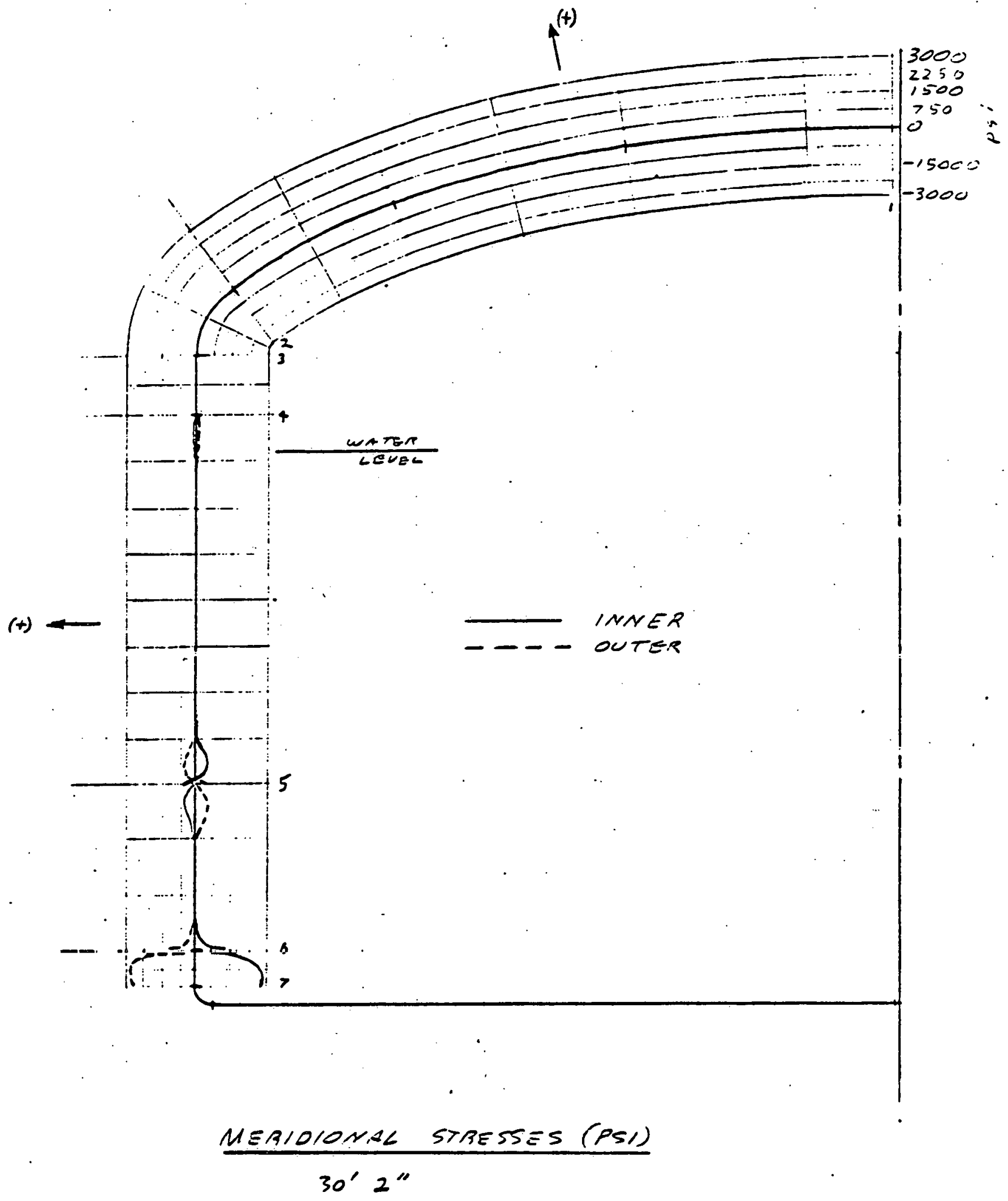




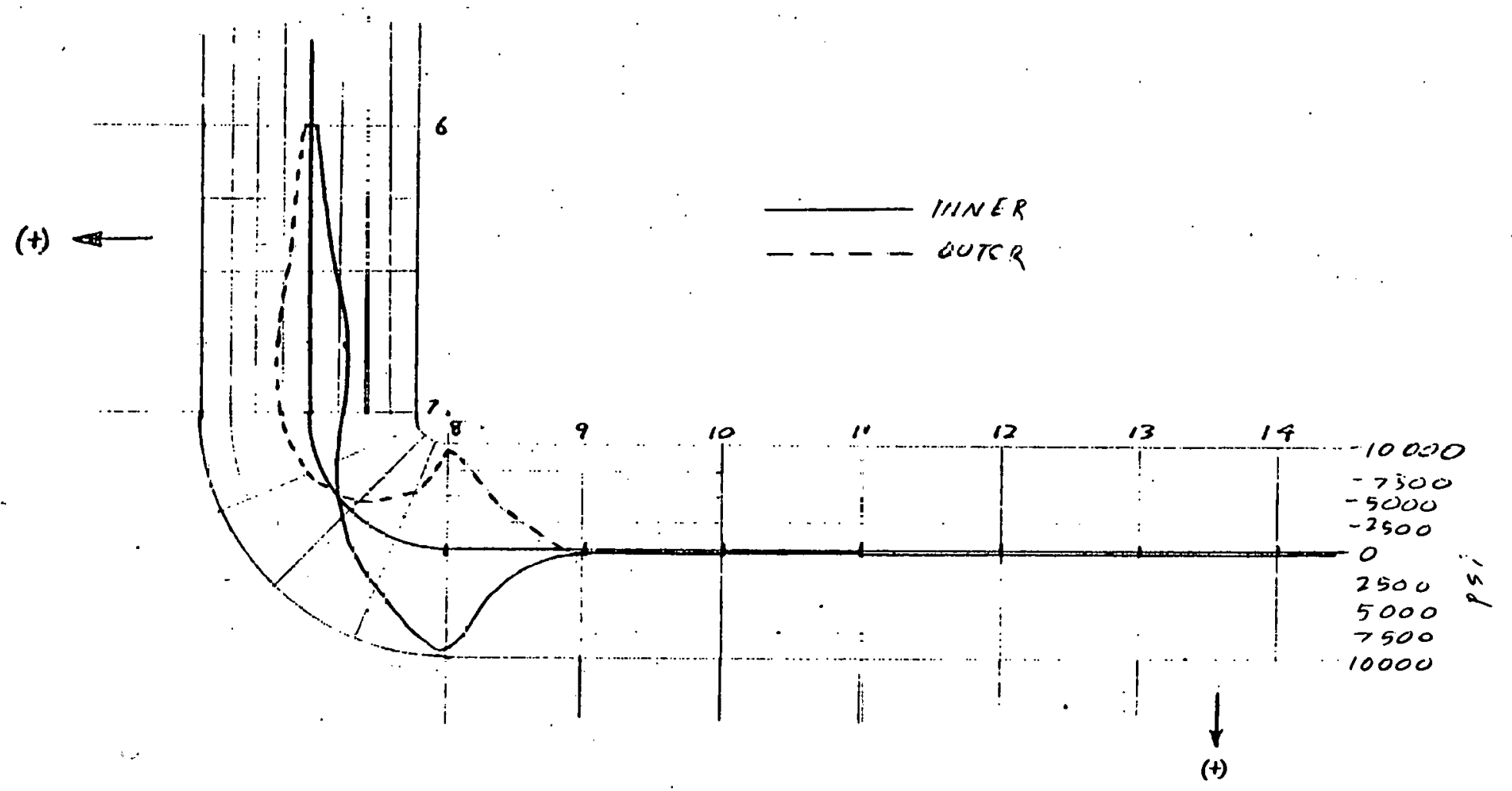

$\frac{\text { NERIOIONAL STRESSES (PST) }}{30^{\prime} 2 \text { " WATER LEVEL }}$ 


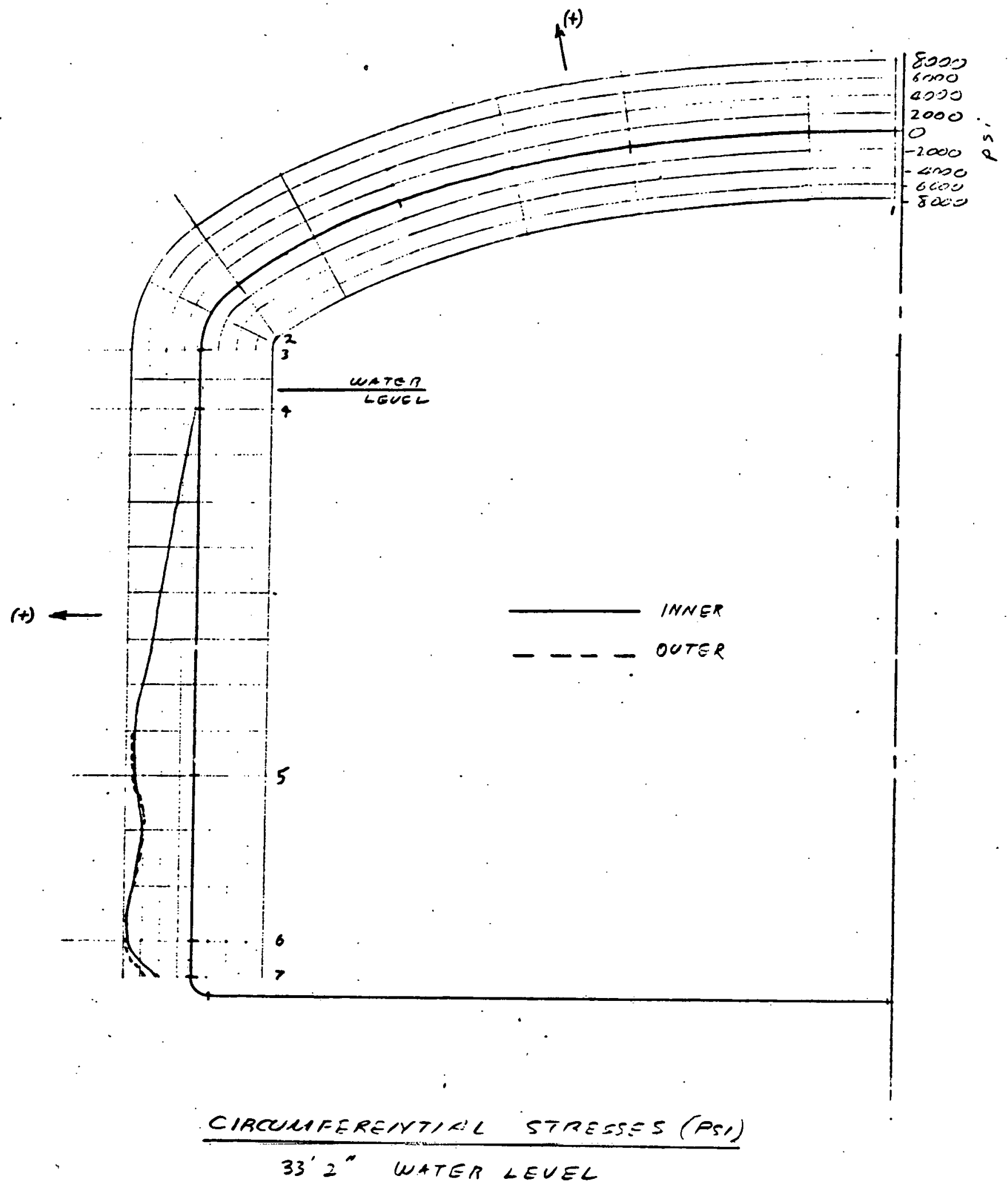




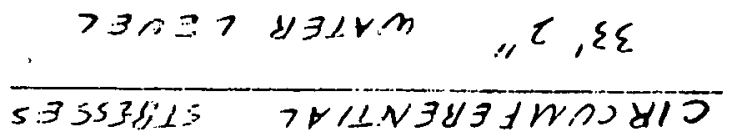

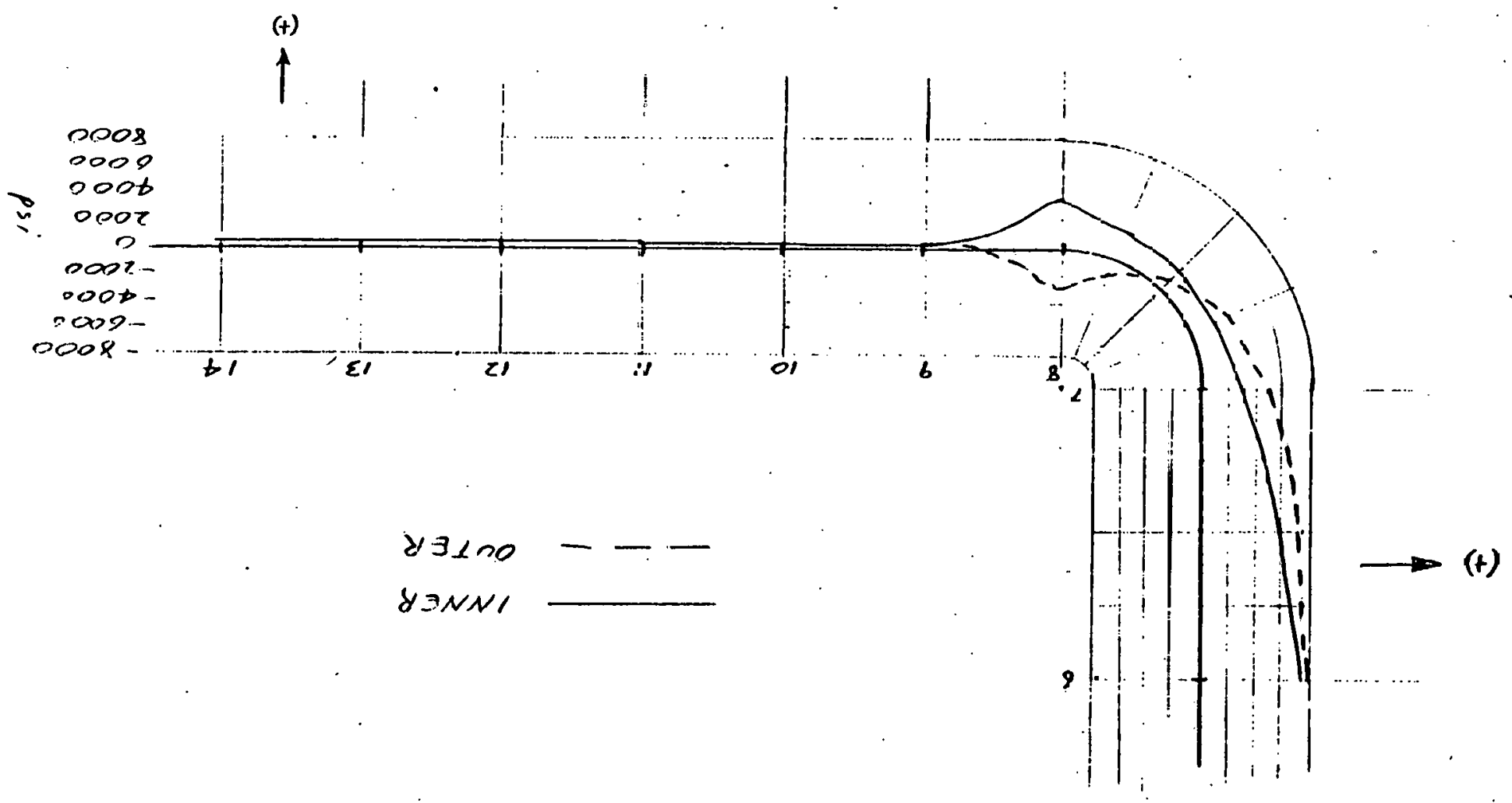




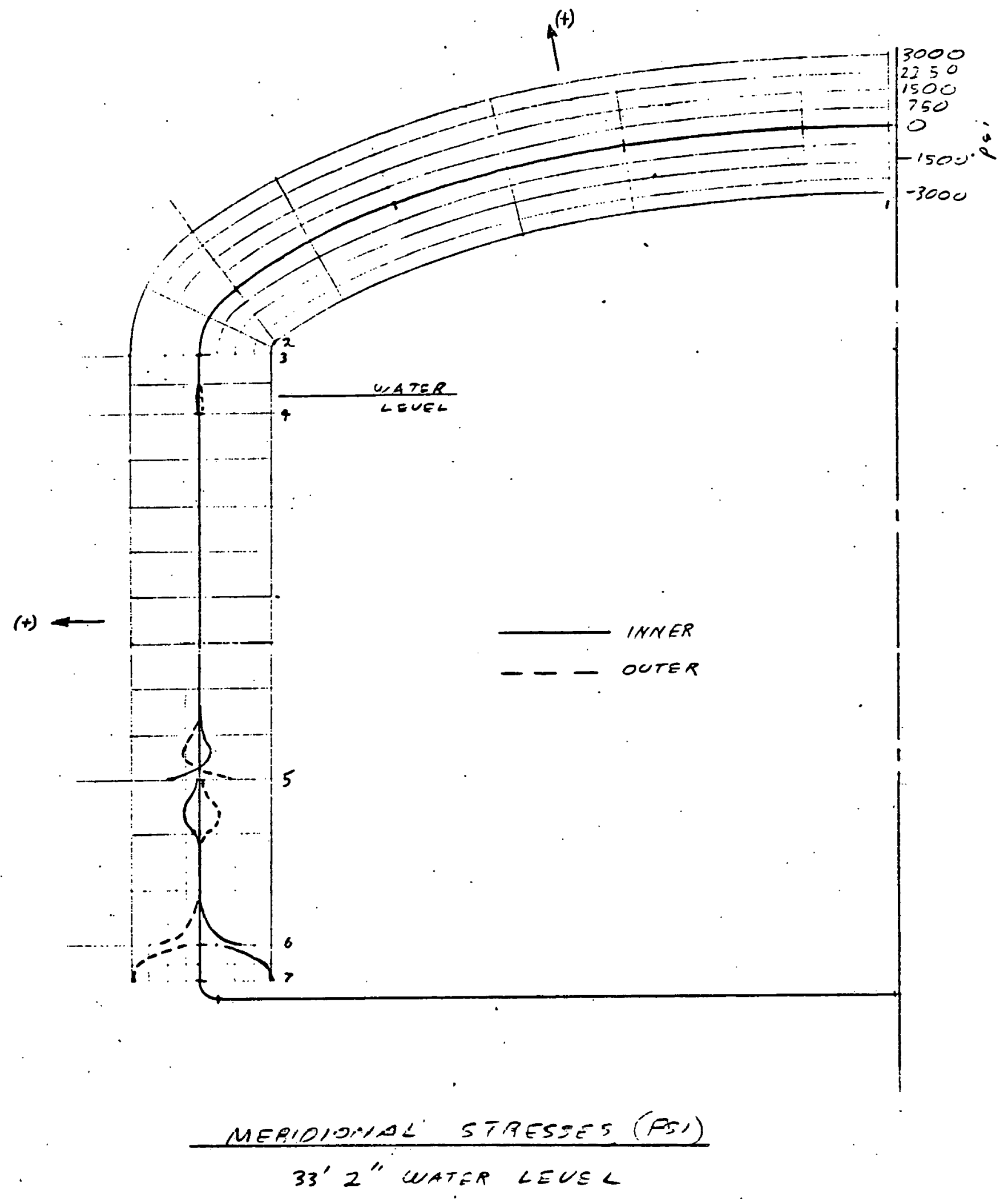




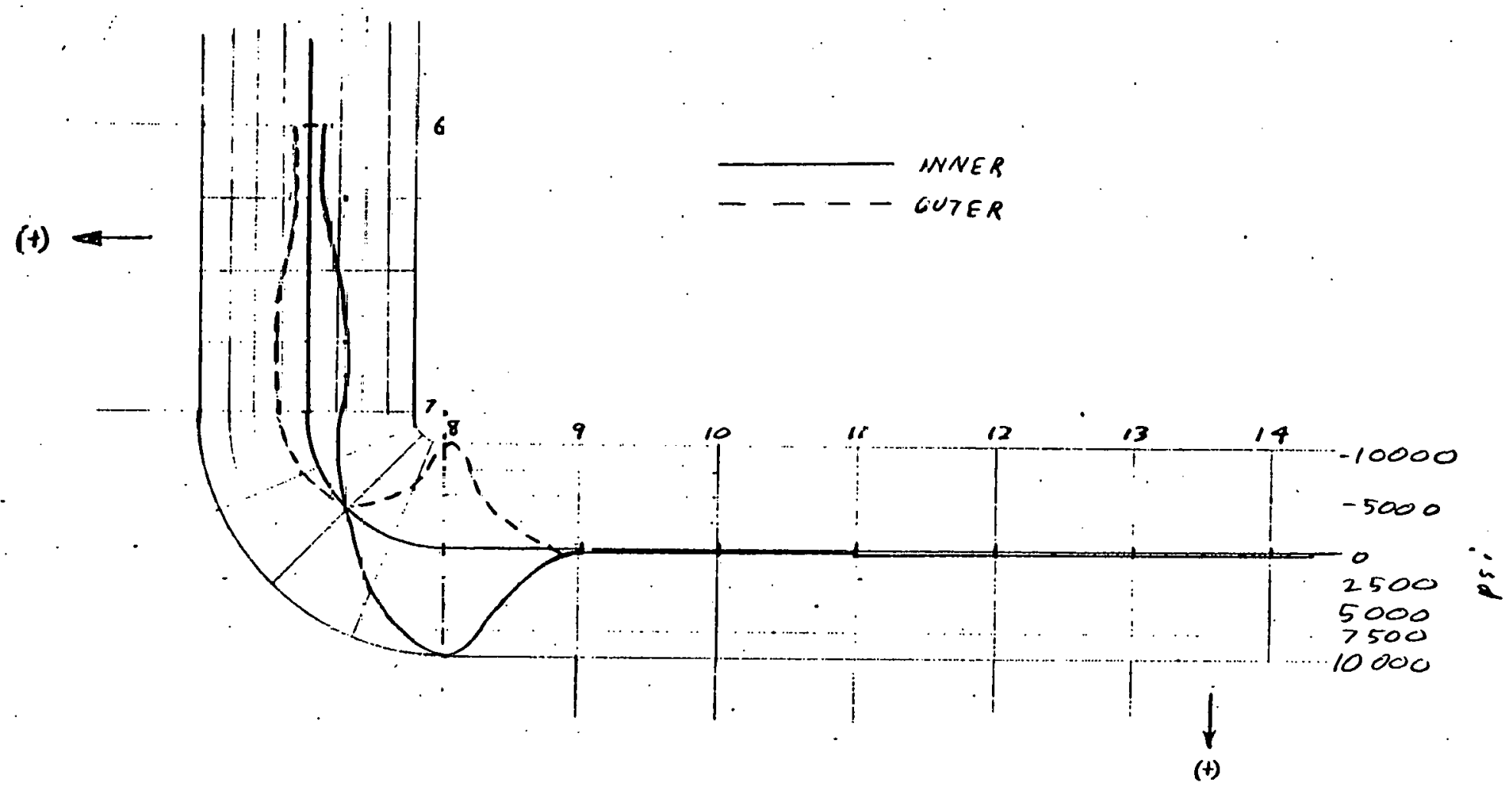

$\frac{\text { MERIDIONAL STRESSEI }}{33^{\prime} 2 \text { " WATER LEUEL }}$ 


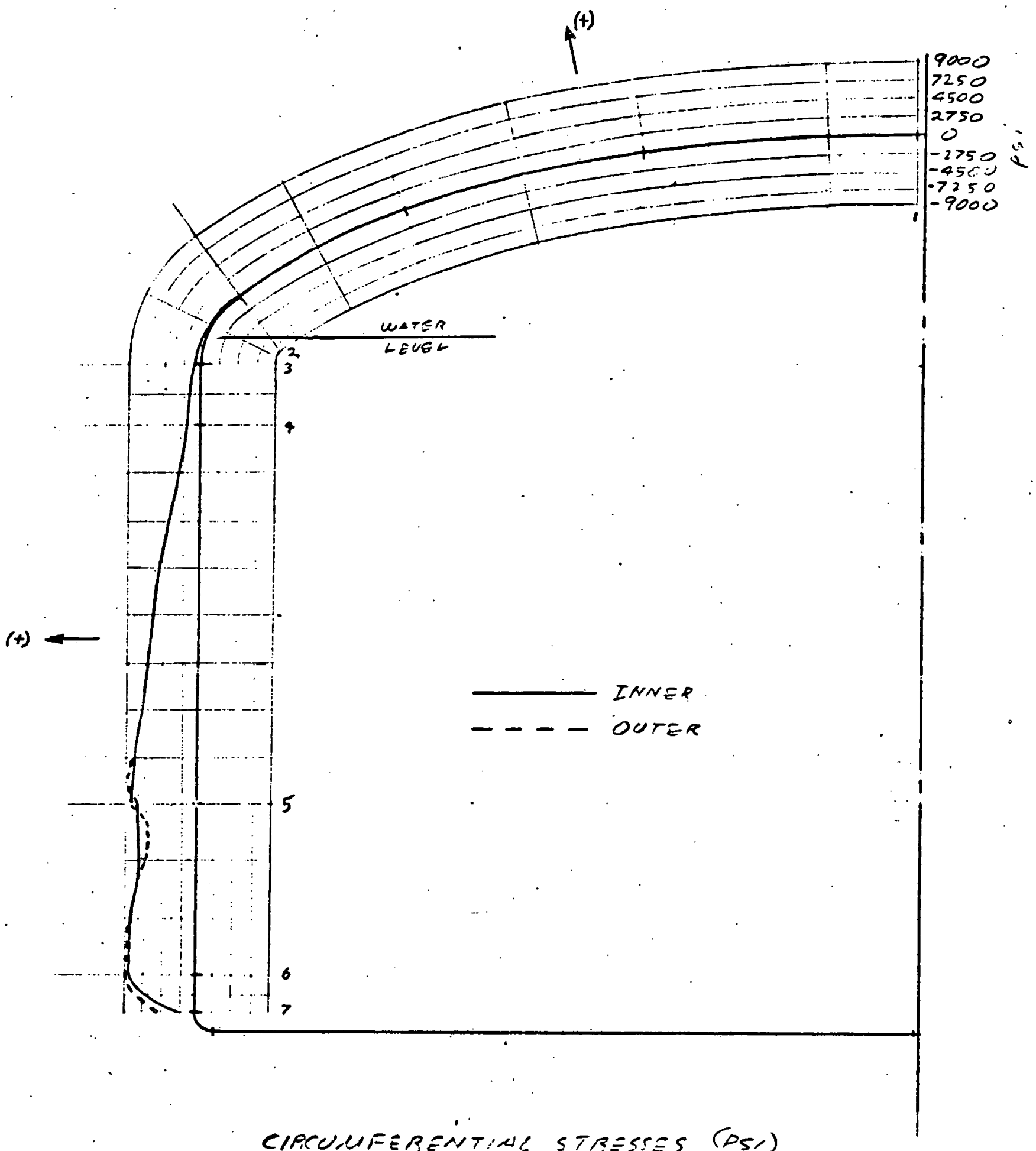

CIPCUNAEERENTINE STRESTES (PSH)

$36^{\prime} 5^{\prime \prime}$ WATER LEUEL 


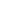

1
0

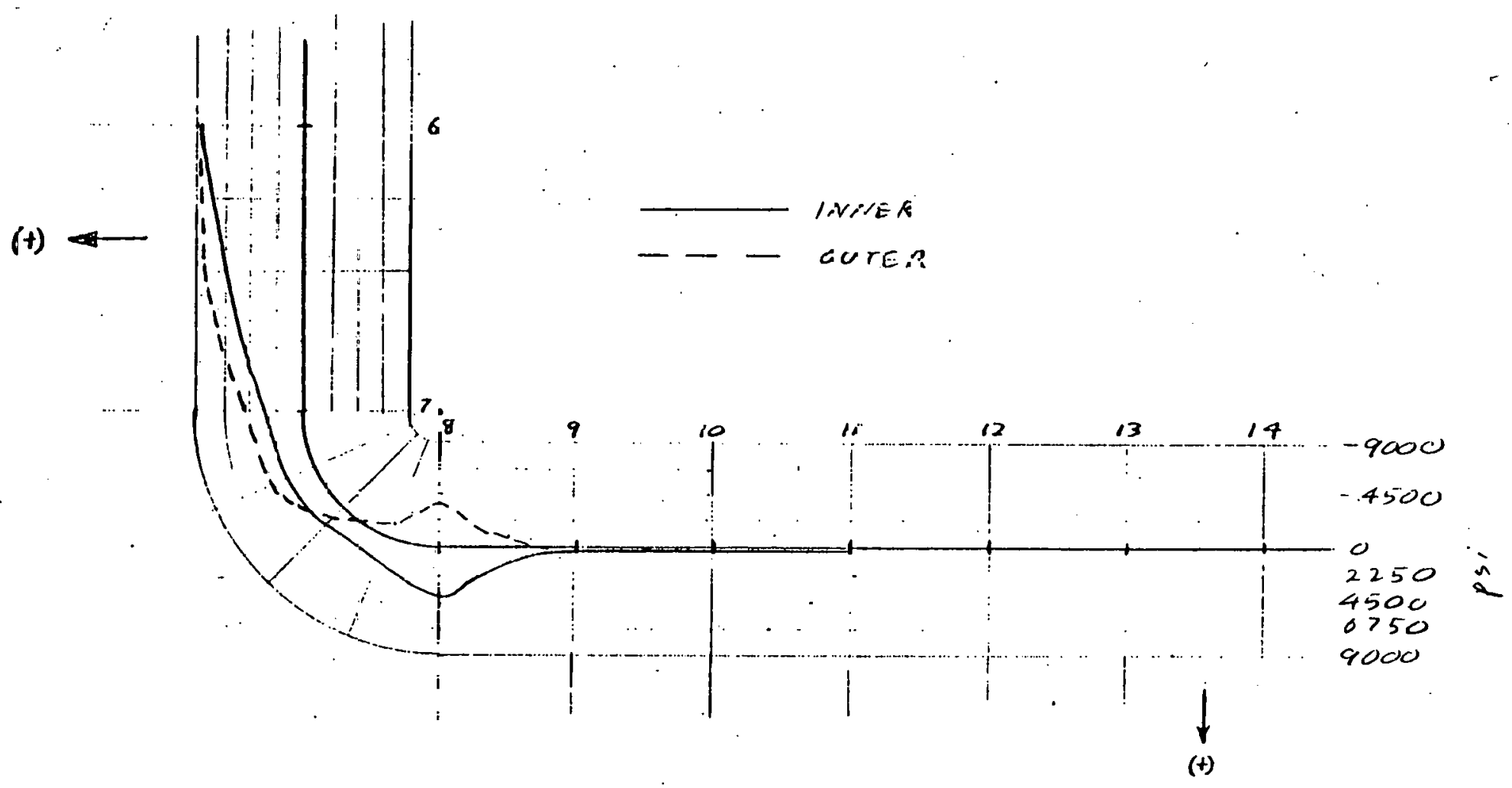

C:RCUUFERENTIAL S75ES5E 5

$36^{\prime} 9^{\prime \prime}$ WATEK CEUEC 


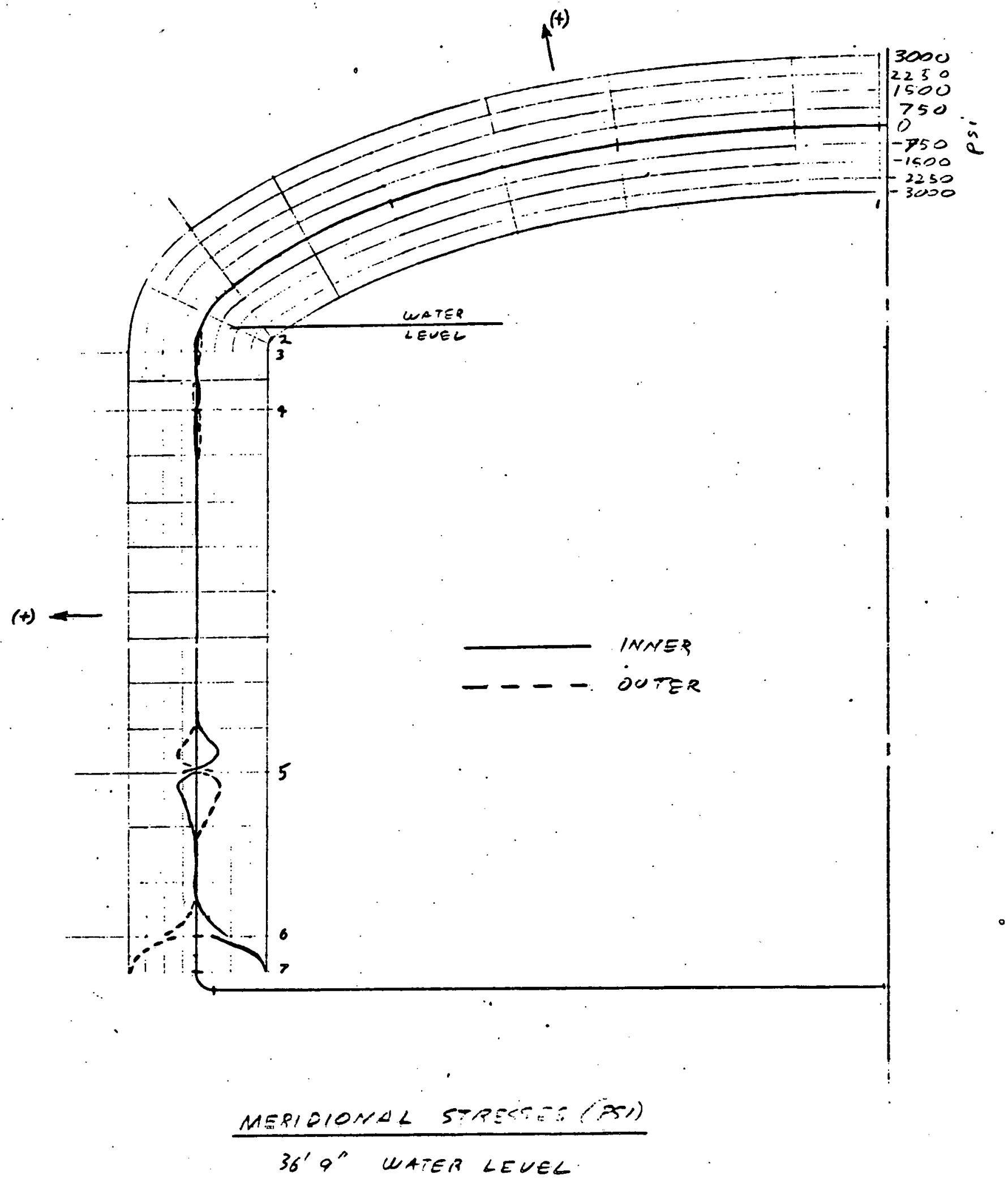




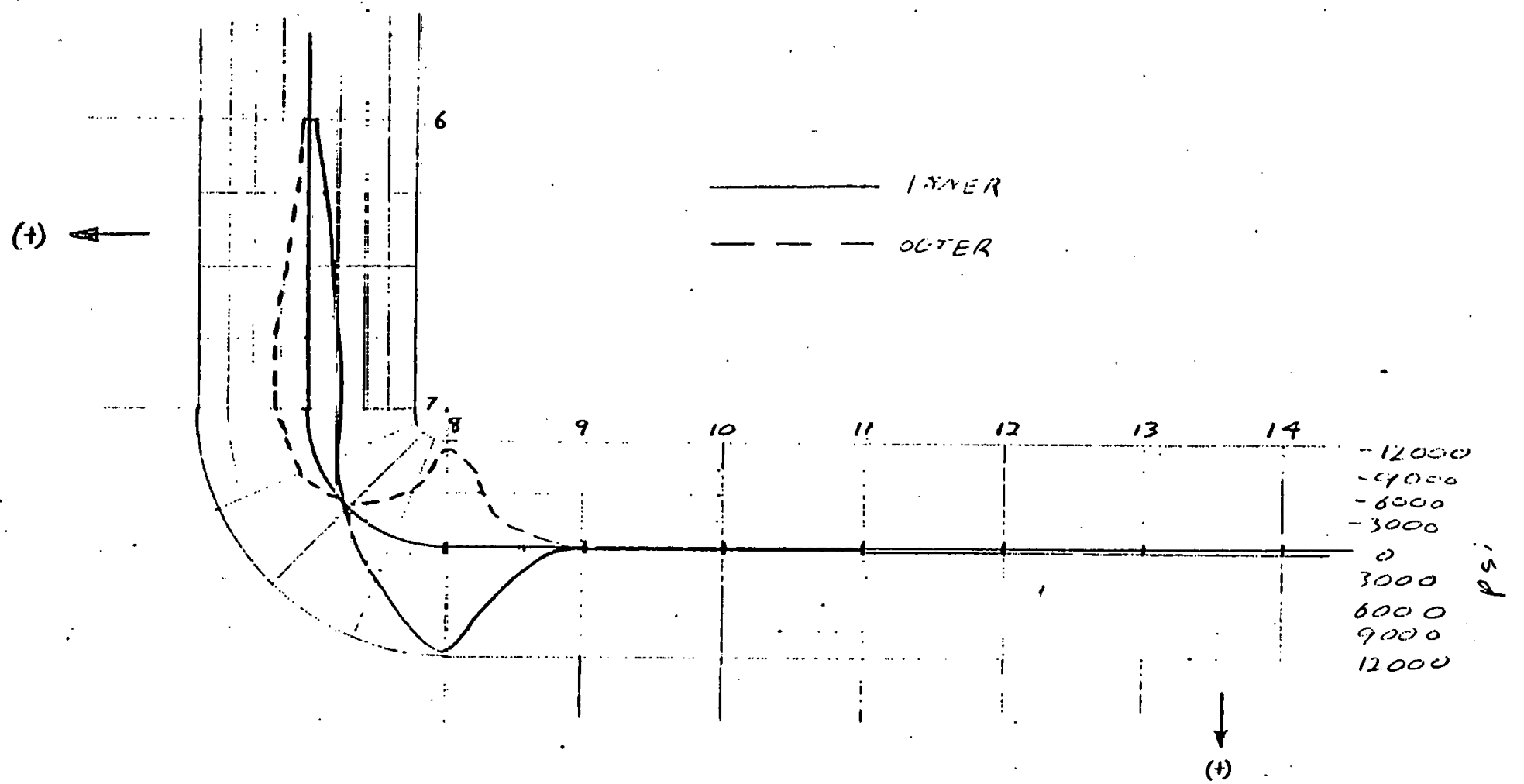

MERIDIONAL STIESSES 


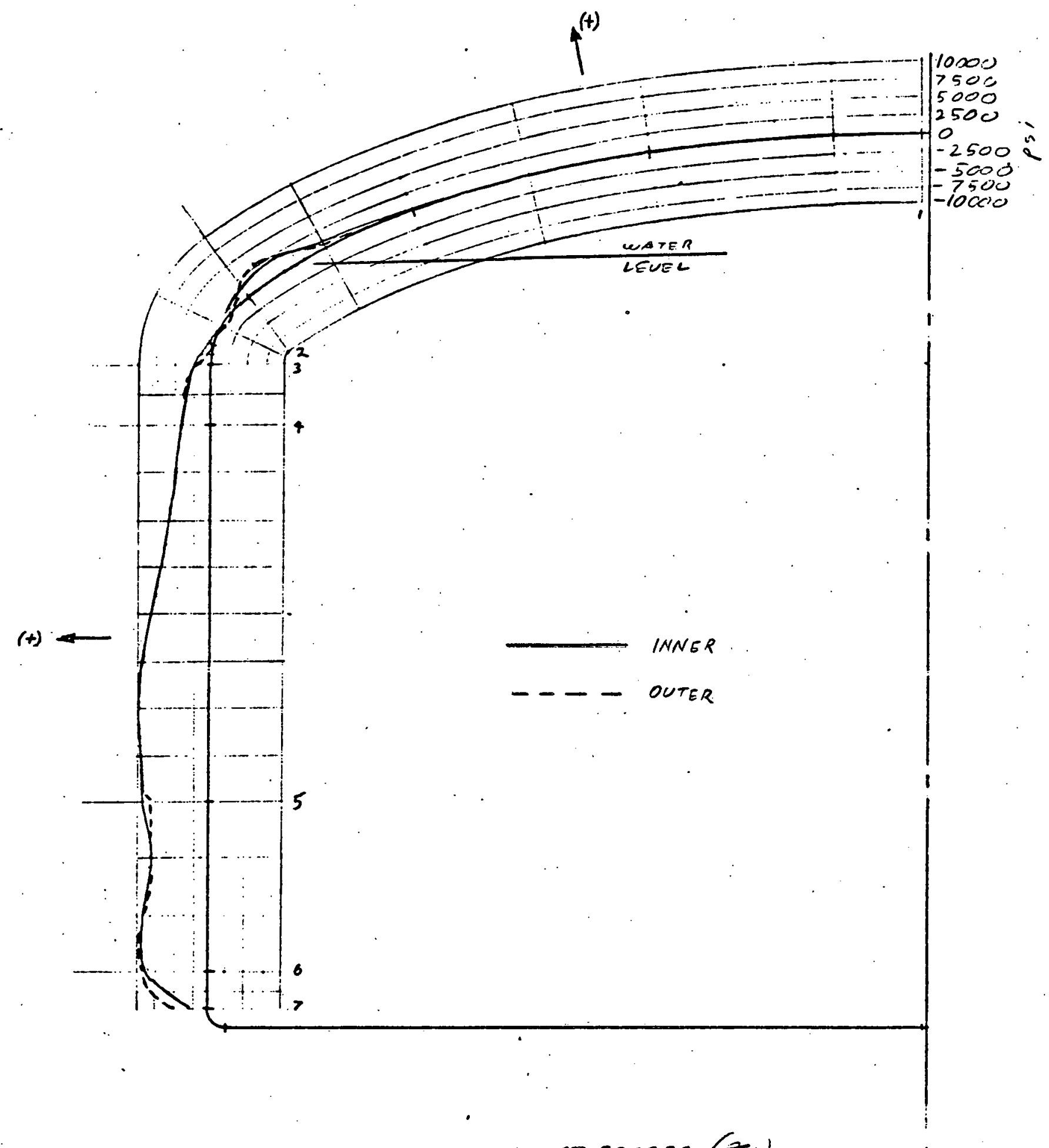

CIRCUNAERENTIAL STIPESSES (FI)

$$
40^{\prime} 9^{\prime \prime} \text {. WATER LEUEL }
$$

$c-43$ 
$n$
$-A$
-1

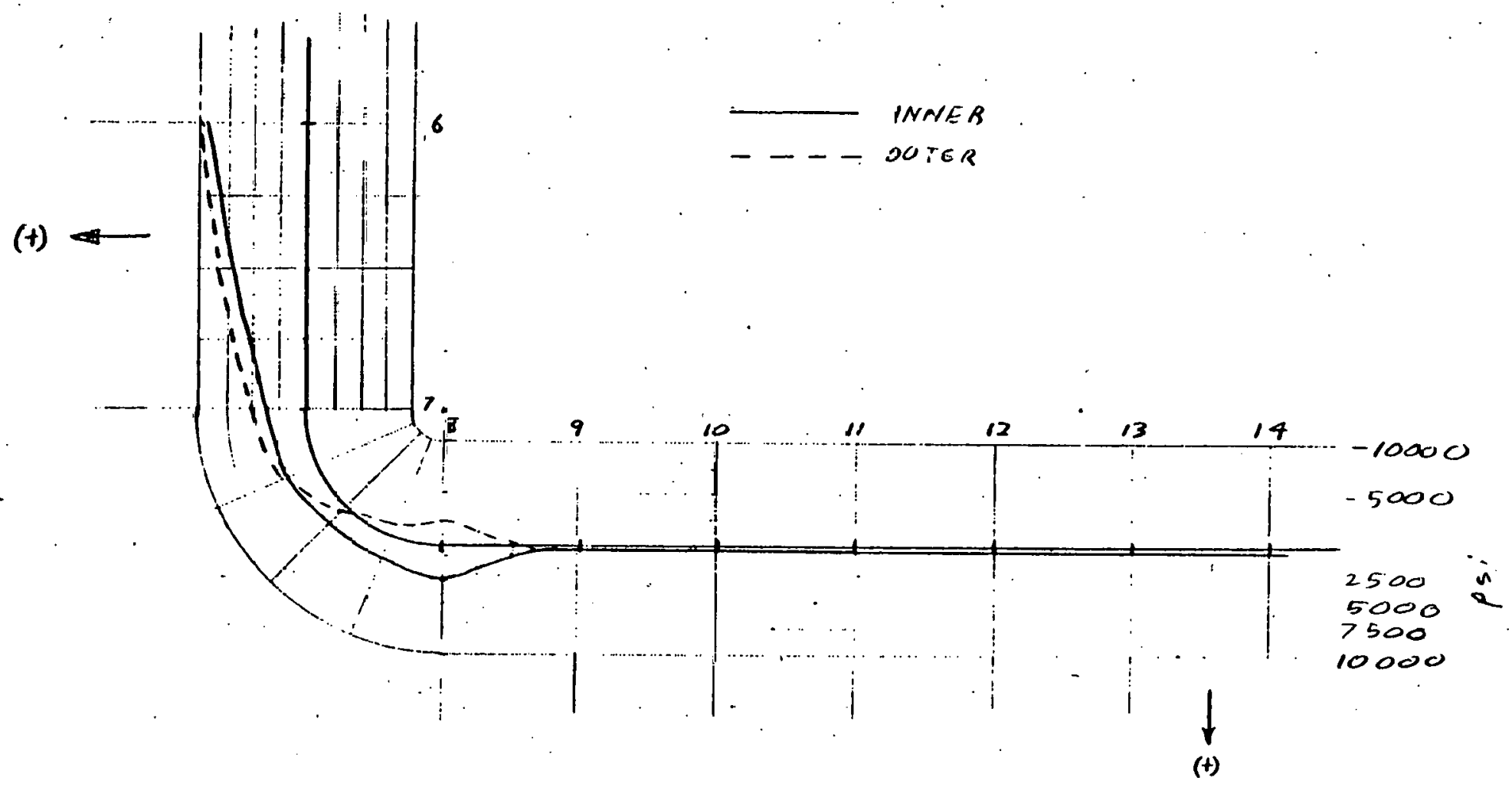

CIBCUMFERENTIAC STBESSES

$40^{\prime} q^{\prime \prime}$ WATER LEVEL 


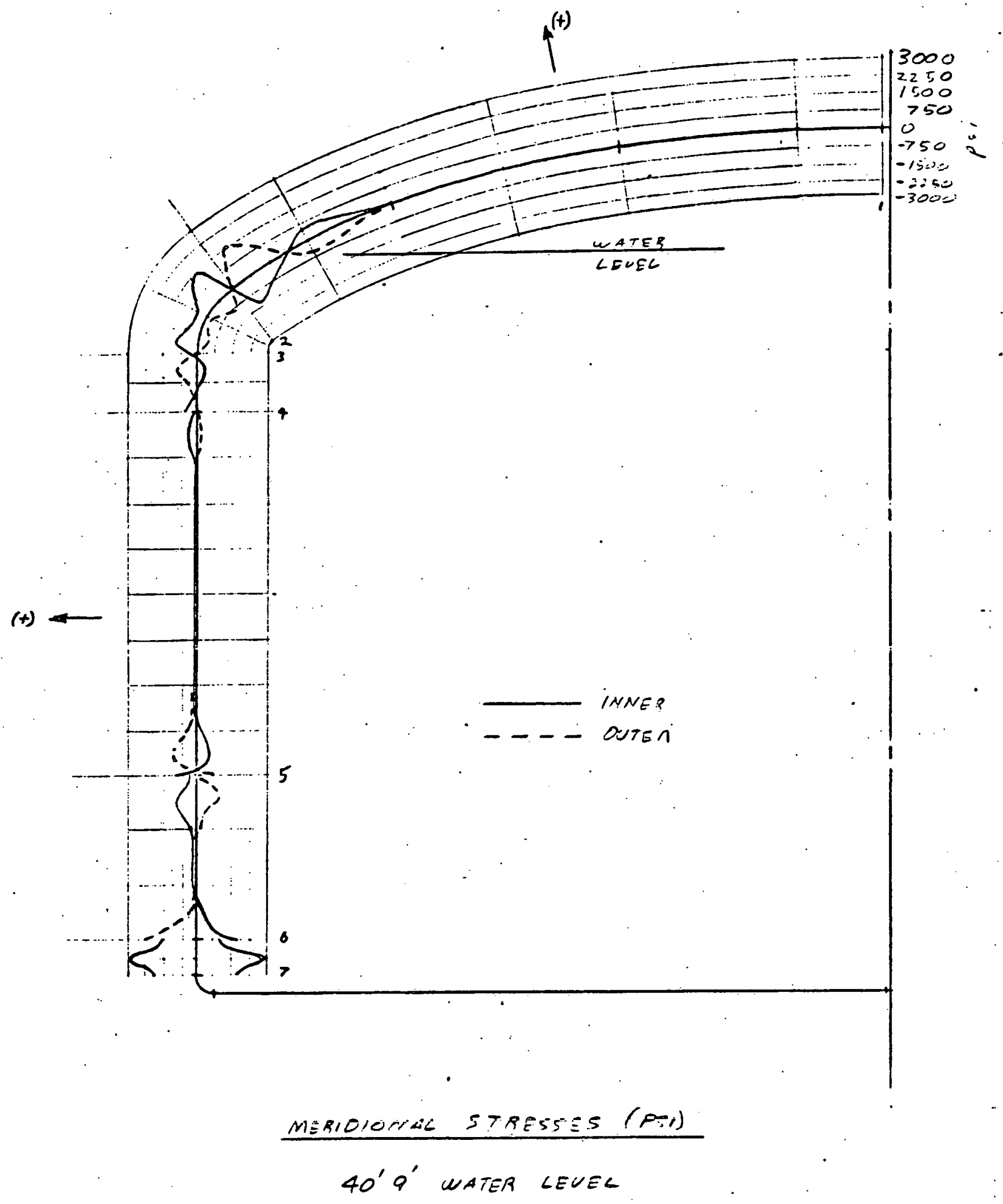




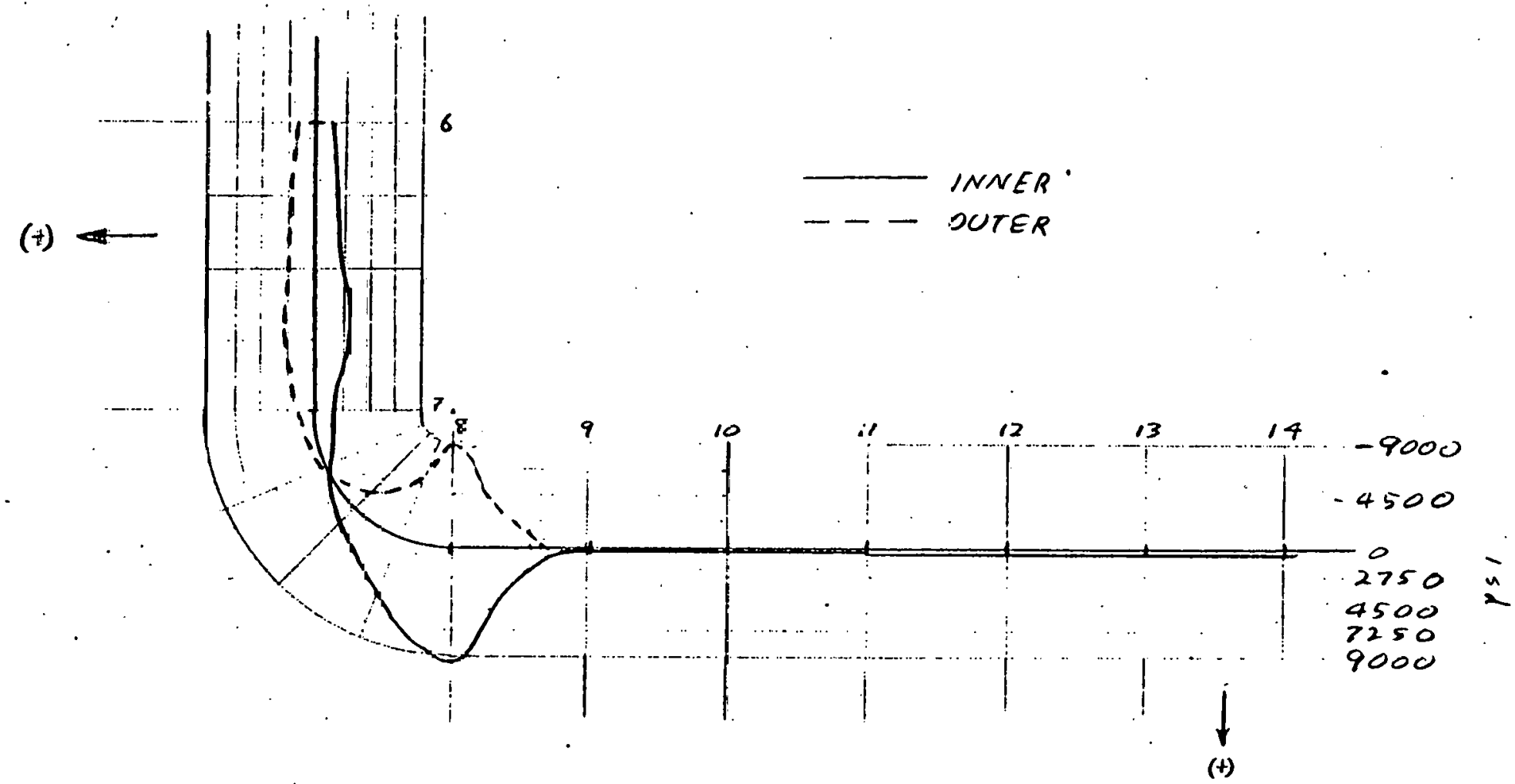

$\frac{\text { MERIDIONAL STIBESSES }}{40^{\prime} q^{\prime \prime} \text { WATER LEUEC }}$ 


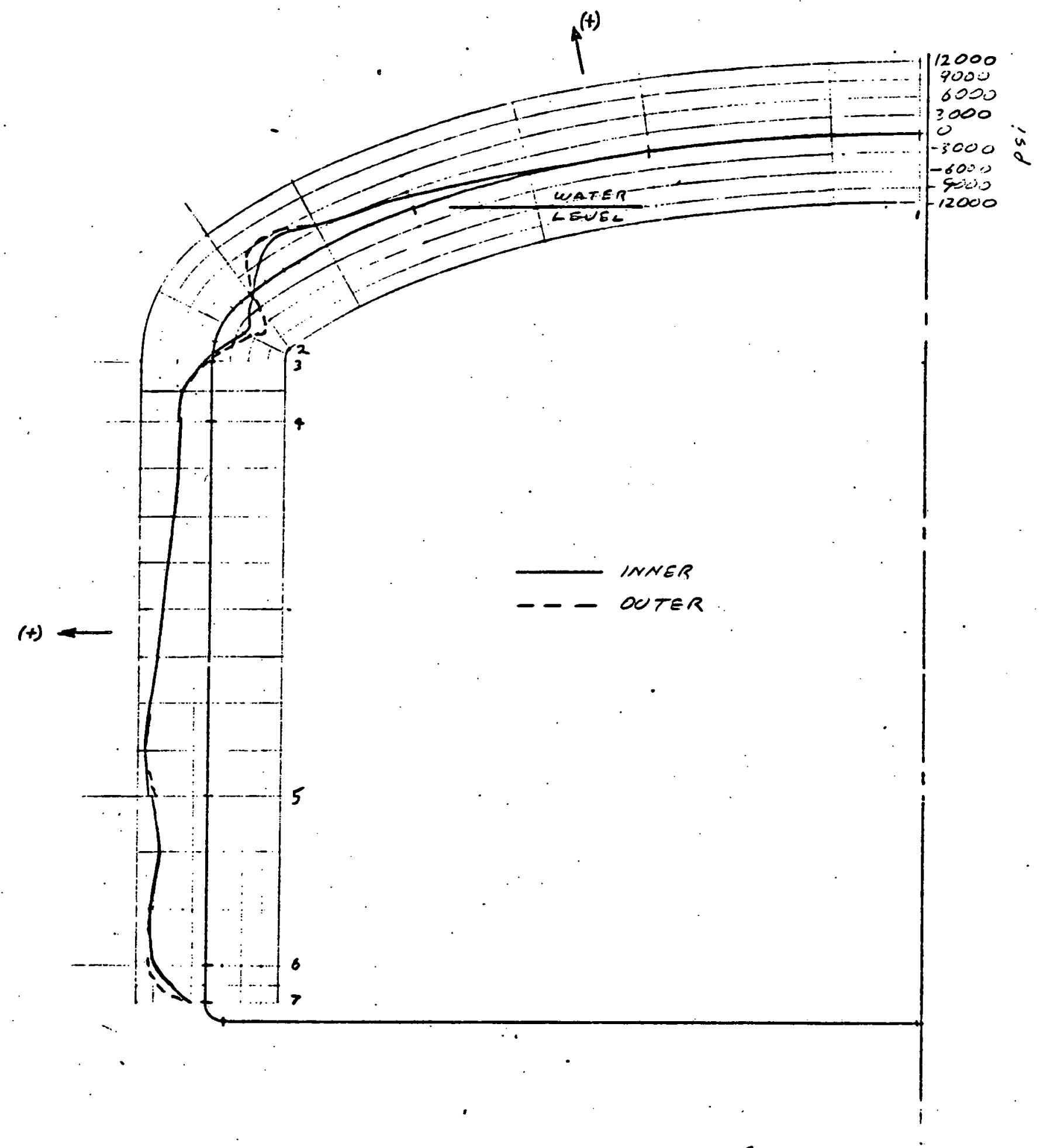

CIRCUMAERENTIAL STIRESSES (ASI) $43^{\prime}>^{\prime \prime}$ WATER LEVEL

$(-4)$ 


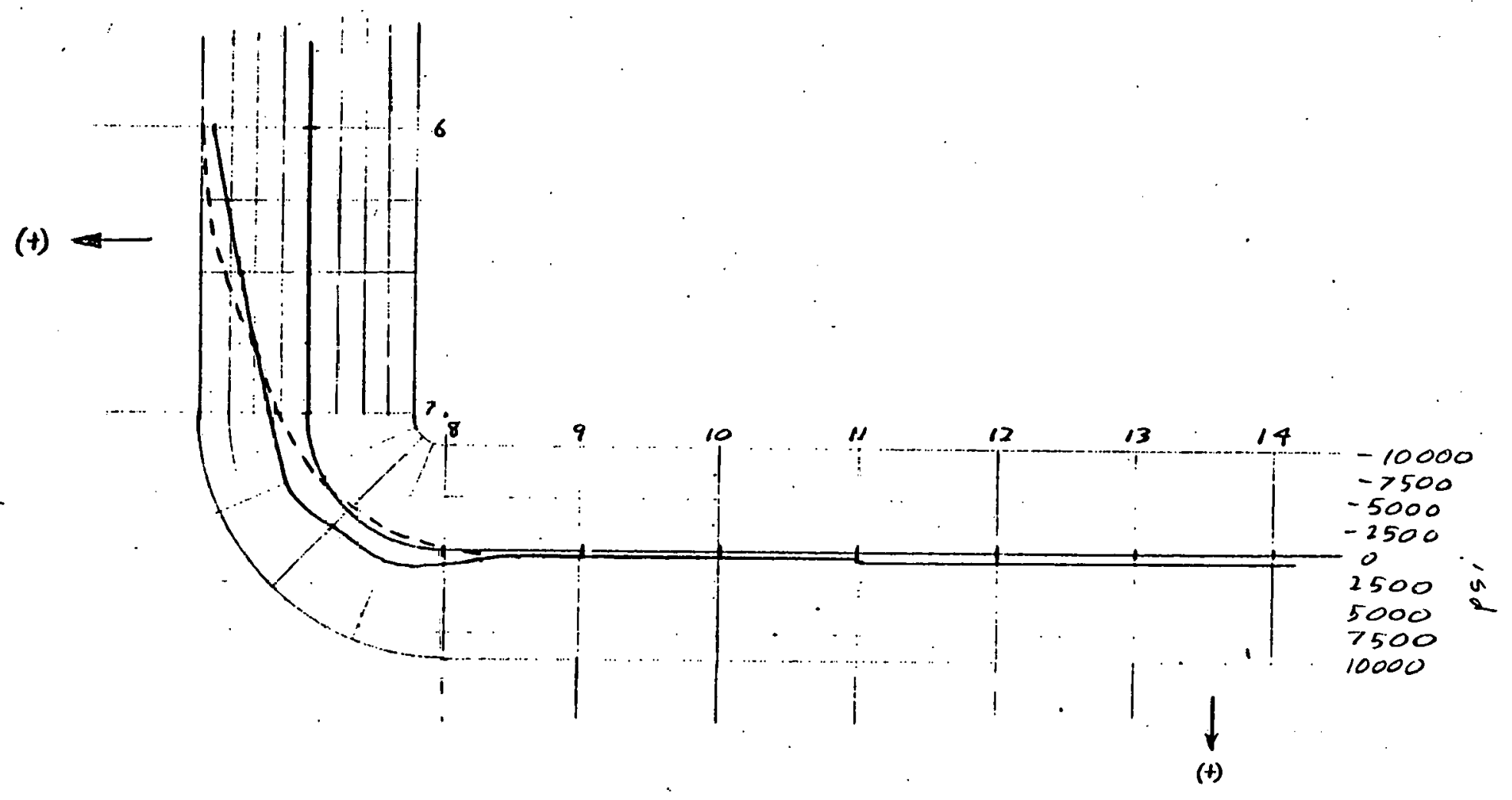

EIBCUMFERENTIAL STIEESES

$43^{\prime}>^{\prime \prime}$ WATER LEUEL 


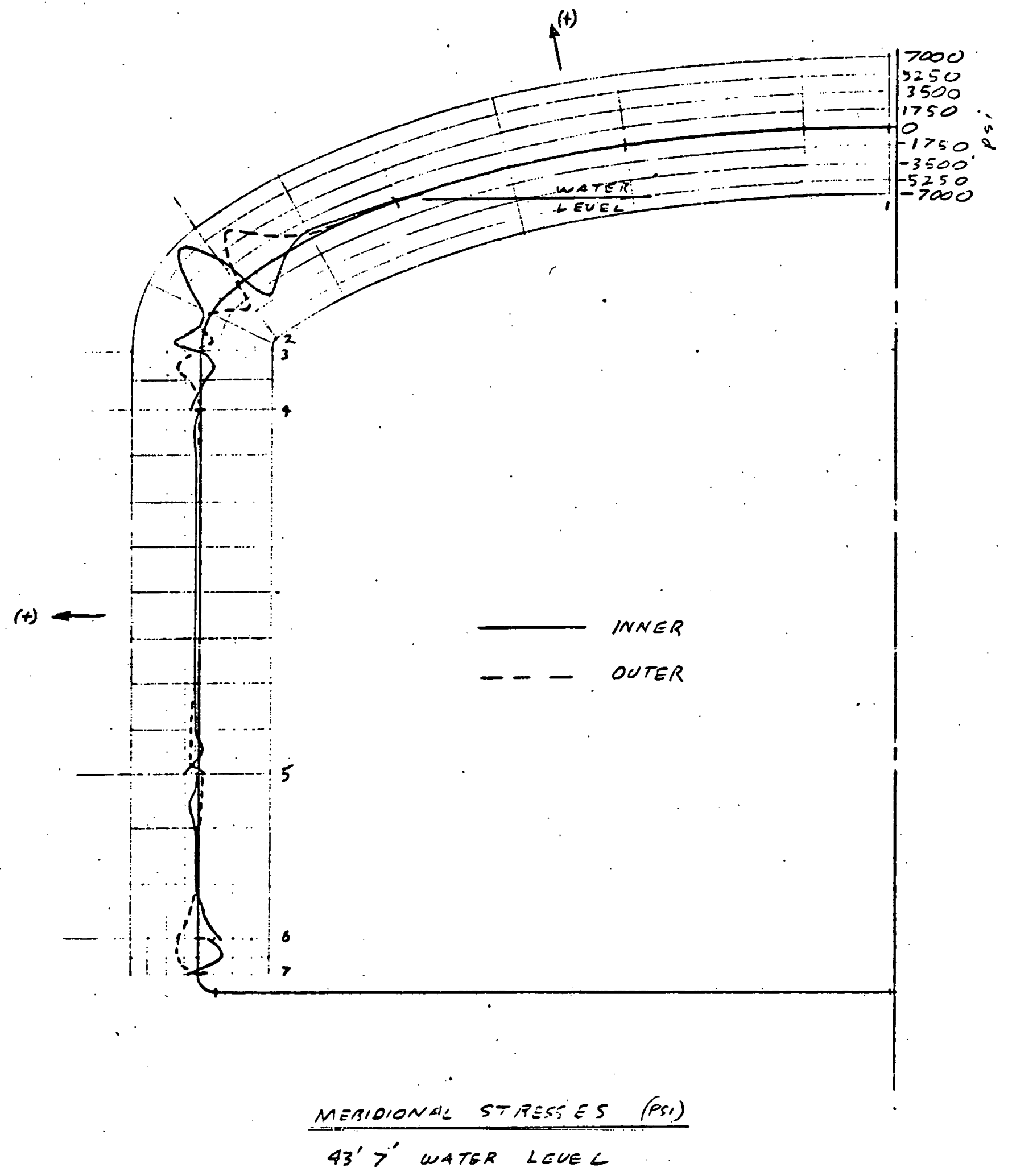




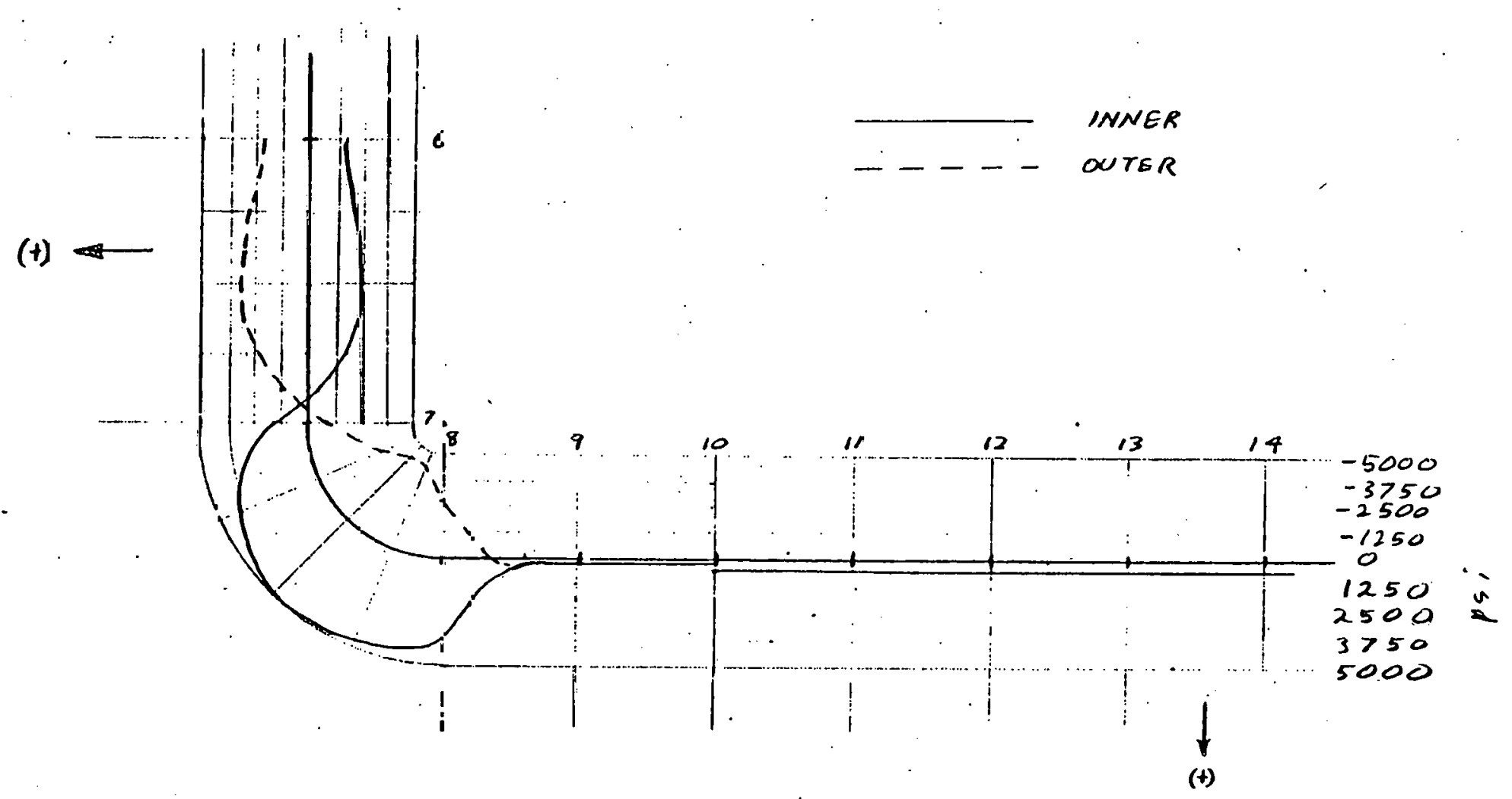

$\frac{\text { MERIDIONAL STRESSES (PS') }}{43^{\prime}>" \text { WATER LEVEL }}$ 


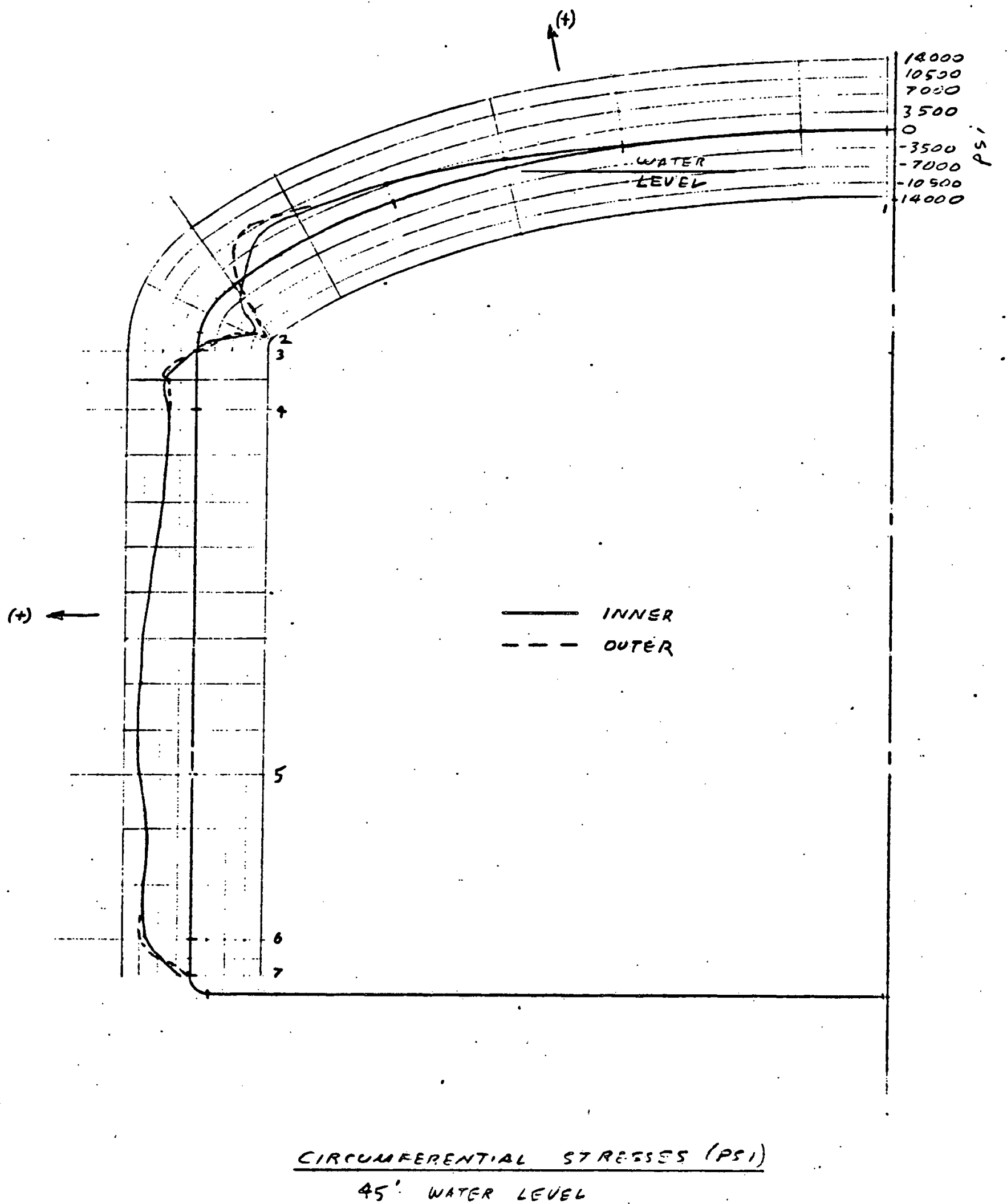




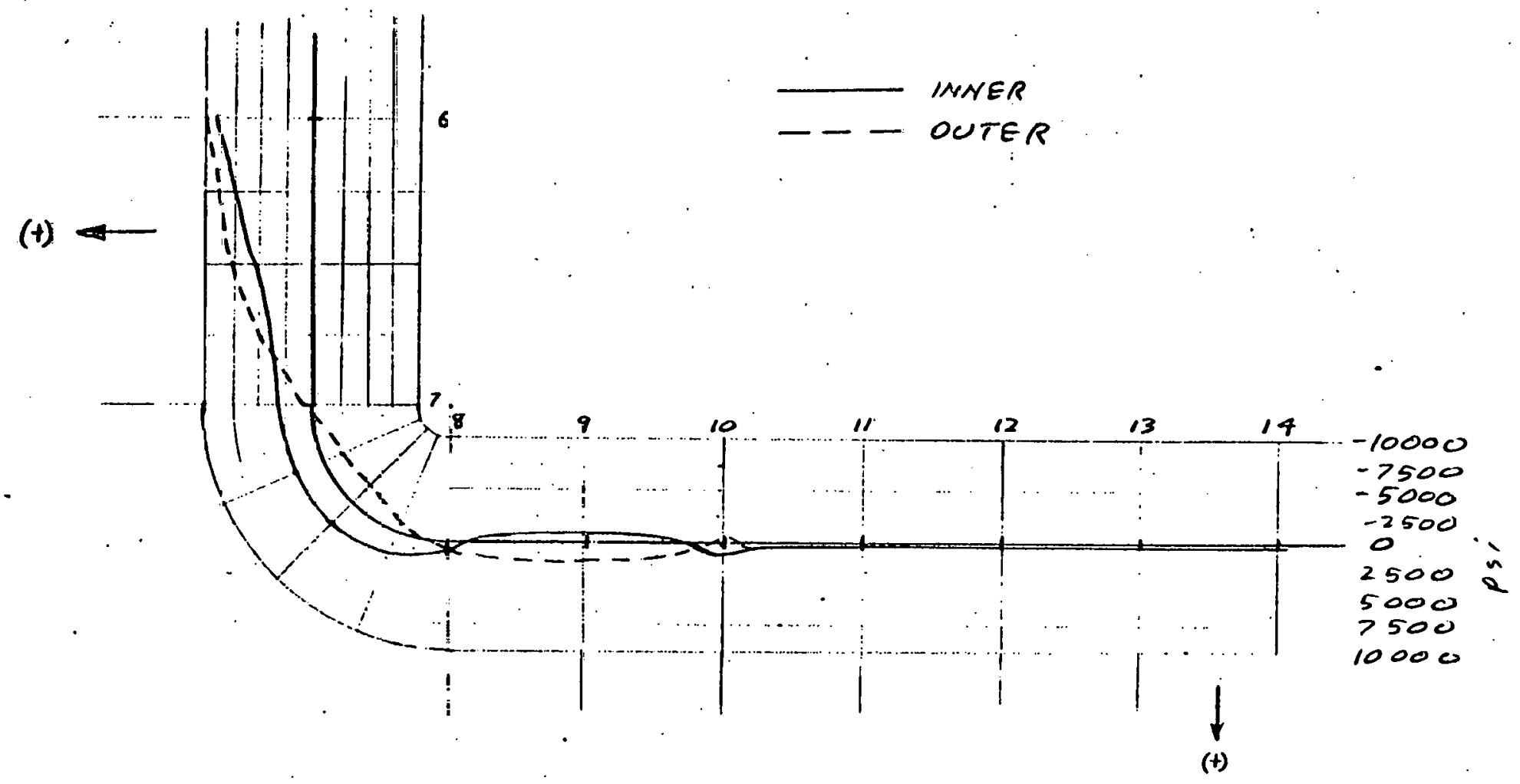

CIRTUMFERENTIAE STBESSES (PSI) 45' WATEA LEVEL. 


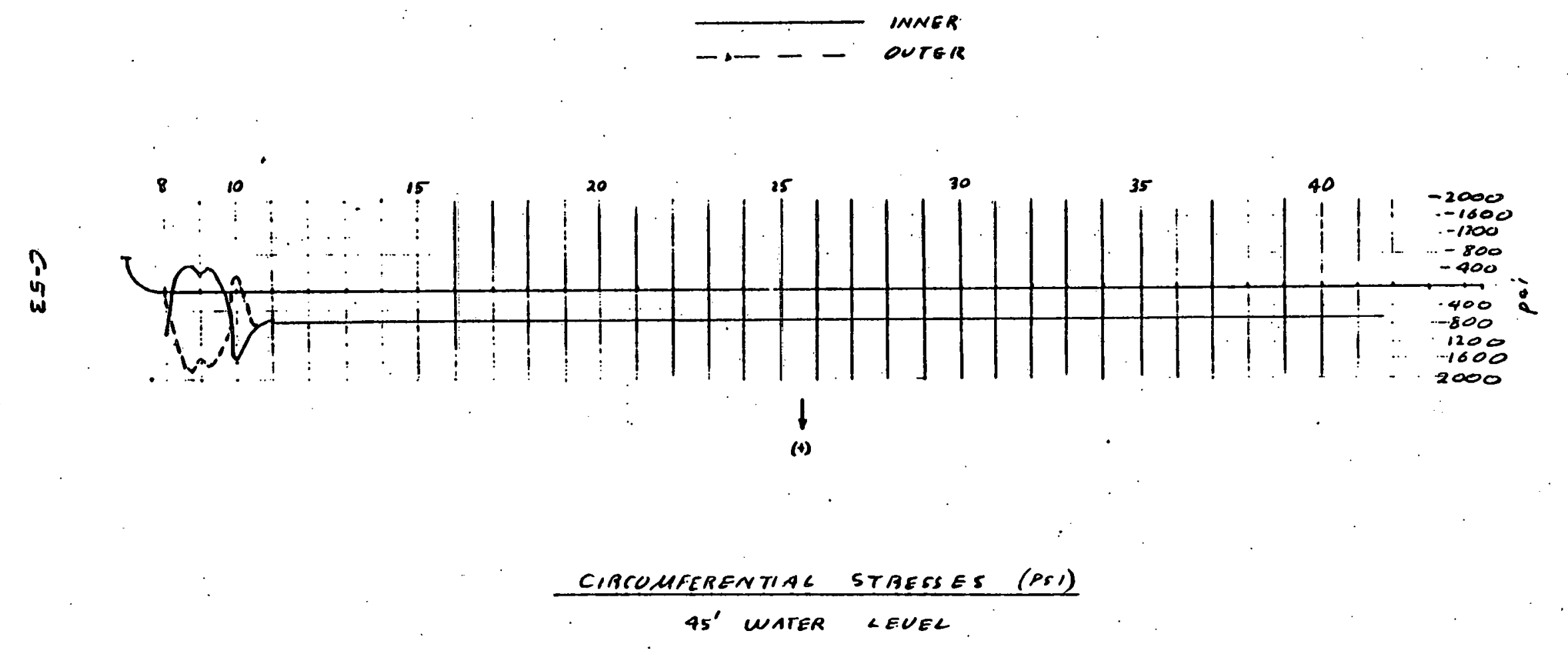




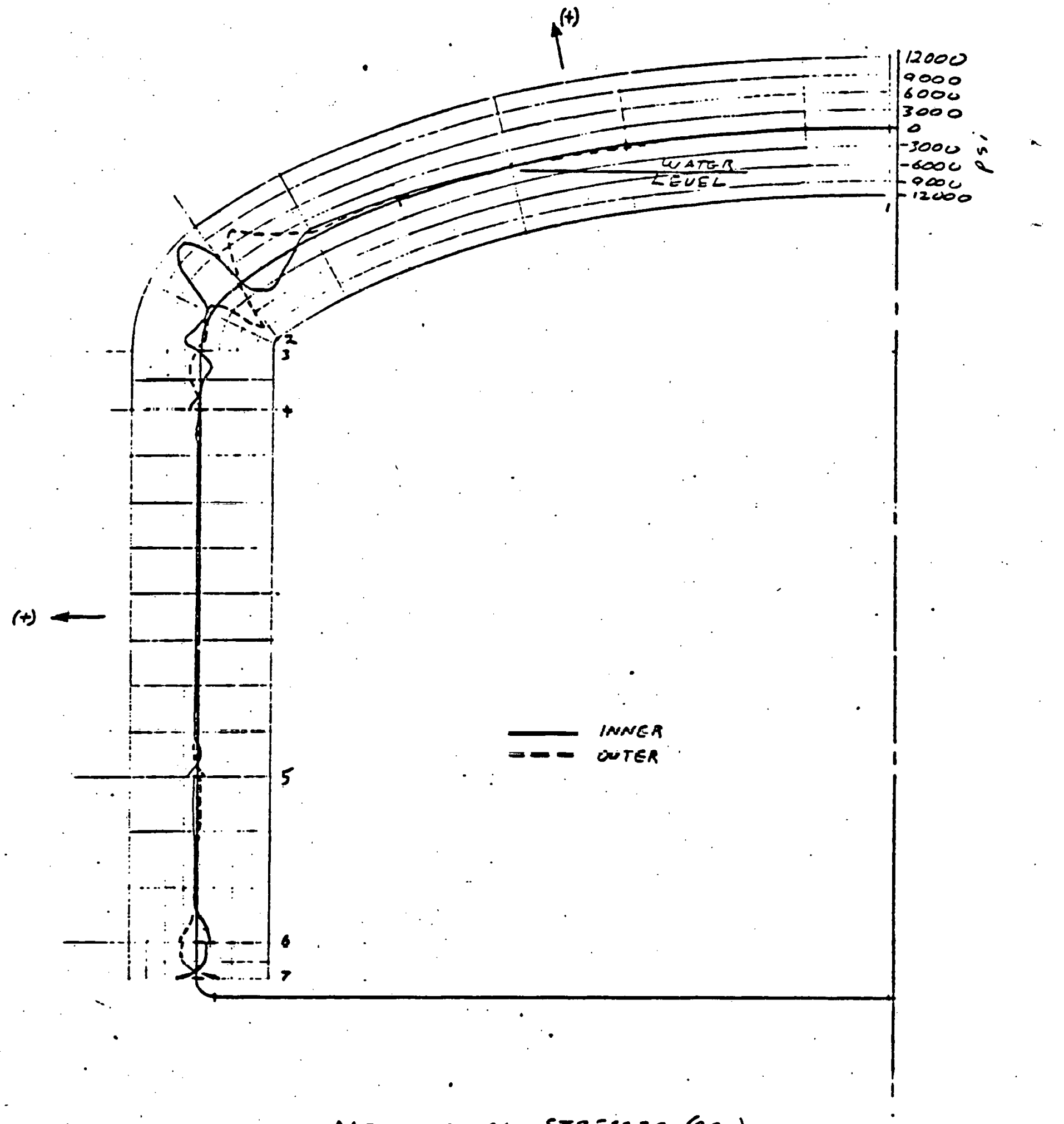

MERTDIONAL STRESSES (PSD) $45^{\prime}$ WATER LEUEL 
$n$
vi
$y$

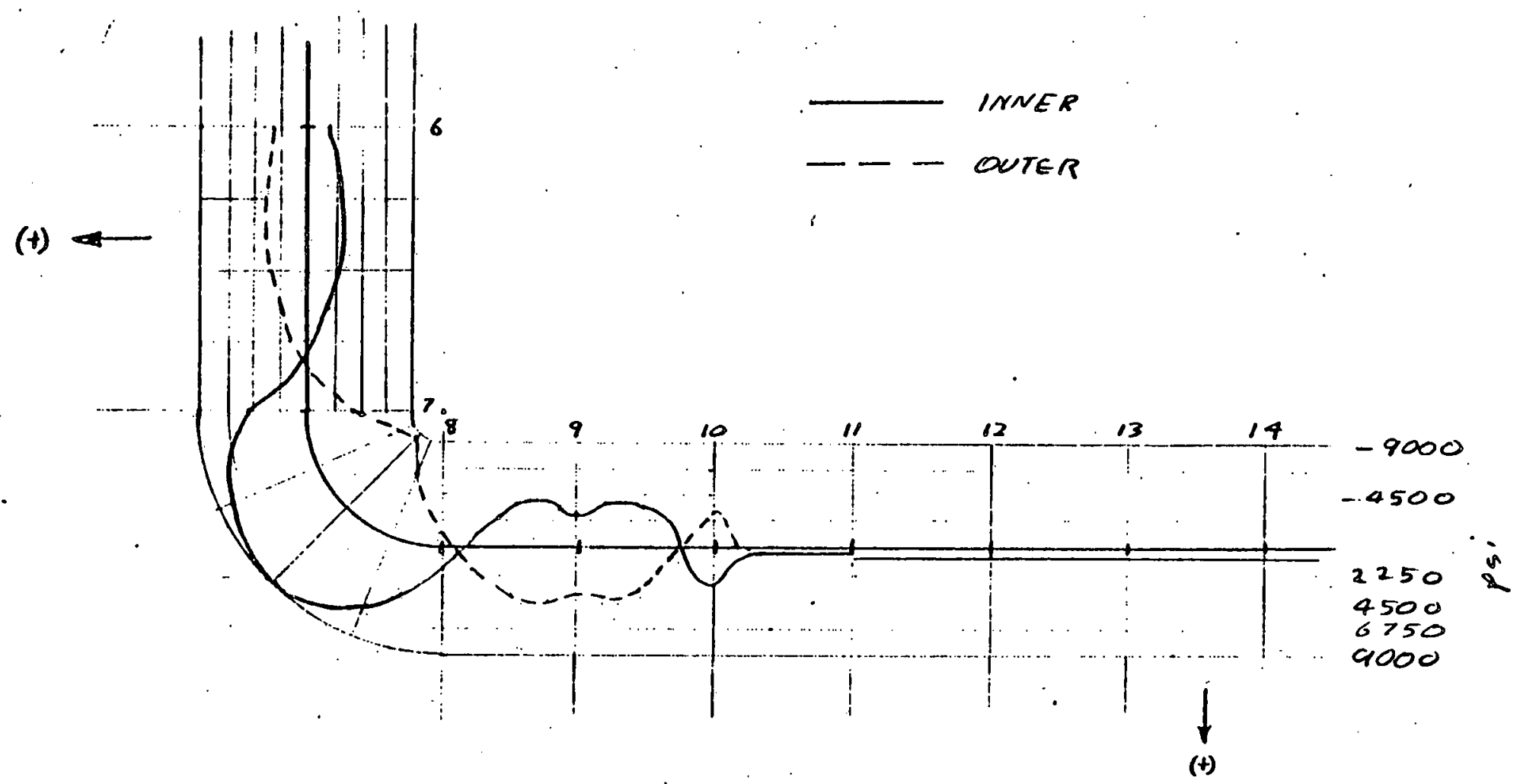

MERIDIONAL STRESSES (PSI)

$45^{\prime}$ WATER LEVEL 


$$
\text { - - outer }
$$

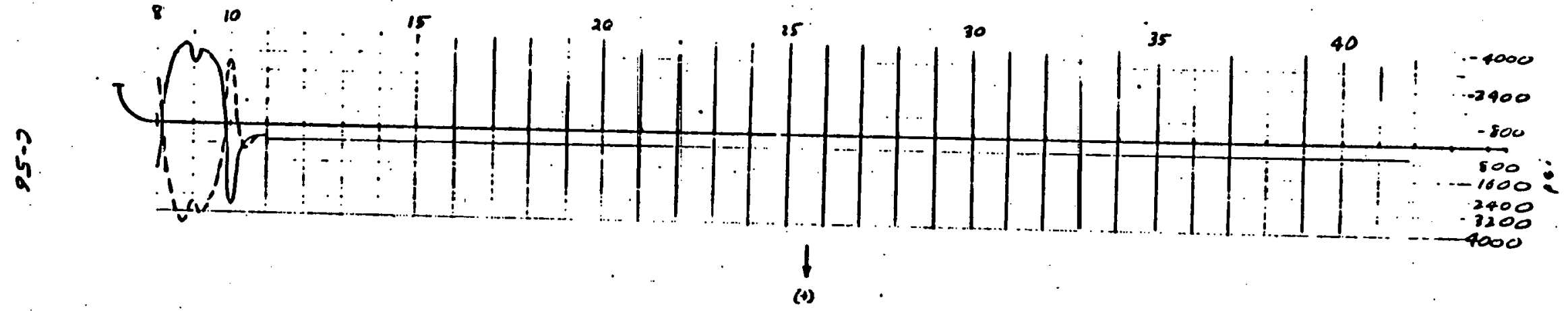

MERIPUONAC ctresies (PST) A5' waren LELE 


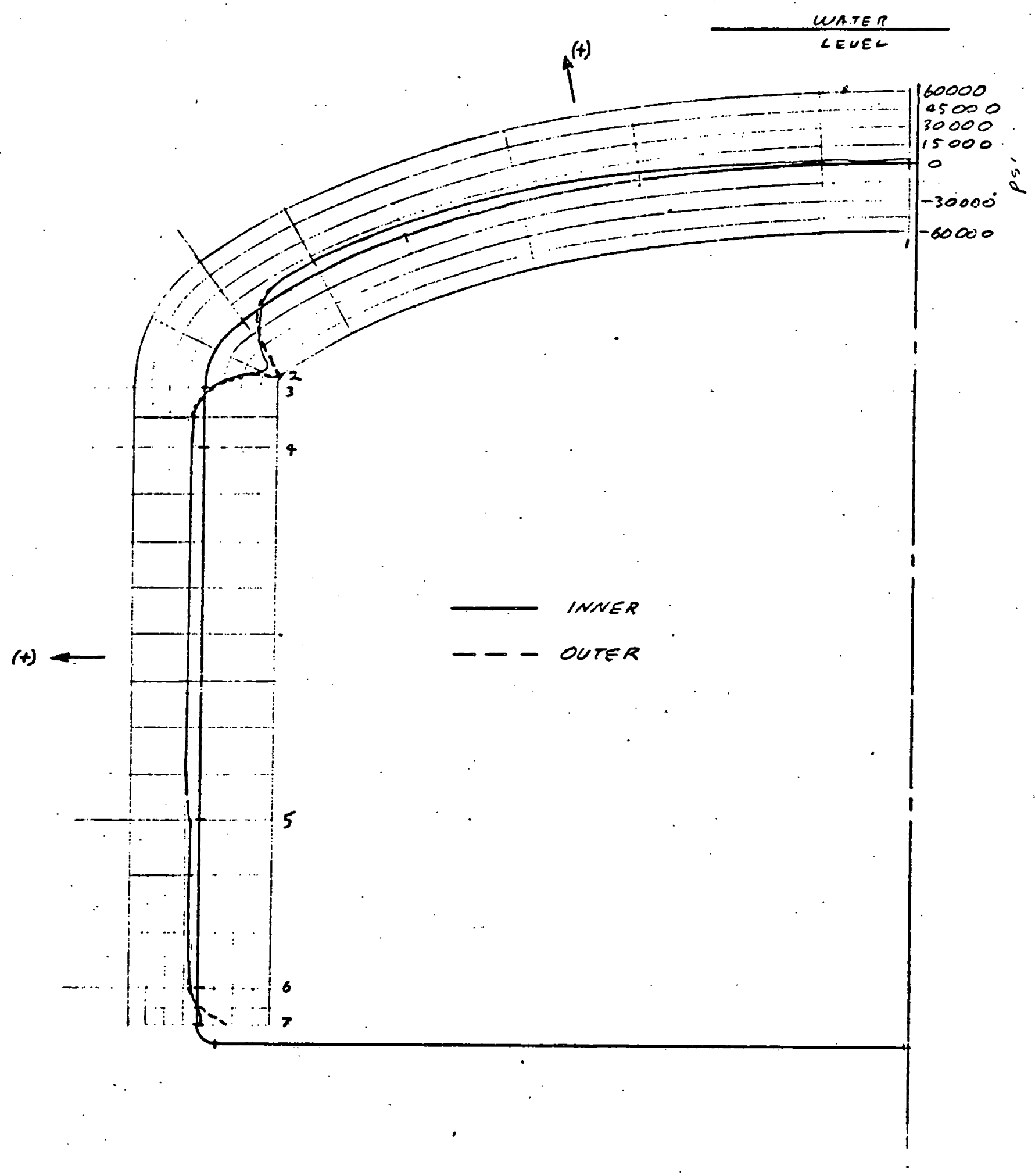

$\frac{\text { CIACUMFERENTIAL STMESGES (PI) }}{\text { TAH HEAD AROUE TANA NEAO }}$

$$
\langle-5\rangle
$$




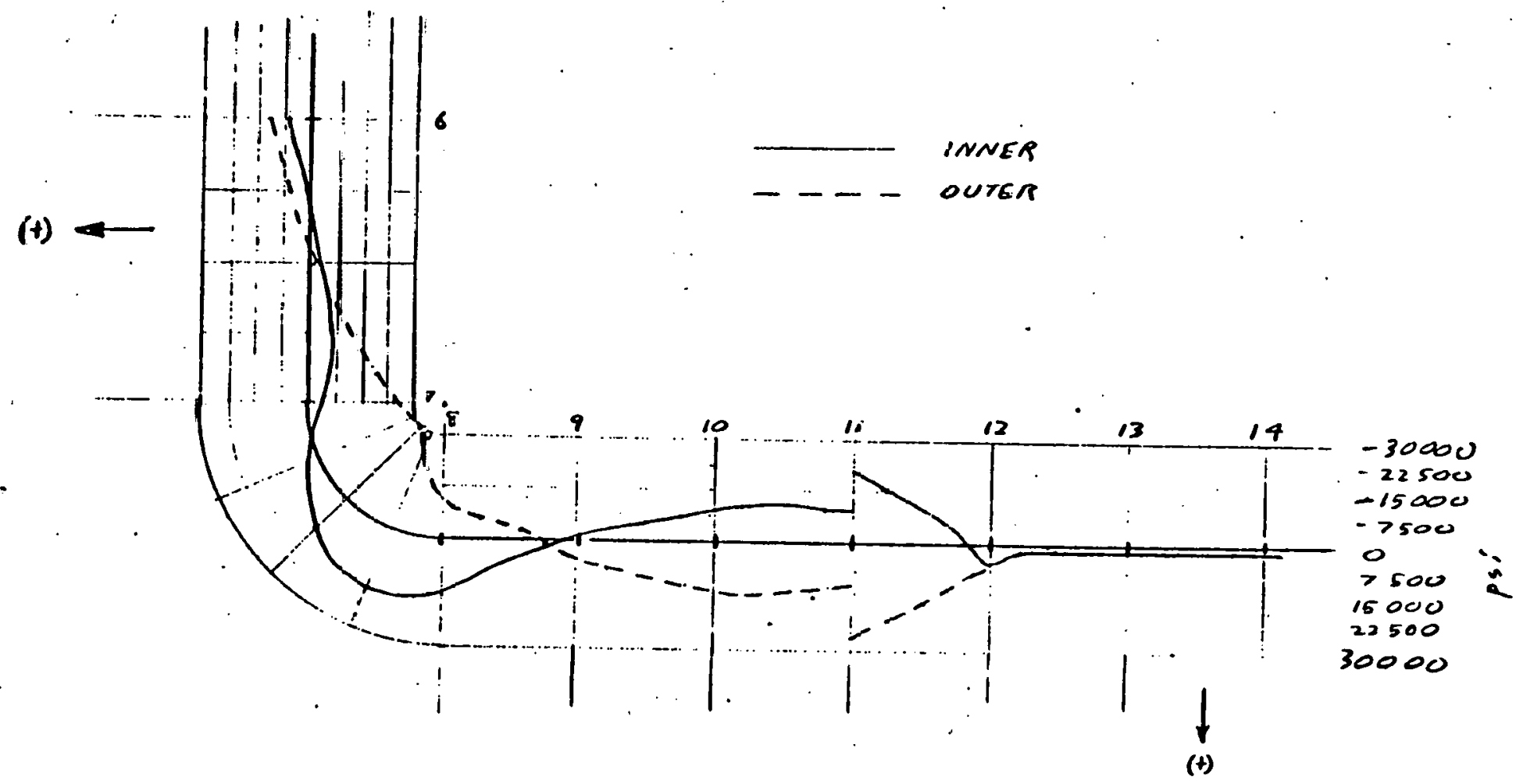

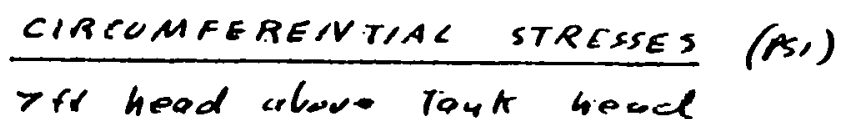




\section{- INNER}

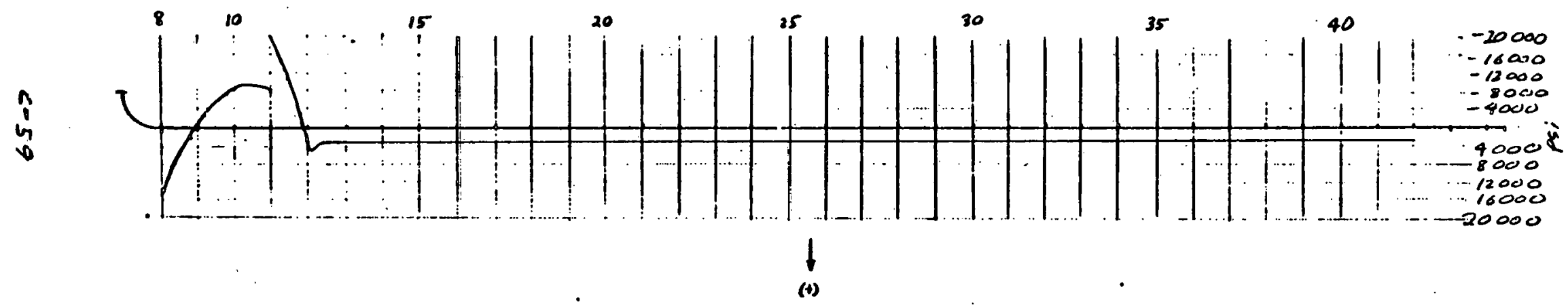

$\frac{\text { CINCUMFERENTIAL STRESSES (ASI) }}{\text { TFH HEAD ABOVE. TANA HEAP }}$ 


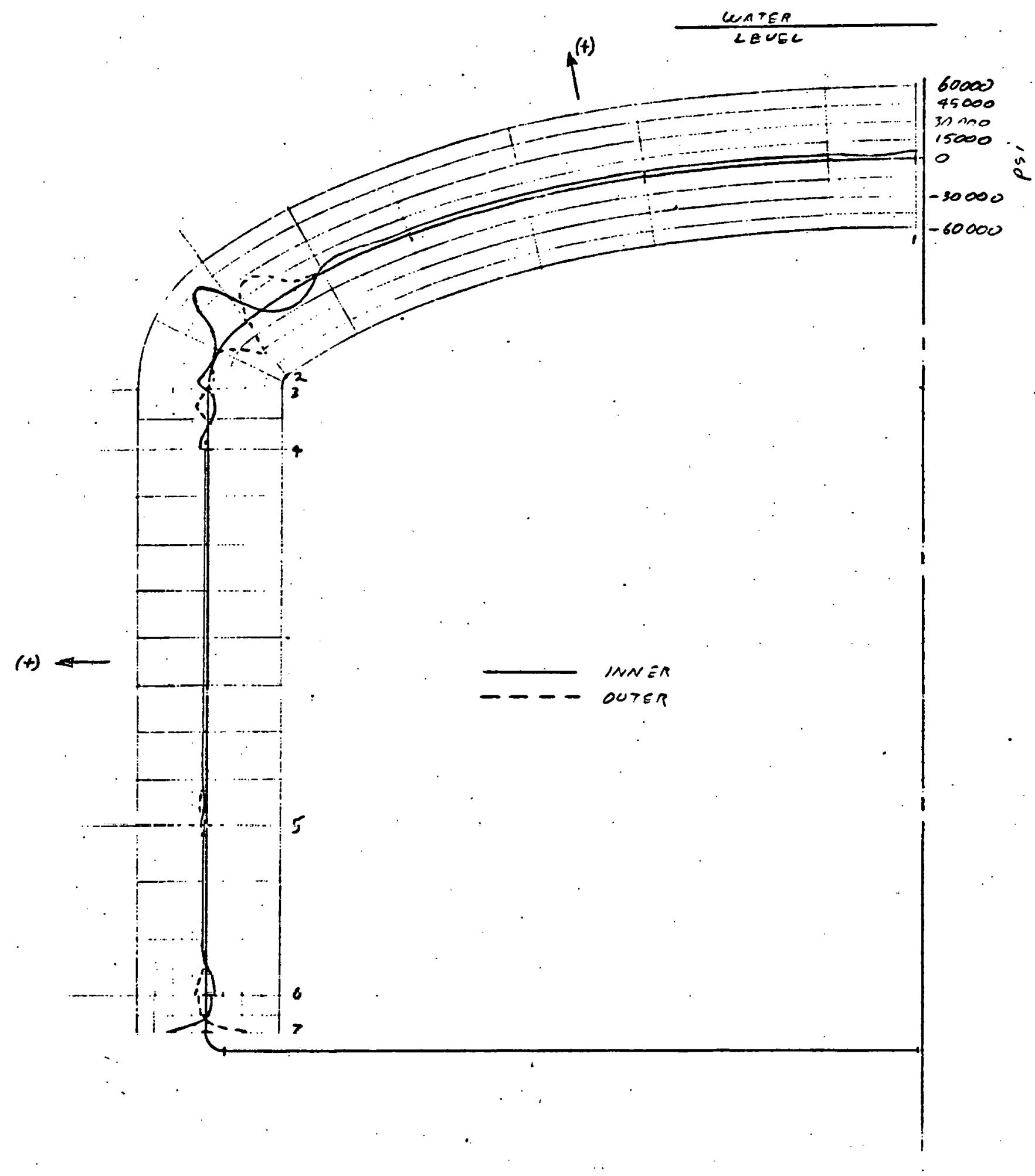

METIDTONAL STRESSES (pSi)

DA MEAD ABOVE TANA HEAD

$c-60$ 

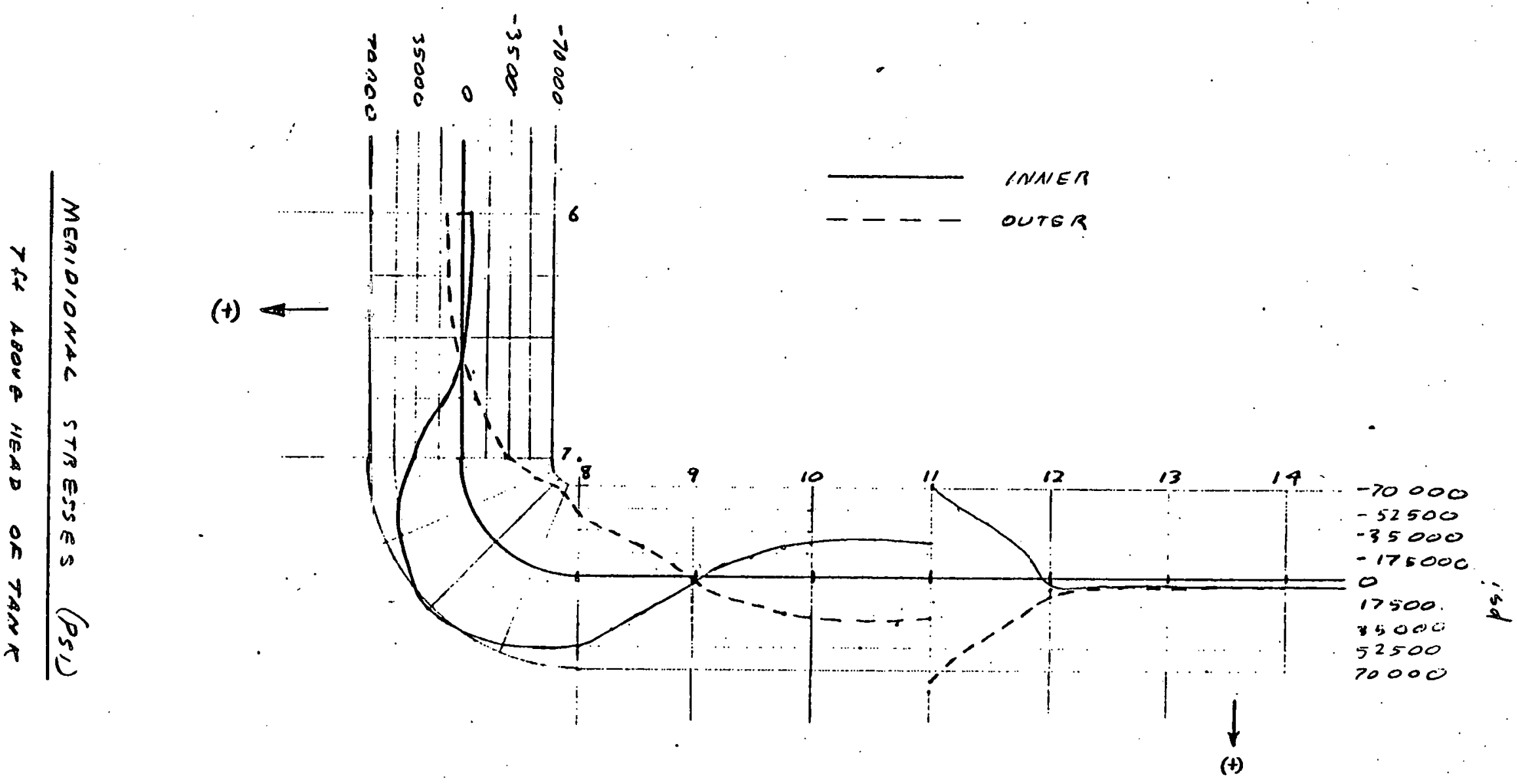


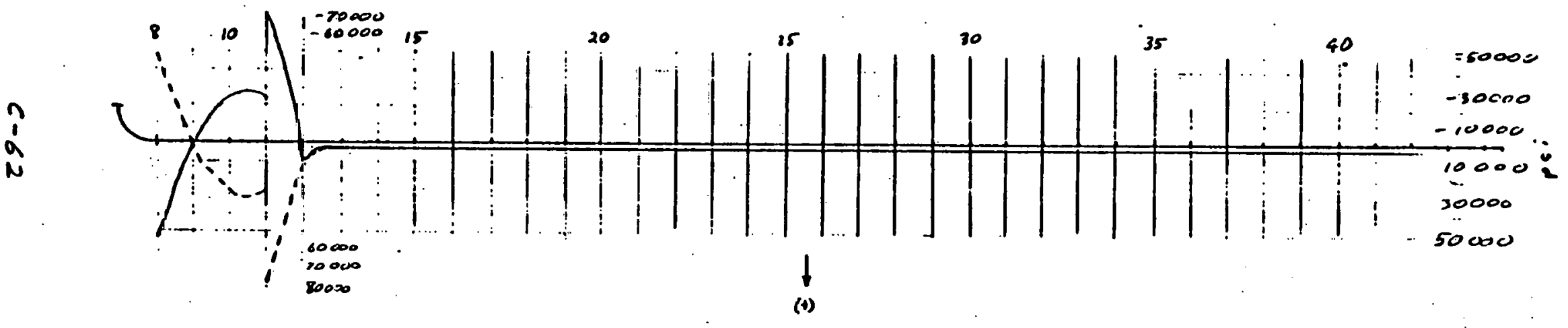

$\frac{\text { MENipioneAL STAESSES (PSI) }}{\text { THE IHEAD ABONE TANA IEAD }}$ 


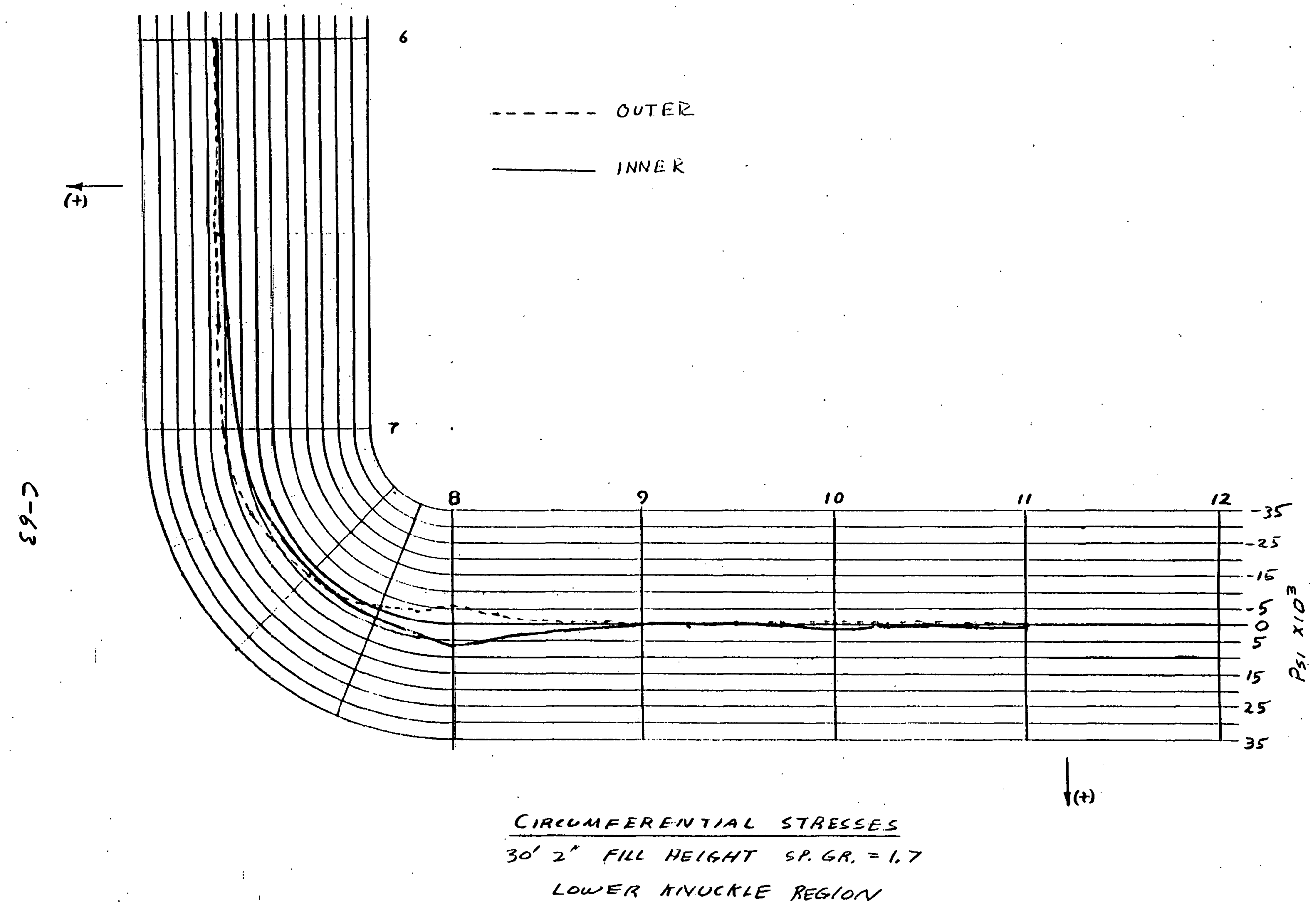




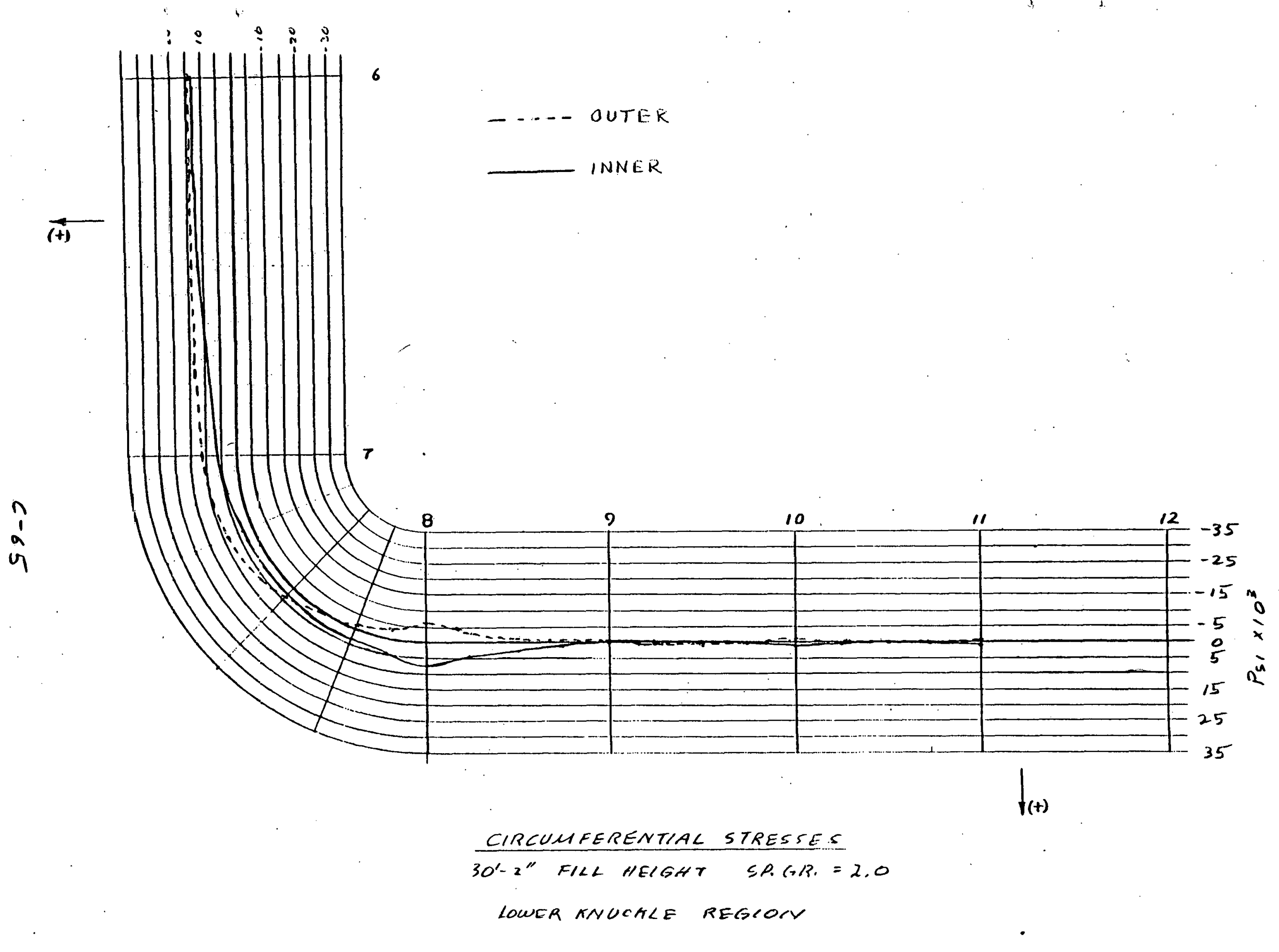




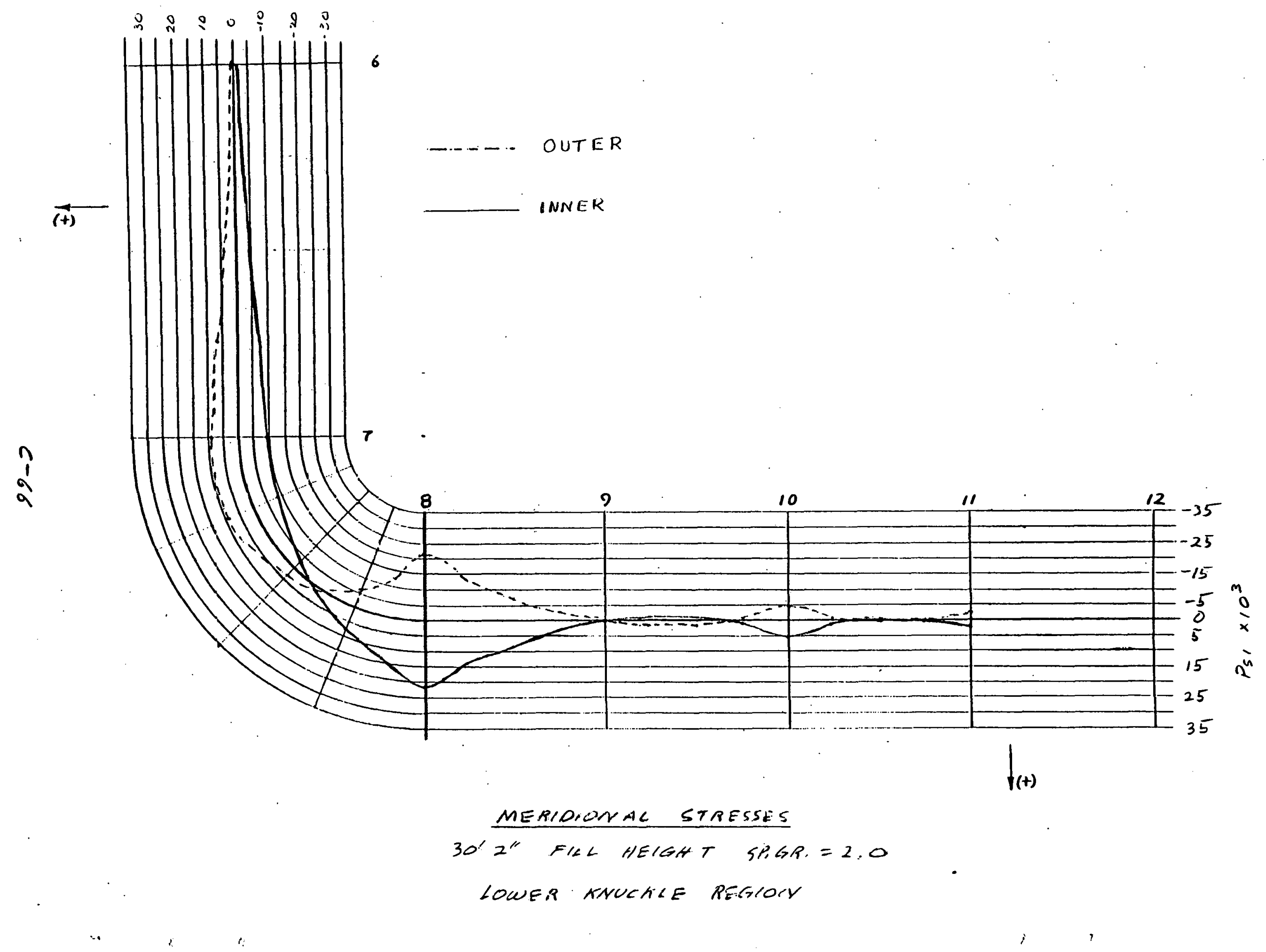


MARC is a large, general purpose finite element computer program designed to solve a wide variety of structural analysis problems. The element library of MARC is sufficiently extensive to model almost any structure or structural component. In addition most elements are of a precision level so as to allow accurate results while using only a moderately refined mesh configuration, thus greatly facilitating input data preparation.

MARC applications may involve static, dynamic, or stability analyses. Considerable versatility is allowed the user in. treating material non-linearities and large displacement, geometrically non-linear problems. Extensive graphics capabilities allow rapid assimilation of solution output as well as facilitate input data preparation.

The MARC program is based on the work of Professor Pedro Marcal and his colleagues at the University of London and Brown University and is currently a proprietary code distributed by MARC Analysis Research Corporation, Providence, Rhode Island. 
LAST PAGE E-18

APPENDIX E

RESULTS FOR THE NON-AXISYMMETRIC ANALYSES 
CONTOUR VALUES (psi)

$$
\begin{aligned}
1 & =-20700 \\
2 & =-17600 \\
3 & =-14600 \\
4 & =-11500 \\
5 & =-8500 \\
6 & =-5440 \\
7 & =-2380 \\
8 & =682 \\
9 & =3740 \\
10 & =6800
\end{aligned}
$$
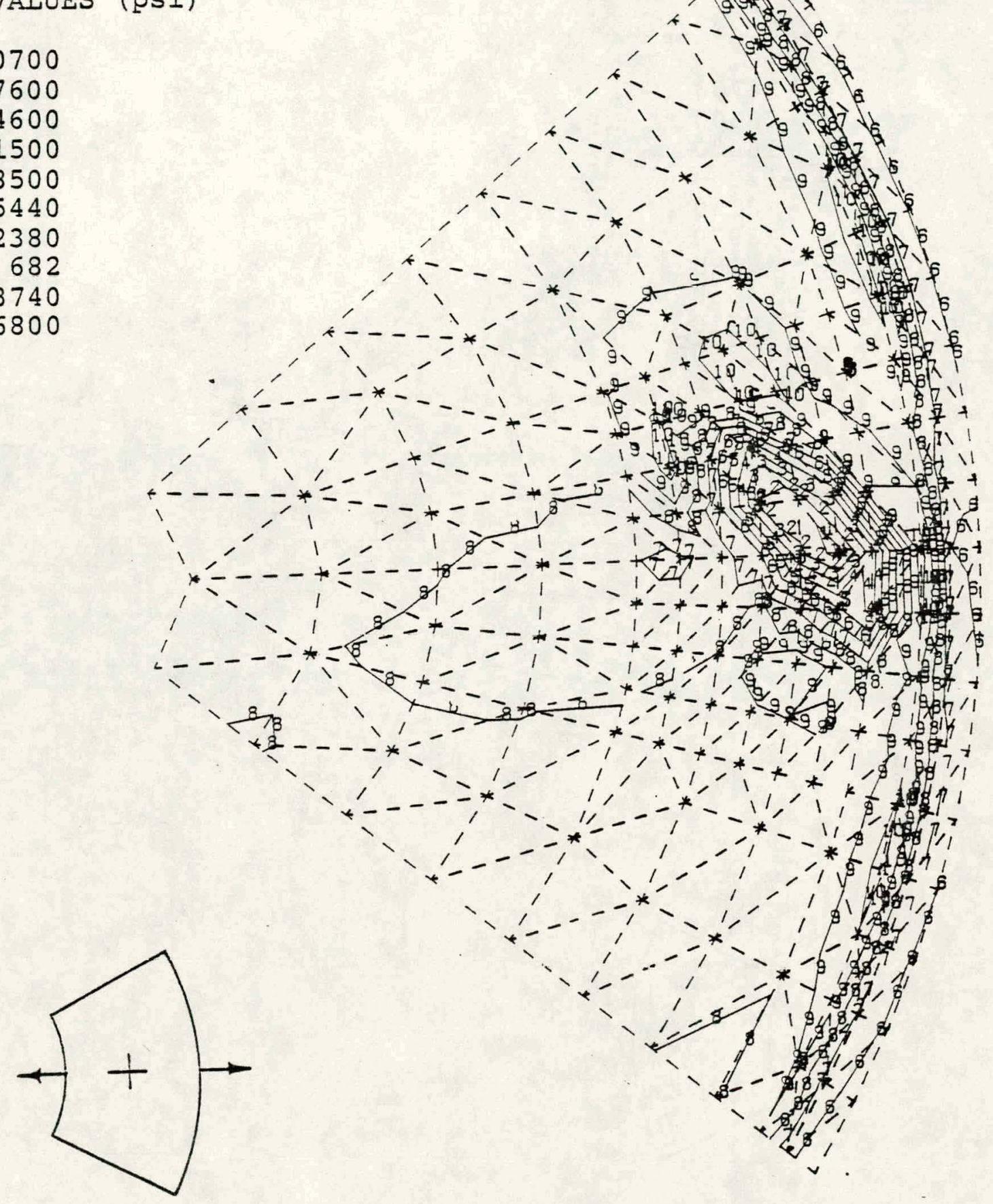

FIGURE E-1. Meridional Stress Results for the Top Surface Iterative Solution (psi) 
CONTOUR VALUES (psi)

$$
\begin{aligned}
1 & =-24700 \\
2 & =-20600 \\
3 & =-16400 \\
4 & =-12200 \\
5 & =-8130 \\
6 & =-3970 \\
7 & =188 \\
8 & =4350 \\
9 & =8510 \\
10 & =12600
\end{aligned}
$$
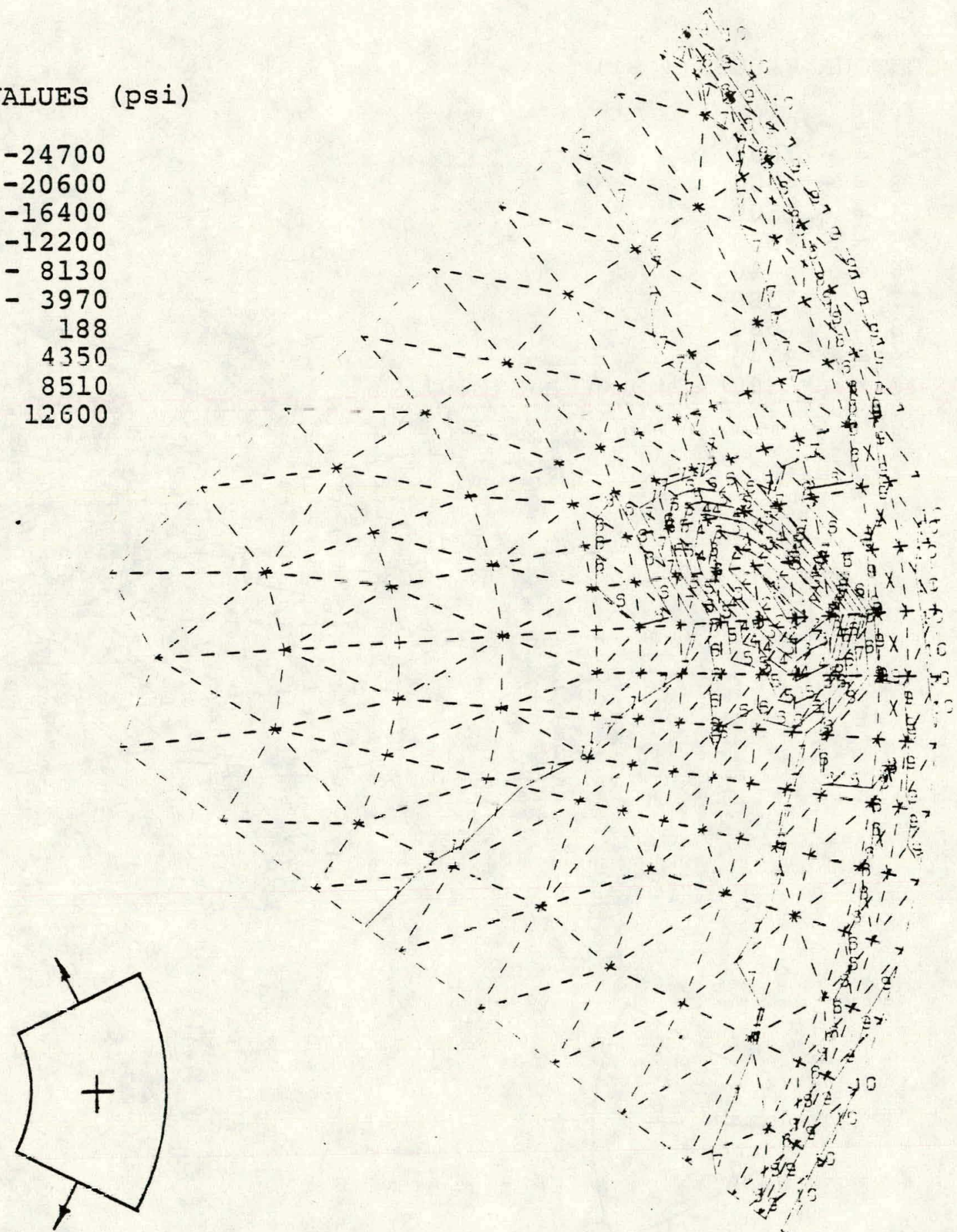

FIGURE E-2. Circumferential Stress Results for the Top Surface, Iterative Solution (psi) 
CONTOUR VALUES (psi)

$$
\begin{aligned}
1 & =-3720 \\
2 & =-2940 \\
3 & =-2160 \\
4 & =-1370 \\
5 & =-596 \\
6 & =186 \\
7 & =969 \\
8 & =1750 \\
9 & =2530 \\
10 & =3310 .
\end{aligned}
$$
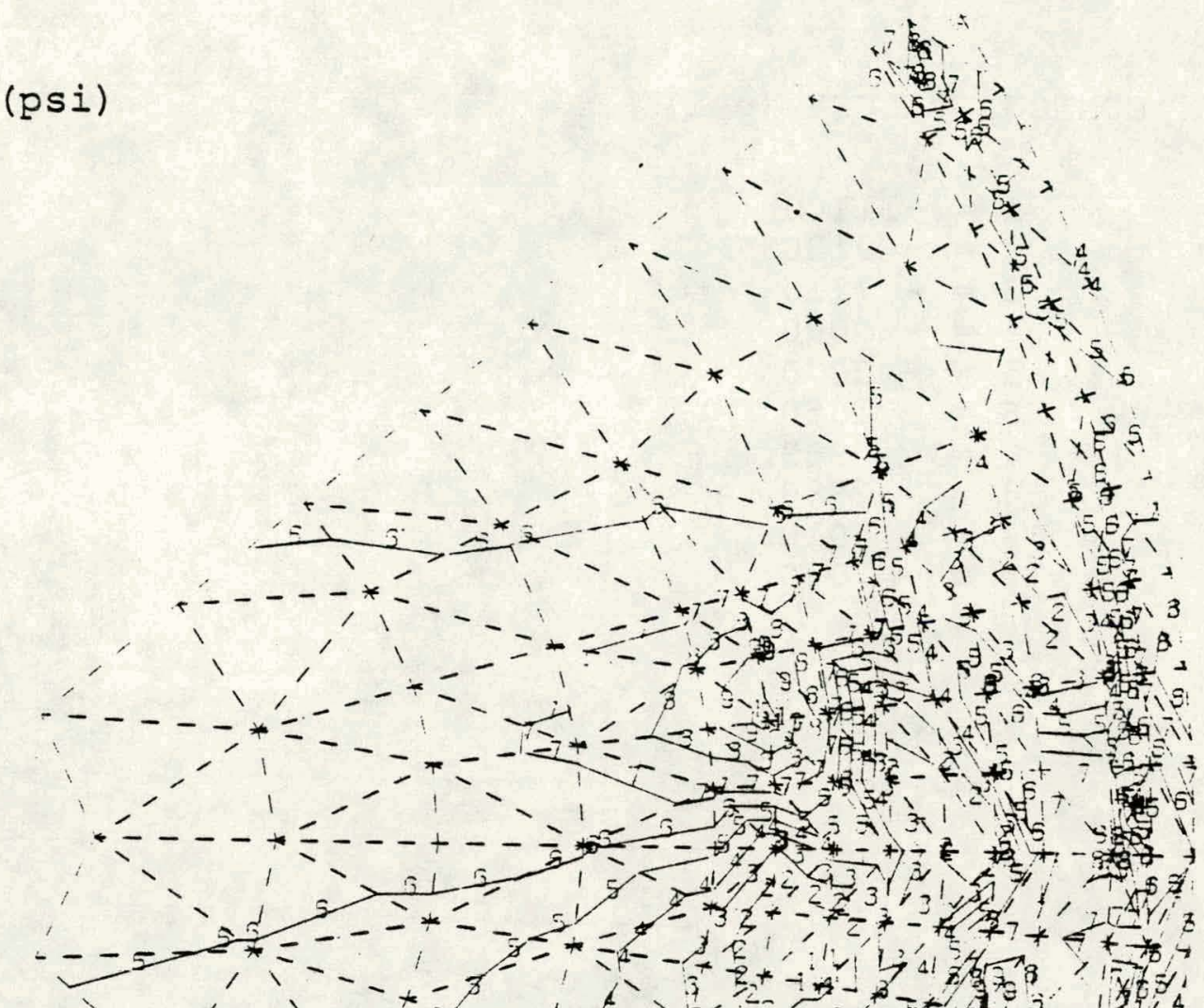

$x+1$
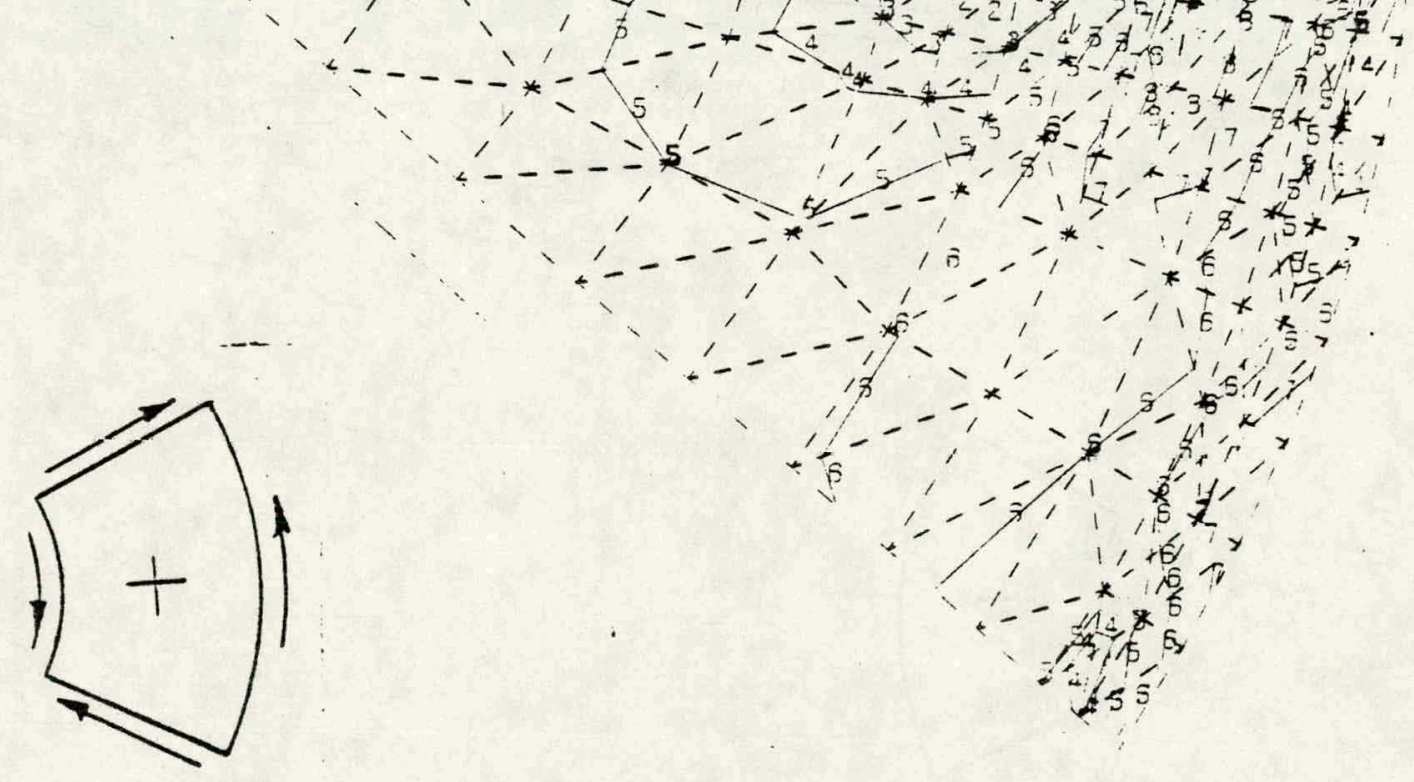

FIGURE E-3. Shear Stress Results for the Top Surface, Iterative Solution (psi) 
CONTOUR VALUES (psi)

$$
\begin{aligned}
1 & =-11100 \\
2 & =-9130 \\
3 & =-7110 \\
4 & =-5090 \\
5 & =-3070 \\
6 & =-1050 \\
7 & =969 \\
8 & =2980 \\
9 & =5010 \\
10 & =7030
\end{aligned}
$$
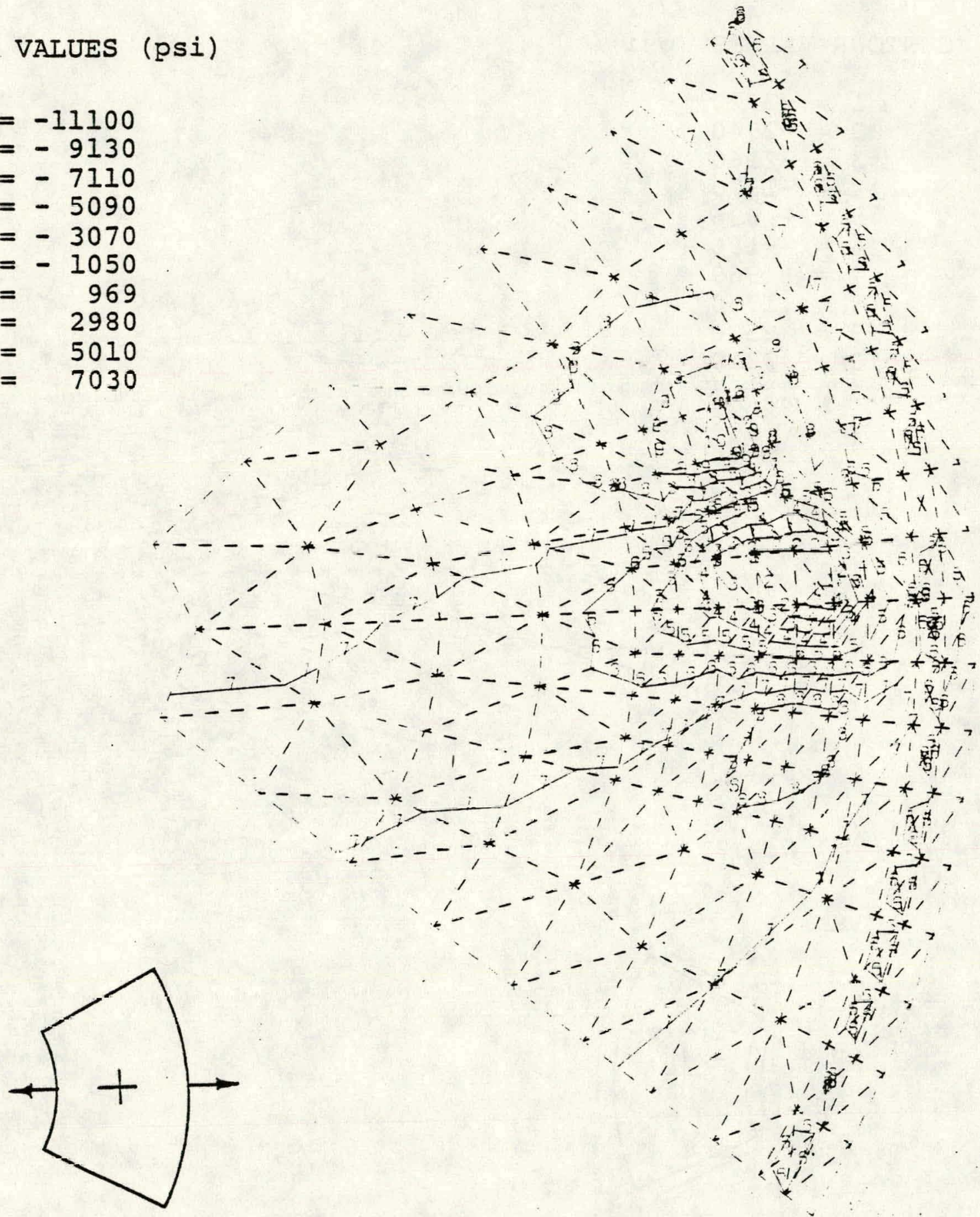

FIGURE E-4. Meridional Stress Results for the Middle Surface, Iterative Solution (psi) 
CONTOUR VALUES (psi)

$$
\begin{aligned}
1 & =-14200 \\
2 & =-11000 \\
3 & =-7880 \\
4 & =-4700 \\
5 & =-1510 \\
6 & =1670 \\
7 & =4850 \\
8 & =8040 \\
9 & =11200 \\
10 & =14400
\end{aligned}
$$
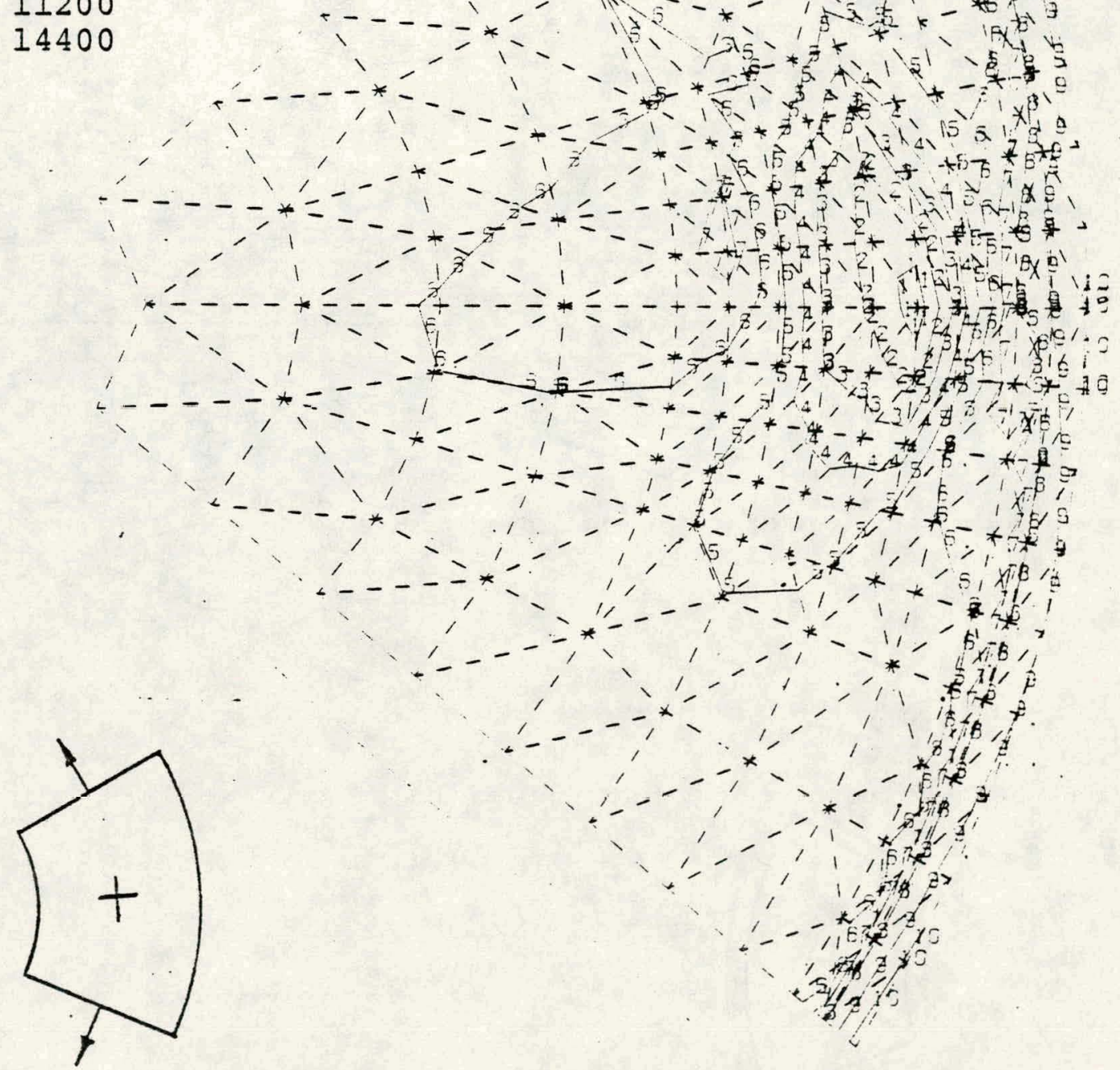

FIGURE E-5. Circumferential Stress Results for the Middle Surface, Iterative Solution (psi) 
CONTOUR VALUES (psi)

$$
\begin{aligned}
1 & =-4540 \\
2 & =-3610 \\
3 & =-2670 \\
4 & =-1740 \\
5 & =-809 \\
6 & =125 \\
7 & =1060 \\
8 & =1990 \\
9 & =2920 \\
10 & =3860
\end{aligned}
$$
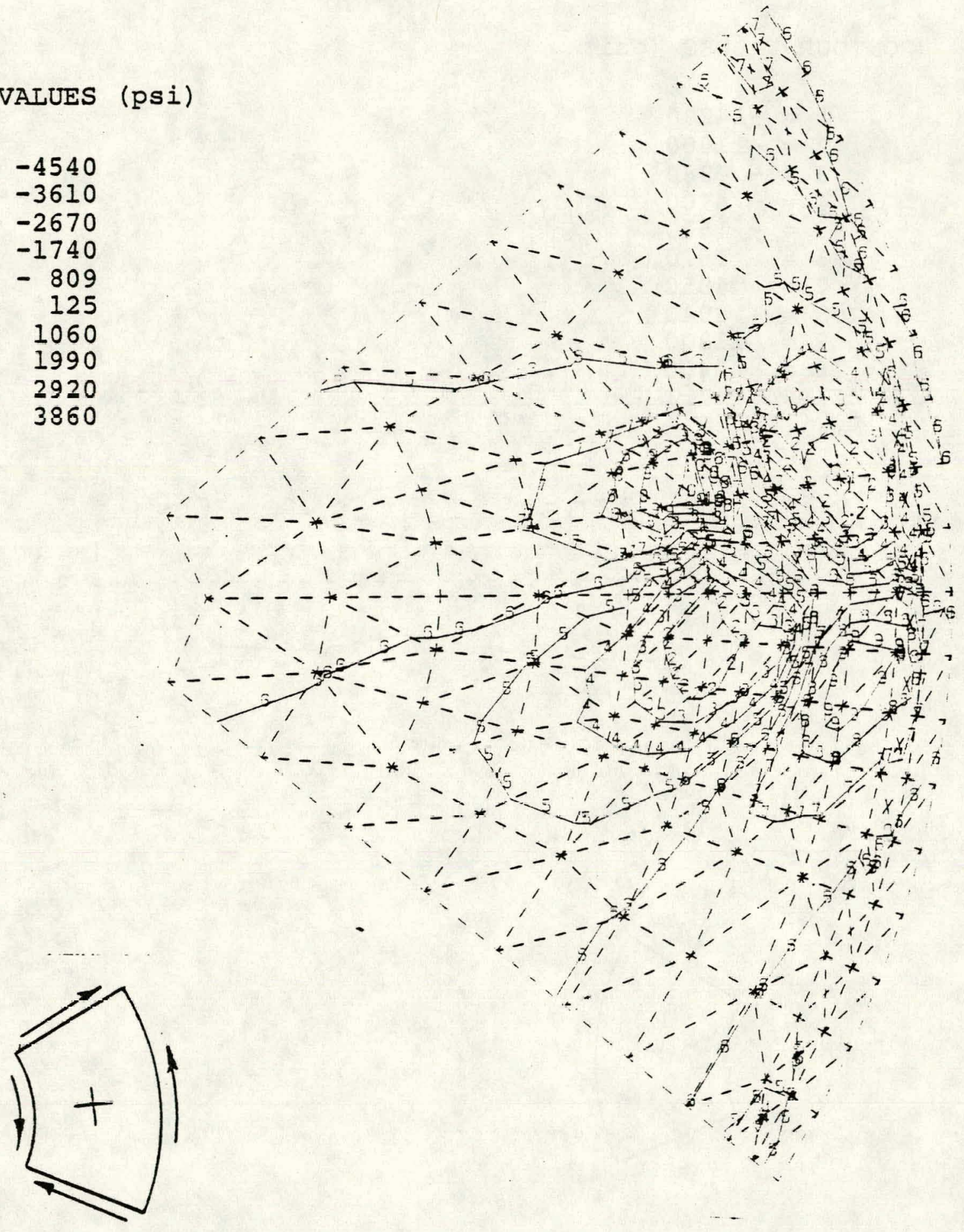

FIGURE E-6. Shear Stress Results for the Middle Surface, Iterative Solution (psi) 
CONTOUR VALUES (psi)

$$
\begin{aligned}
1 & =-9170 \\
2 & =-7730 \\
3 & =-5740 \\
4 & =-3750 \\
5 & =-1770 \\
6 & =213 \\
7 & =2190 \\
8 & =4180 \\
9 & =6170 \\
10 & =8150
\end{aligned}
$$

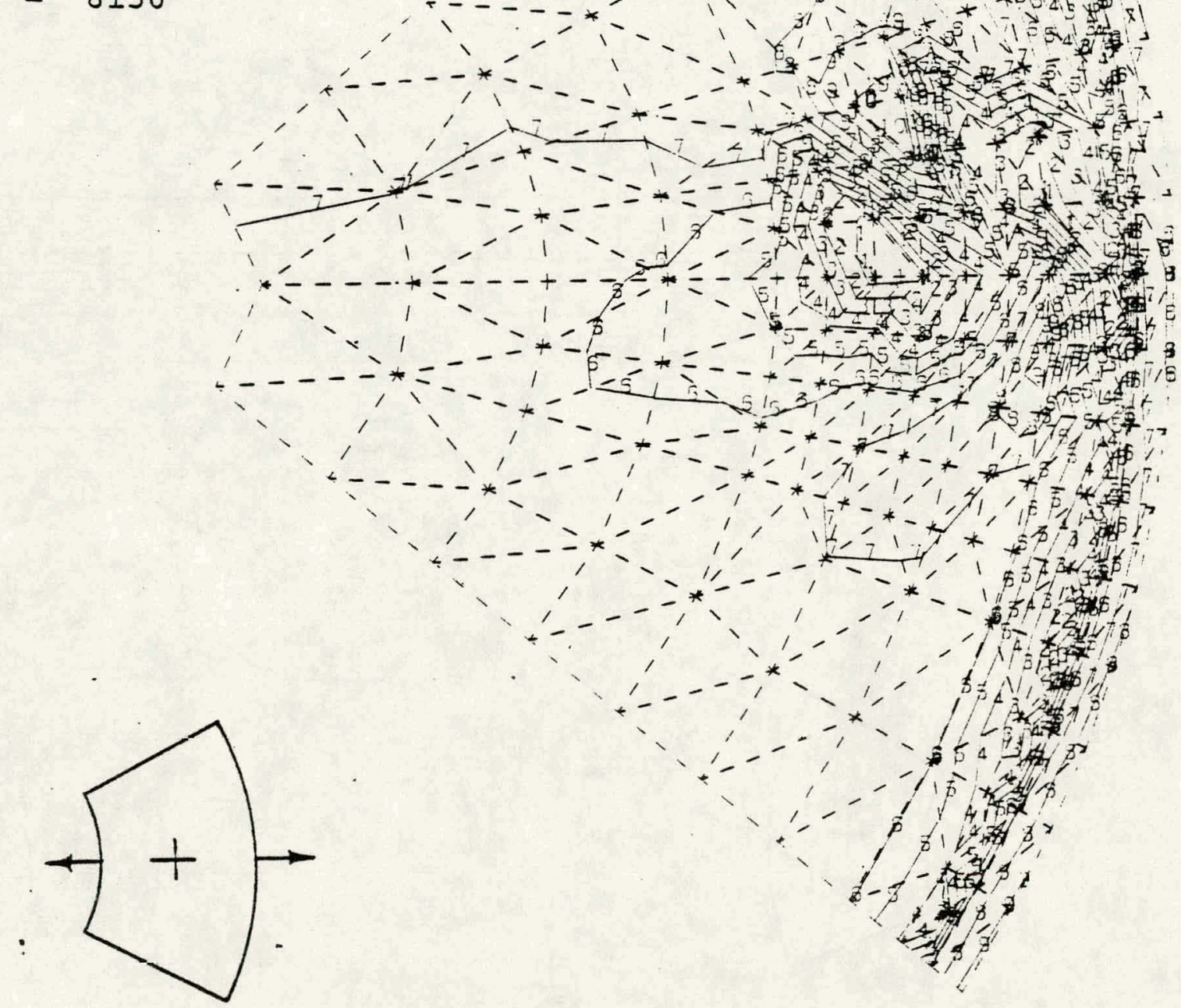

FIGURE E-7. Meridional Stress Results for the Bottom Surface, Iterative Solution (psi) 
CONTOUR VALUES (psi)

$$
\begin{aligned}
1 & =-14000 \\
2 & =-10600 \\
3 & =-7320 \\
4 & =-3940 \\
5 & =-575 \\
6 & =2790 \\
7 & =6170 \\
8 & =9540 \\
9 & =12900 \\
10 & =16200
\end{aligned}
$$
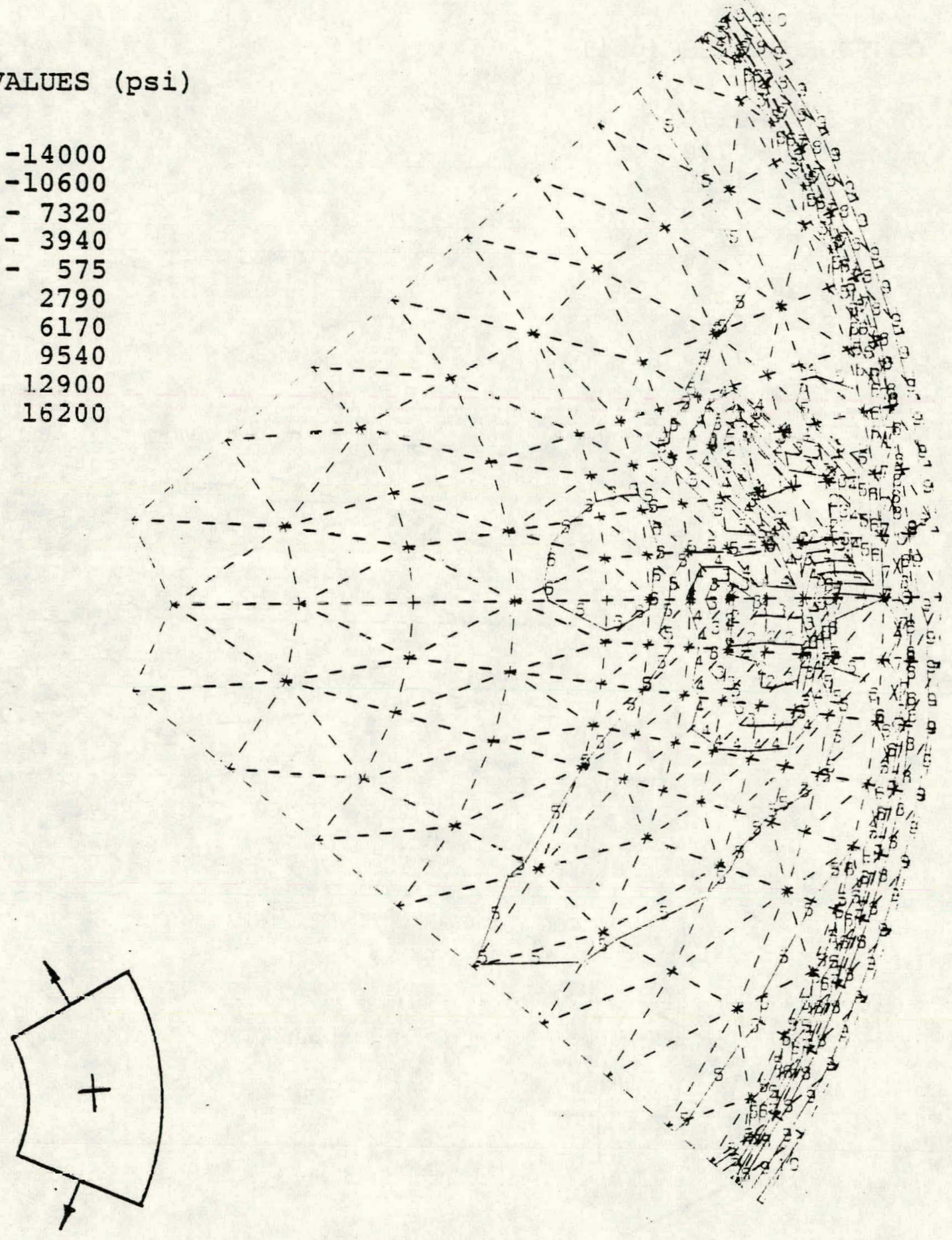


$$
\begin{aligned}
1 & =-7300 \\
2 & =-5740 \\
3 & =-4190 \\
4 & =-2630 \\
5 & =-1080 \\
6 & =473 \\
7 & =2020 \\
8 & =3580 \\
9 & =5140 \\
10 & =6690
\end{aligned}
$$
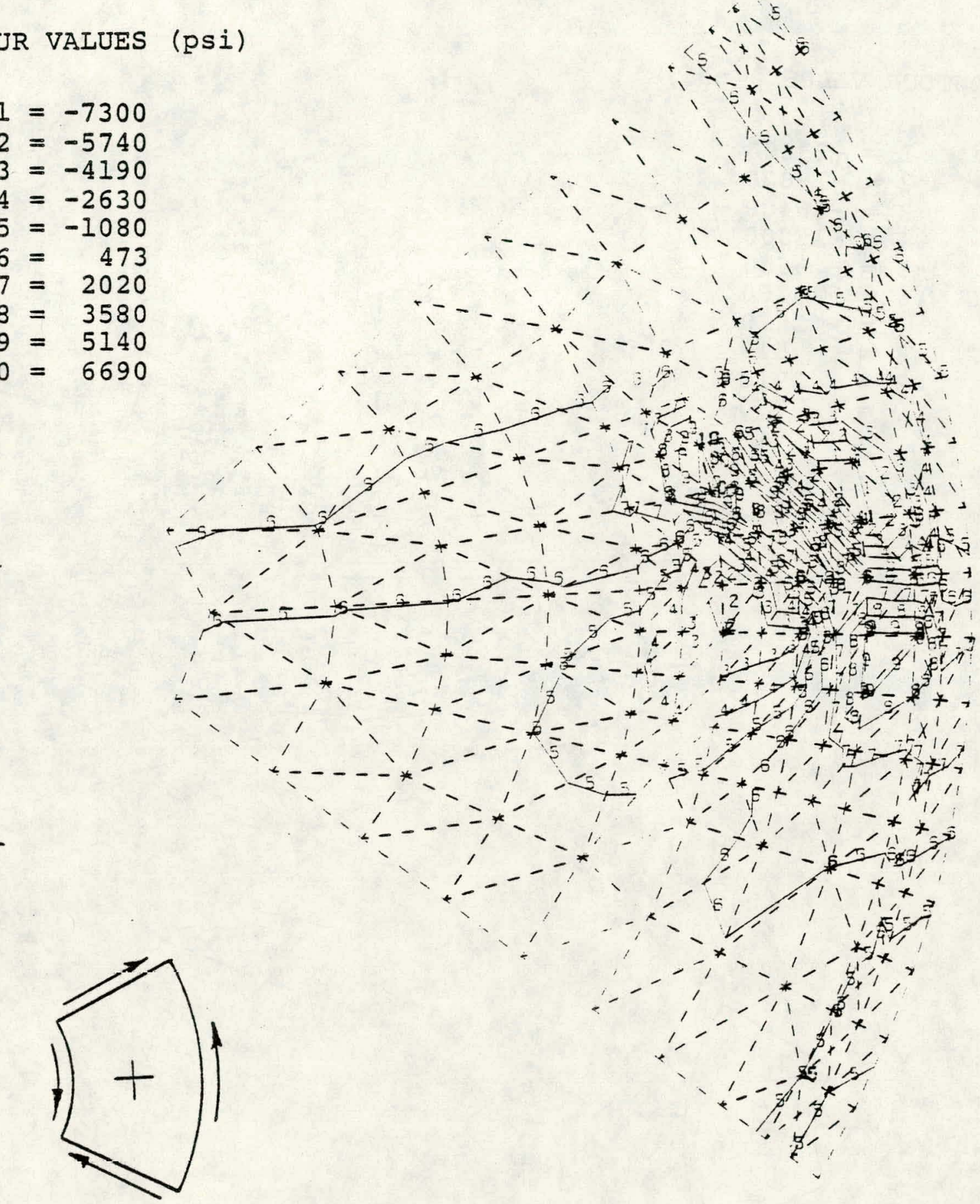

FIGURE E-9. Shear Stress Results for the Bottom Surface, Iterative Solution (psi) 
CONTOUR VALUES (psi)
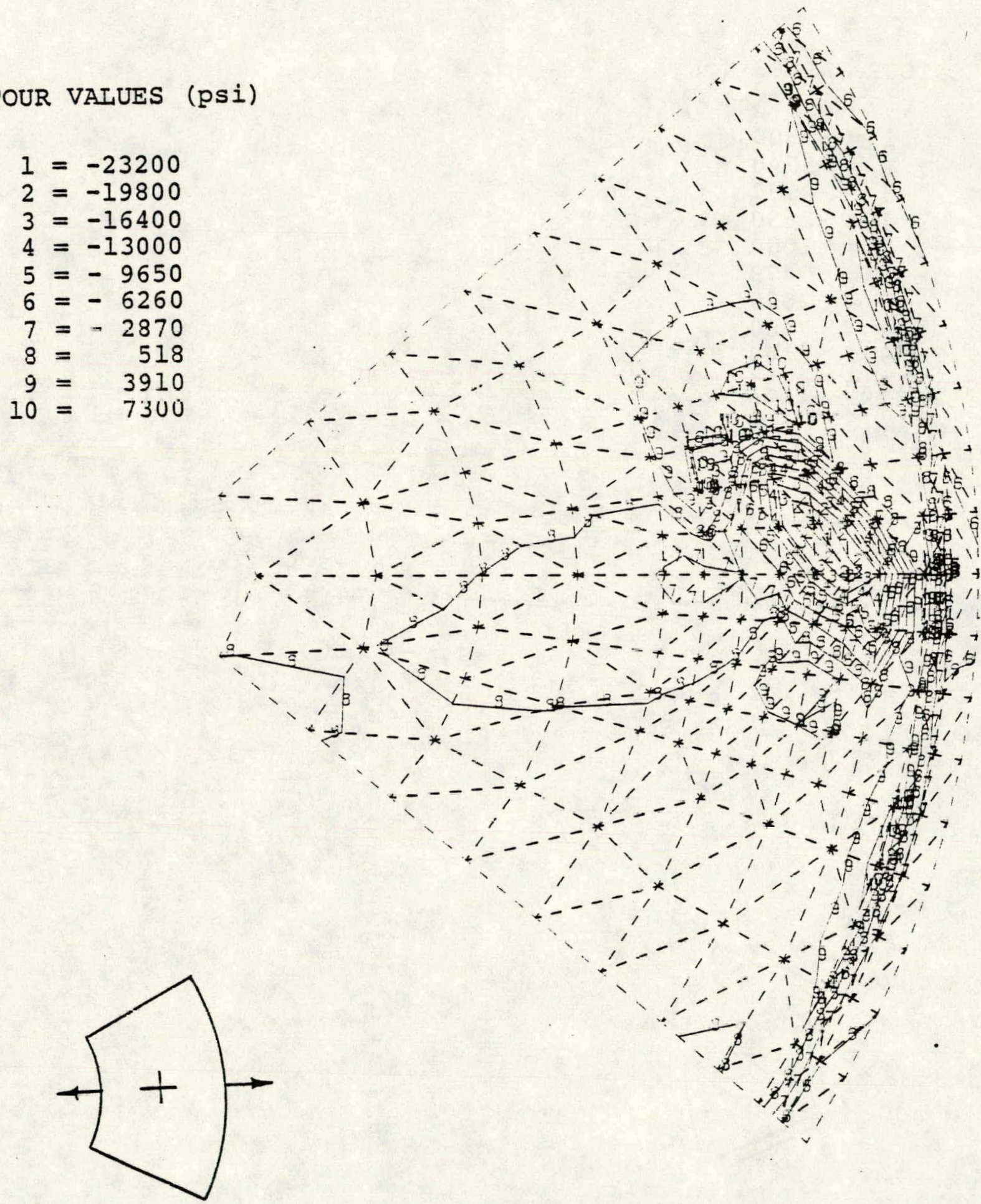

FIGURE E-10. Meridional Stress Results for the Top Surface, Constrained Solution (psi) 
CONTOUR VALUES (psi)
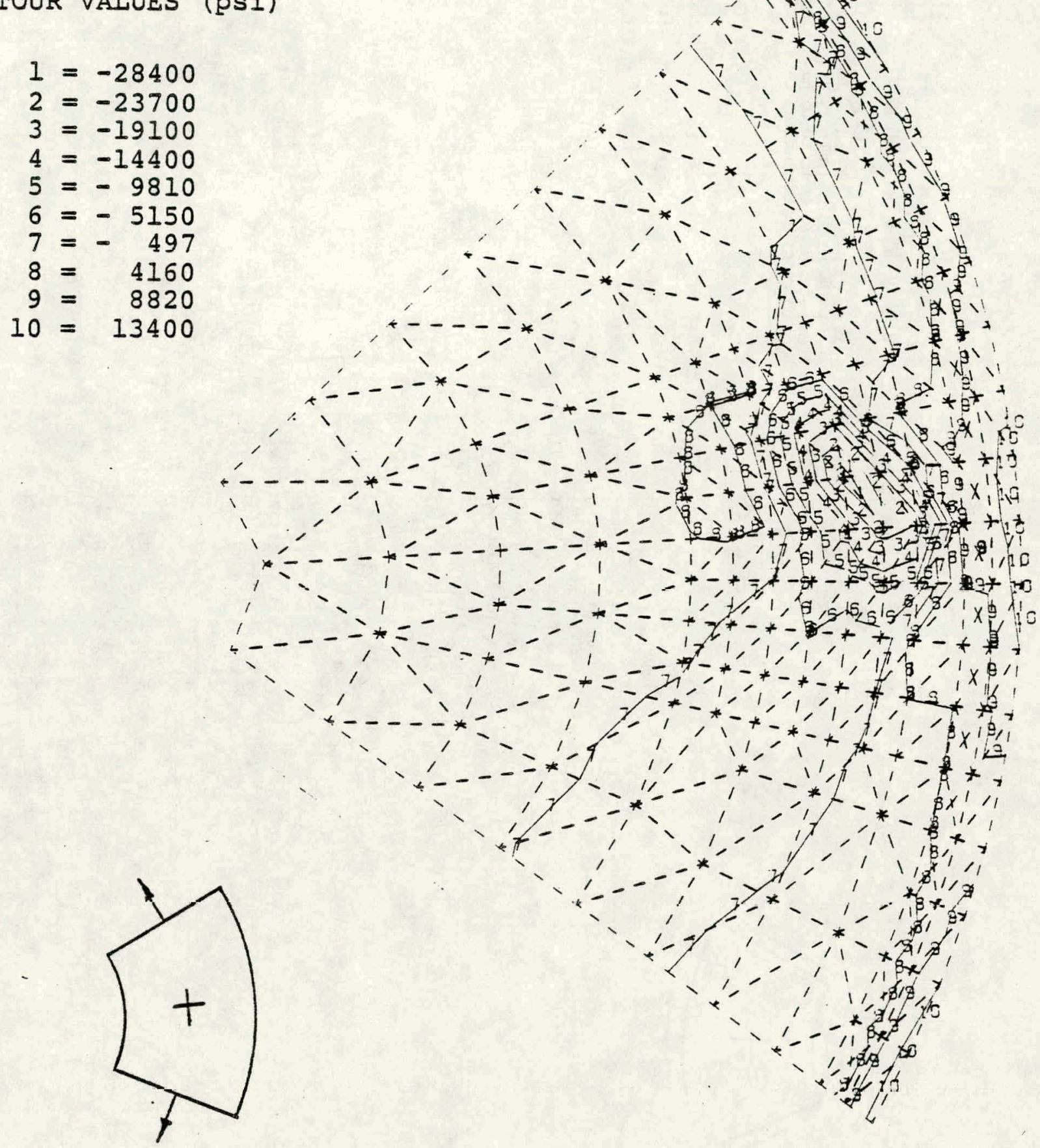

i

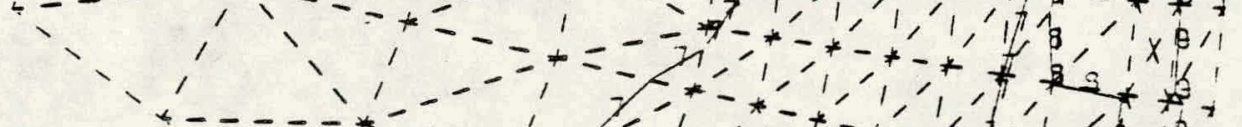

FIGURE E-11. Circumferential Stress Results for the TOP Surface, Constrained Solution (psi) 
CONTOUR VALUES (psi)

$$
\begin{aligned}
1 & =-4420 \\
2 & =-3480 \\
3 & =-2530 \\
4 & =-1590 \\
5 & =-655 \\
6 & =286 \\
7 & =1220 \\
8 & =2170 \\
9 & =3110 \\
10 & =4050
\end{aligned}
$$

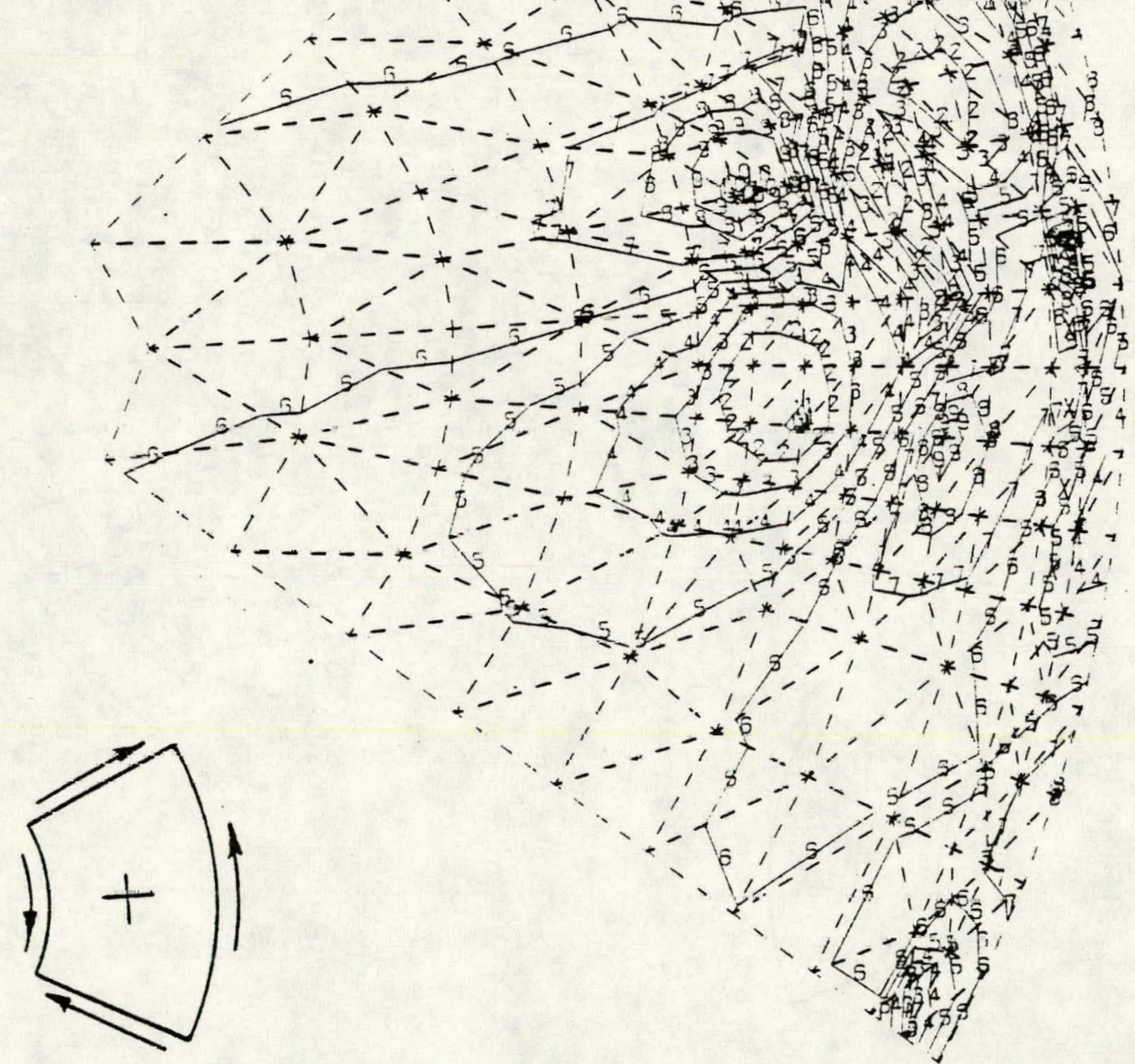

FIGURE E-12. Shear Stress Results for the Top Surface, Constrained Solution (psi) 
CONTOUR VALUES (psi)

$$
\begin{aligned}
1 & =-12300 \\
2 & =-10100 \\
3 & =-7860 \\
4 & =-5610 \\
5 & =-3360 \\
6 & =-1110 \\
7 & =1120 \\
8 & =3370 \\
9 & =5620 \\
10 & =7870
\end{aligned}
$$
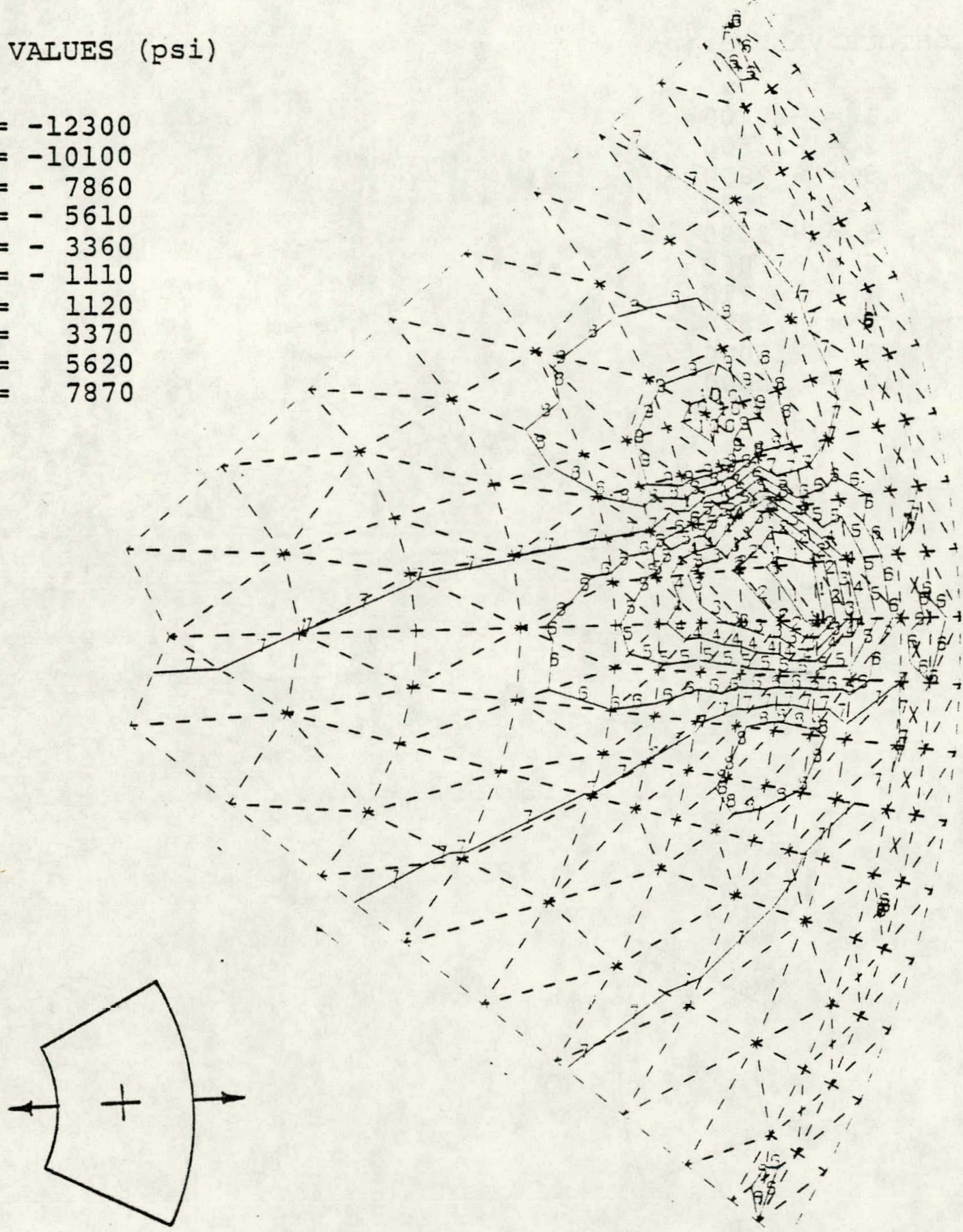

FIGURE E-13. Meridional Stress Results for the Middle Surface, Constrained Solution (psi) 
CONTOUR VALUES (psi)

$$
\begin{aligned}
1 & =-17200 \\
2 & =-13500 \\
3 & =-9900 \\
4 & =-6250 \\
5 & =-2590 \\
6 & =1060 \\
7 & =4710 \\
8 & =8370 \\
9 & =12000 \\
10 & =15600
\end{aligned}
$$

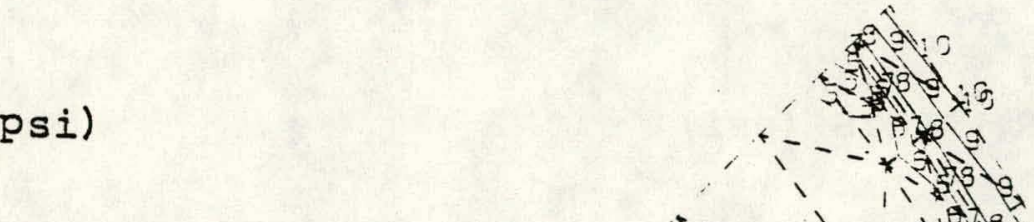


CONTOUR VALUES (psi)

$$
\begin{aligned}
1 & =-5320 \\
2 & =-4160 \\
3 & =-3010 \\
4 & =-1850 \\
5 & =-699 \\
6 & =456 \\
7 & =1610 \\
8 & =2760 \\
9 & =3920 \\
10 & =5080
\end{aligned}
$$

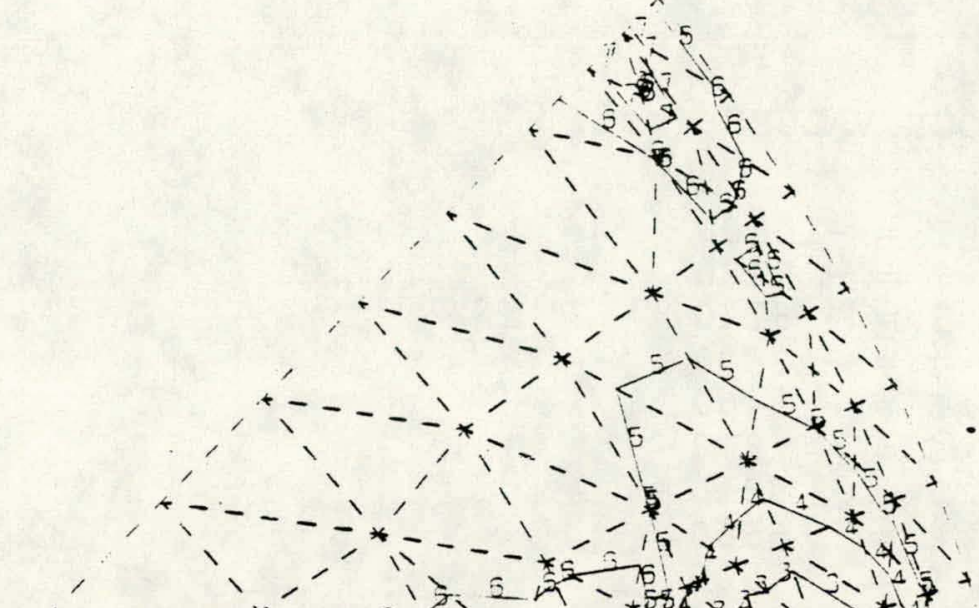

$$
\text { . }
$$


CONTOUR VAIUES (psi)
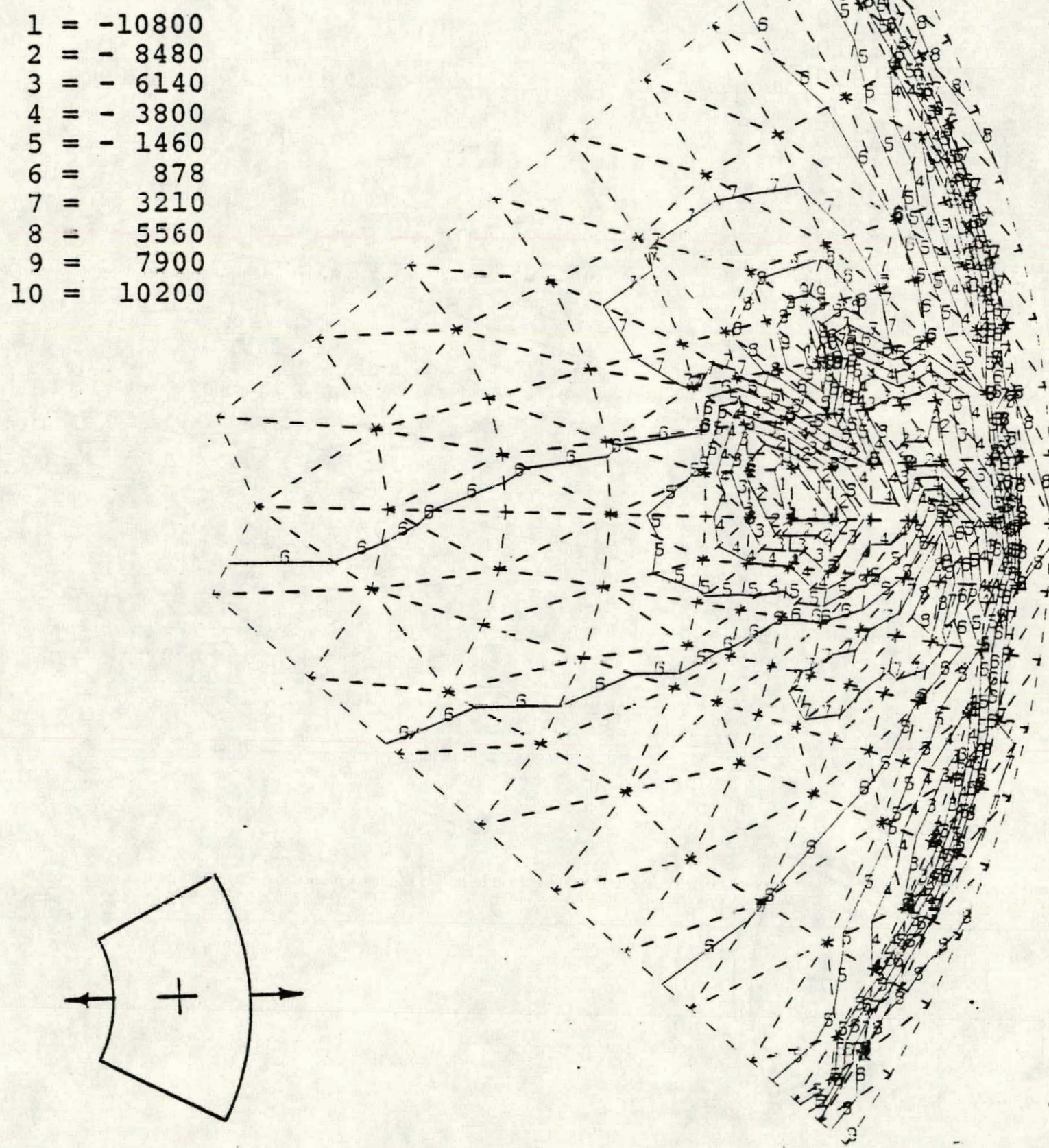

FIGURE E-16. Meridional Stress Results for the Bottom Surface, Constrained Solution (psi) 
CONTOUR VALUES (psi)

$$
\begin{aligned}
1 & =-16700 \\
2 & =-12800 \\
3 & =-9040 \\
4 & =-5200 \\
5 & =-1360 \\
6 & =2480 \\
7 & =6320 \\
8 & =10100 \\
9 & =14000 \\
10 & =17800
\end{aligned}
$$
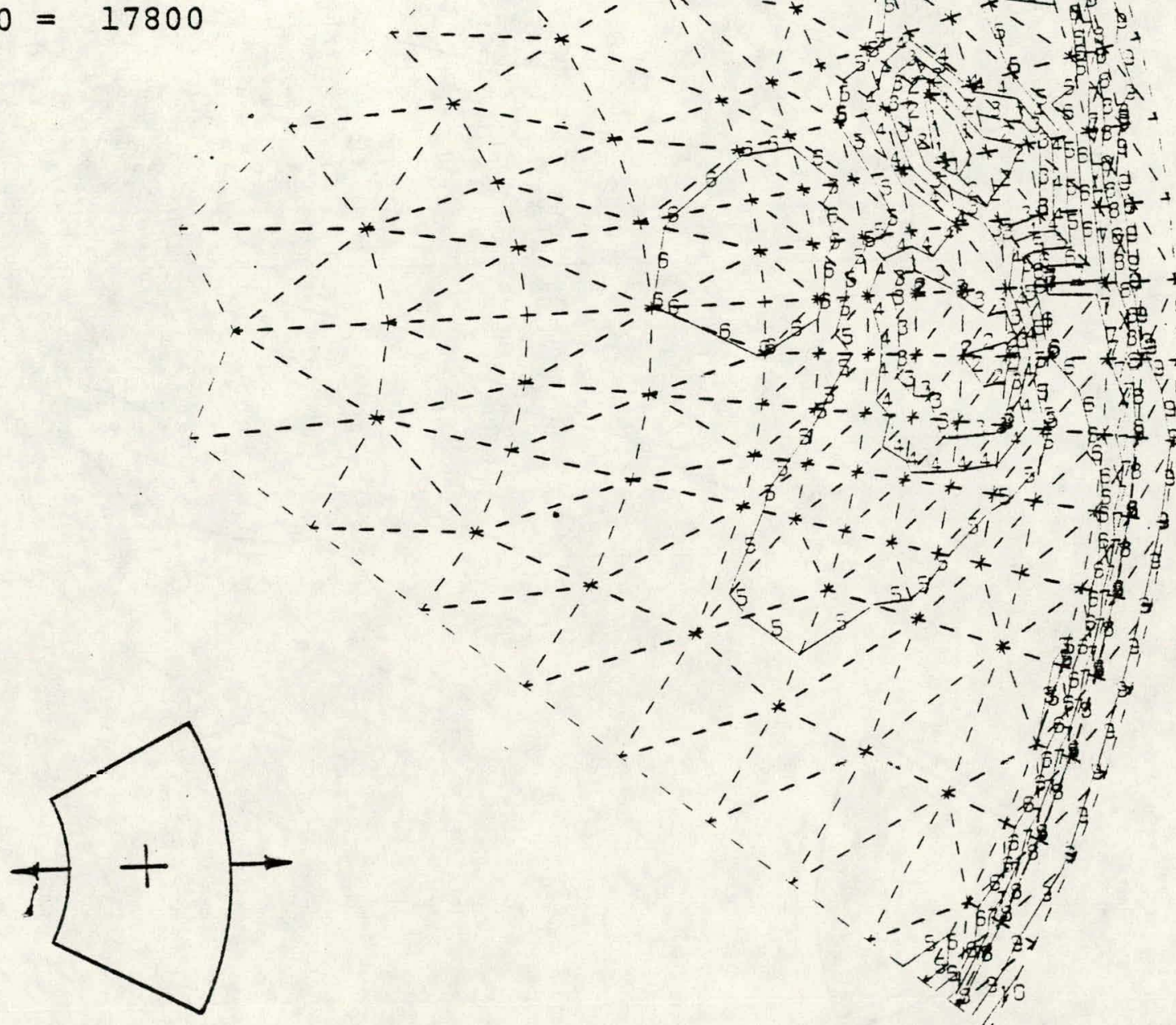

FIGURE E-17. Circumferential Stress Results for the Bottom Surface Constrained Solution (psi) 
CONTOUR VALUES (psi)

$$
\begin{aligned}
1 & =-8190 \\
2 & =-6520 \\
3 & =-4850 \\
4 & =-3180 \\
5 & =-1510 \\
6 & =1540 \\
7 & =1820 \\
8 & =3490 \\
9 & =5160 \\
10 & =6830
\end{aligned}
$$
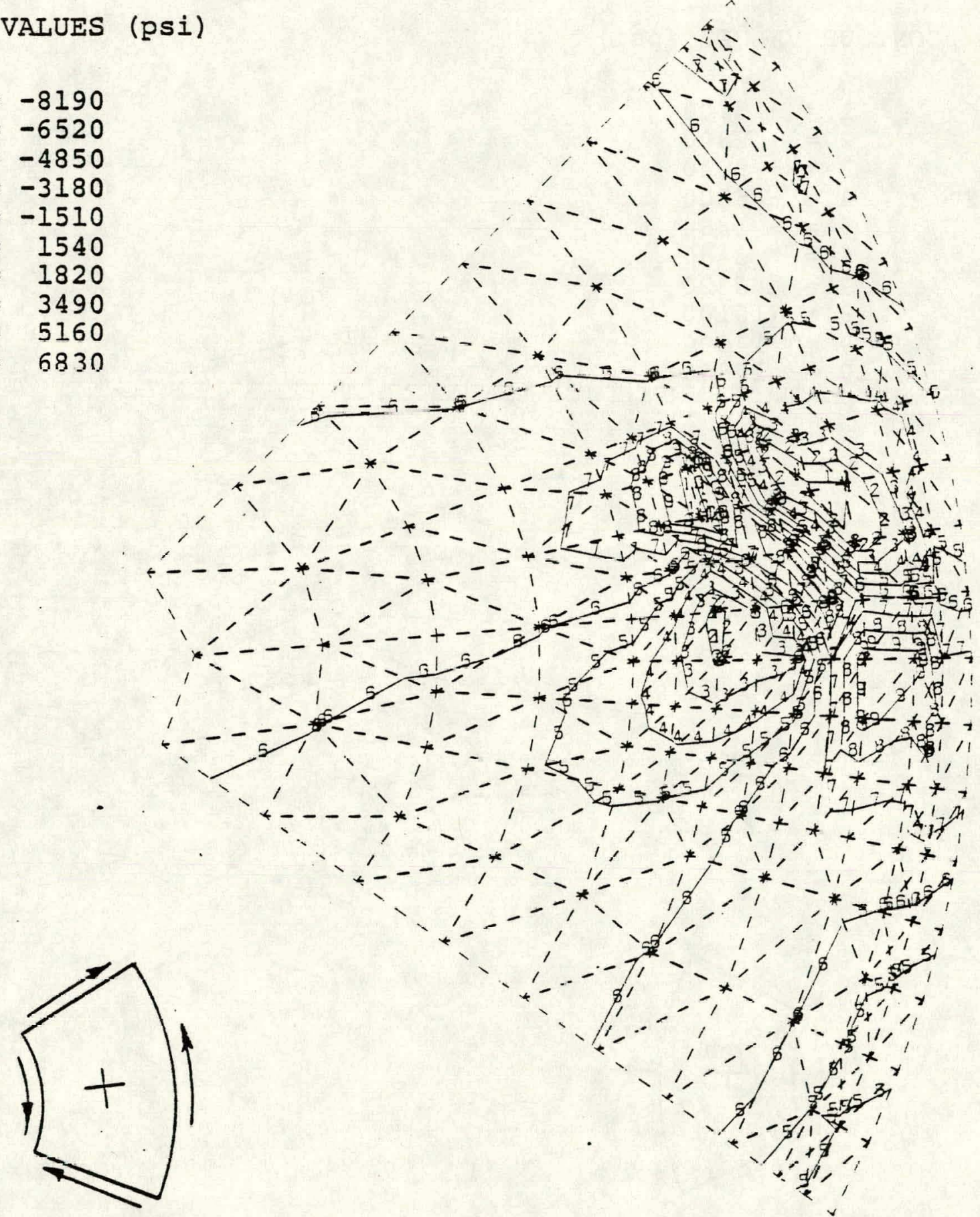

FIGURE E-18. Shear Stress Results for the Bottom Surface, Constrained Solution (psi) 
BNWL-B-4.75

APPENDIX F

(INCOMPLETE) 


\section{APPENDIX G \\ STRESS CORROSION SUSCEPTIBILITY OF TANK SY-103 \\ AS EVALUATED BY WE ANDERSON (BNW)}

The stress analyses of the bumps or wrinkles in the bottom of tank SY-103 are accepted to be reasonable values. That is, there is very little area on the inner surface of the tank which is liable to be stressed beyond minimum expected yield of the tank liner material while in normal expected service.

The ultimate question addresses whether or not the tank is likely to leak seriously very soon after being placed in service, and, sort of in between, whether or not reasonable engineering judgment has been applied to the decision for accepting a manufactured tank that is slightly out of the contractually specified fabrication limits.

My answers to these questions are no and yes, respectively. They have been answered this way for the following reasons:

a) following the stress-relief treatment, the near-yield residual stresses in the regions along the welded joints have been substantially dissipated; Ref. 3

b) the calculations indicate no interior surface area associated with the bump or wrinkle region is likely to exceed tensile yleld stress of the material when it is flattened by the internal pressure loads in service: Ref. 4

c) stress corrosion leaks of significant extent appear to require both the probability of initiation due to yield or near-yield tensile stresses ocruring over a substantial area exposed to the corrodent and far-field stresses which overcome the self-equilibrating stresses in the region where a stress-corrosion crack may have initiated;

Ref. 5 
BNWI-B-475

d) we can expect similar tanks of similar construction and filled with similar corrodents to have minor constructional deviations from perfection which, under service conditions, would be expected to have local, self-equilibrating stresses of similar magnitude extending over regions similar to those likely to be experienced by the subject tanks when put into service; and Ref. 6

e) serviee experience with similar tanks and corrodents has not produced any detectable leaking which might be the result of stress corrosion at local regions due to self-equilibrating stresses caused by the service loadings; and $\operatorname{Ref} .7$

f) the far-field stresses which might be of concern have not caused detectable stress-corrosion cracking in similar stress-relieved tanks of similar materials and of similar construction and containing similar corrodents.

Ref. 7

Taken altogether, these arguments lead to the conclusion that leaking of the subject tank is unlikely and that the decision to accept the slightly out-of-tolerance bump or wrinkle is a reasonable engineering judgment.

It is worth noting that the calculated stresses arising out of service flattening of the existing bump or wrinkle are only marginally below minimum expected yield strength; therefore, the present criteria for bump or wrinkle acceptance seem prudent (though incomplete) requirements for fabrication control. The principal missing parameter from the present acceptability criteria can be shown by analysis to be that of control on local curvatures. 
The magnitude of local, flexure stresses caused by flattening bumps or wrinkles is determined primarily from the amount of curvature that is flattened by service pressure loading. If the initial curvature is sharp, resulting stresses from the flattening are large. The present requirements do not impose a limit on the acuteness of the curvature in the bump or wrinkle region.

It is therefore urged that an additional requirement on curvature be added to the present acceptance criteria.

We note, again, that the subject bump is assessed by calculation to be acceptable. However, this does not guarantee that subsequent bumps or wrinkles in subsequent tank bottoms may not have curvatures associated with them which are more acute than those in the subject tank. A curvature limit would cover this salient point and provide reasonable opportunity to assess future cases in a more conclusive manner, without engineering analysis.

Finally, we note that the current technology regarding stress-corrosion in large engineering structures is weak. That is, the laboratory-size specimens from which stress corrosion data have been obtained have not included the normal service situation or significant far field stresses; the test situations simply have not been realistic in this regard. Our conclusions as to reasonably expected satisfactory performance of the subject tank hinges on reference to apparently satisfactory field experience with similar tanks under similar situations. We believe this is a tenuous position to hold for conducting design calculations and materials selection for future tanks that may not be subjected to similar service conditions. It seem prudent, therefore, to urge development of stress-corrosion tests on realistically stressed specimens of sufficient size that the behavioral results more credibly relate to the full-scale situation. 
BNWL $-B-475$

$\cup C-70$

\section{DISTRIBUTION}

No. of

Copies

\section{OFFSITE}

1 ERDA Chicago Patent Group 9800 South Cass Avenue

Argonne, II 60439

10 ERDA Technical Information Center
No. of

Copies

ONSITE

1 ERDA Richland Operations Office

Programs Division

Art Lassila

7. Battelle-Northwest

W. E. Anderson

R. I. England

J. R. Friley

M. Vagins (4)

3 Technical Information Files

7 ARHCO

J. F. Albaugh

E. I. Moore

V. D. Schrag (5)

11 Total this side

18 Total this side 